University of San Diego

Digital USD

1984

\title{
The Effects of Clinical and Traditional Supervision Methods on the Satisfaction Levels of Higher and Lower-Order Need Teachers
}

George James Cameron EdD

University of San Diego

Follow this and additional works at: https://digital.sandiego.edu/dissertations

Part of the Leadership Studies Commons

\section{Digital USD Citation}

Cameron, George James EdD, "The Effects of Clinical and Traditional Supervision Methods on the Satisfaction Levels of Higher and Lower-Order Need Teachers" (1984). Dissertations. 477.

https://digital.sandiego.edu/dissertations/477

This Dissertation: Open Access is brought to you for free and open access by the Theses and Dissertations at Digital USD. It has been accepted for inclusion in Dissertations by an authorized administrator of Digital USD. For more information, please contact digital@sandiego.edu. 
THE EFFECTS OF CLINICAL AND TRADITIONAL SUPERVISION

METHODS ON THE SATISFACTION LEVELS OF HIGHER

AND LOWER-ORDER NEED TEACHERS

\author{
by \\ George J. Cameron \\ A dissertation submitted in partial fulfillment \\ of the requirements for the degree of \\ Doctor of Education \\ 1984 \\ Dissertation Committee \\ William P. Foster, Ed.D., Director \\ Janet Blenner, Ph.D. \\ Ronald Hockwalt, Ph.D. \\ Susan Zgliczynski, Ph.D.
}


(C) 1984

\section{GEQRGE JAMES CAMERON}

\section{All Rights Reserved}


THE EFFECTS OF CLINICAL AND TRADITIONAL SUPERVISION METHODS ON THE SATISFACTION LEVELS OF HIGHER AND LOWER-ORDER NEED TEACHERS

\author{
William P. Foster, Ed.D., Director
}

The researcher in this study sought to examine the relationship between clinical and traditioral supervision models and teacher need strength. The problem that this study addressed can best be stated in the form of a question: What (if any) effect does clinical and traditional supervision have on the satisfaction levels of higher and lower-order need teachers?

The study which extended from October, 1983, through February, 1984, was a field experiment conducted in fifteen school districts in southern California. The sample consisted of 157 teachers--74 supervised via clinical methods and 83 by traditional approaches. The study also included 10 clinical and 10 traditional principals.

The instruments used to gather data focused on teacher need strengths and teacher perceptions of supervision. The Higher-order Need Strength Measure B was used to identify teacher need preferences and categorize teachers into higher-order or lower-order groups. The Teacher Supervision Practices Questionnaire was used to obtain a satisfaction rating from teachers who had clinical supervisors and those who had traditional supervisors. 
Statistical procedures were tested on ten null hypotheses by analysis of variance (ANOVA). Findings were significant when they reached the .05 level of probability. As a result, nine hypotheses were accepted and one was rejected. Significant differences in the satisfaction levels of teachers were found between teachers who had clinical principals and teachers who had traditional principals. Further summary data indicated that there were no significant relationships between need strength and teacher classification to supervision.

The researcher concluded that (1) clinical supervision enhances more positive perceptions and higher levels of satisfaction among teachers when contrasted to traditional supervision; (2) clinical supervisors are perceived more favorably than traditional supervisors when assessed for methods of evaluating the performance of a lesson, methods for helping teachers improve instruction, methods for collecting data and providing feedback, and methods for fostering interpersonal relations; (3) clinical supervision engenders high levels of satisfaction among higher-order and lower-order teachers and those in tenured and non-tenured positions; (4) clinical supervision is in a better position than traditional supervision in helping lower-order need teachers develop a desire for improving their teaching skills; (5) clinical supervision is in a better position than traditional supervision in helping higher-order need teachers continue their desire for professional skill development; (6) clinical supervision is found to be confining 
by some higher-order need teachers, and (7) clinical principals tend to spend more time in supervision than traditional principals as evidenced by the number of classroom observations conducted during the study. 
DEDICATION

To

Wendy and DeeDee

Their joy will be something their

daddy will cherish forever.

AND

To

My father, Roy Cameron

His support and encouragement of my educational

pursuits served to strengthen my resolve.

Reproduced with permission of the copyright owner. Further reproduction prohibited without permission. 
The completion of this dissertation was not without due credit to the many people who were a valuable resource.

I am most grateful to Dr. William Foster for his leadership of my committee and the interest and commitment he devoted to my subject. My heartfelt thanks also go to Dr. Susan Zgliczynski and Dr. Ron Hockwalt. I am thankful for their helpful feedback and guidance which served to strengthen my study. My regards also go to $\mathrm{Dr}$. Janet Blenner for her valuable input and support.

A special debt is owed to the teachers who participated in this study and who shared their honest thoughts with me, and most especially, to their principals who accepted this task mindful of any risk. A further debt of gratitude is due to Patti Hicks, my typist, for her positive attitude and quality of work.

Lastly, I wish to thank my wife, Edie, and my dear family. The many evenings and weekends devoted to reading, writing, and refining this research was made possible because of their understanding and support, and because what I was doing was important to them too.

To all these people, I am sincerely thankful. 
Where the willingness is great, the difficulties cannot be great.

Nicolo Machiavelli 
CHAPTER 1

INTRODUCTION OF THE SUBJECT AND STATEMENT OF THE PROBLEM • $I$

Statement of the Problem. . . . . . . . . . 12

Statement of Null Hypothesis. . . . . . . . . 14

Delimitations of the Study. . . . . . . . . . 16

Limitations of the Study. . . . . . . . . . . 16

Definitions of Terms. . . . . . . . . . . . 17

Organization of Study Chapters. . . . . . . . . 18

\section{CHAPTER 2}

REVIEW OF THE RELATED LITERATURE . . . . . . . . . . 20

Historical Perspective of Supervision . . . . . . . 21

Assessment of Contemporazy Instructional Supervision

Basic Assumptions Undergirding Models. . . . . . 30

Focus of Supervision . . . . . . . . . . 39

Role of the Supervisor ............ 47

Structure of the Models. . . . . . . . . 51

Clinical and Traditional Supervision Research . . . . 75

Need Strengths in Teachers. . . . . . . . . . 78

Review of the Literature. . . . . . . . . . 80

CHAPTER 3

RESEARCH DESIGN AND METHODOLOGY. . . . . . . . . 85

Description of the Subjects ............ 85 
Description of the Instrumentation. . . . . . 89

Description of the Procedures .......... 96

Treatment of the Data ........... 99

\section{CHAPTER 4}

PRESENTATION AND ANALYSIS OF THE DATA. ........ 101

Teacher Need Strength Results........... 101

Analysis of the Statistical Findings. . . . . 105

Open-Ended Format Question Results.......... 112

Open-Ended Results Sumnary. . . . . . . . . 134

\section{CHAPTER 5}

SUMMARY, CONCLUSIONS AND RECOMMENDATIONS . . . . . 137

Summary

Purpose of the Study . . . . . . . . 137

Review of the Literature .......... 138

Review of the Hypotheses.......... 142

Review of the Methods. .......... 143

Summary of the Hypotheses. . . . . . . . 144

Conclusions

Summary of Findings, Interpretations, and Literature

Support ............... 146

Recommendations

Discussion of the Problems and Limitations.... 149 
Discussion of the Practical Implications ..... 150

Recommendations for Future Research. . . . . . 151

REFERENCES. . . . . . . . . . . . 153

APPENDICES

Appendix A - School Districts Included in Study . . . 162

Appendix B - Higher-Order Need Strength Measure B . • 164

Appendix C - Letter of Invitation to Field Test

Measure B .......... 168

Appendix D - Teacher Supervision Practices Questionnaire 170

Appendix E - Letter of Transmittal to School Principals 176

Appendix F - Observation Log of Randomly Shadowed

Clinical and Traditional Principals . . 180

Appendix G - Letter of Permission to Use Higher-Order

Need Strength Measure B . . . . . 183

Appendix H - Need Strength Scores for Clinical Group. . 185

Appendix I - Need Strength Scores for Traditional Group 187

vii 
Table 1 - Comparison in Numbers of Clinical and Traditional Principals by Sex............ 86

Table 2 - Frequency and (percentage) of Sample by Age . . 87

Table 3 - Frequency and (percentage) of Sample by Years of Experience ............. 88

Table 4 - Frequency and (percentage) of Sample by Teachers Classification ............ 88

Table 5 - Item Intercorrelation Distribution. . . . . . 94

Table 6 - Comparability of Split-Half Correlation ..... 95

Table 7 - Teacher Sample. . . . . . . . . . 98

Table 8 - Need Strength Scores. . . . . . . . . 103

Table 9 - Mean Scores for Clinical and Traditional Samples. 105

Table 10 - Analysis of Variance of Satisfaction Toward

Clinical or Traditional Supervision. . . . . 106

Table 11 - Item Means, Standard Deviations, F-Ratios and

Correlations for Satisfaction Rating . . . . 107

Table 12 - Summary of the Mean Satisfaction Scores for the

Higher and Lower-Order Teachers by Supervision Type ................. 108

Table 13 - Analysis of Variance of Satisfaction Scores for Higher and Lower-Order Teachers. . . . . . 109 
Table 14 - Summary of Mean Satisfaction Scores for Tenured and Non-tenured Teachers by Supervision Type. . 110

Table 15 - Analysis of Variance of Satisfaction Scores for Tenured and Non-tenured Teachers. . . . . . 111

Table 16 - Summary of the Mean Satisfaction Scores for the Tenured and Non-tenured Teachers with Higher and Lower-Order Need Strengths in Clinical and Traditional Settings. . . . . . . . . 111

Table 17 - Validation of Clinical Supervision Practices . . 113

Table 18 - Teacher Perceptions of Traditional Supervision Practices................ 114

Table 19 - Frequency of Classroom Observations Reported by Ciinical and Traditional Teachers........ 115

Table 20 - Frequency of Responses to Research Inquiry 2 by Clinical Sample .............. . 117

Table 21 - Reported Areas of Need Fulfillment in Clinical Sample.................. 118

Table 22 - Frequency of Responses to Research Inquiry 2 by Traditional Sample. ............. 122

Table 23 - Reported Areas of Need Fulfillment in Traditional Supervision .. . . . . . . . . . . 123

Table 24 - Reasons for Lack of Fulfillment in Traditional. Supervision .. . . . . . . . . . 124

Table 25 - Beneficial Aspects of Supervision Reported by Higher and Lower-Order Traditional Sample . . . 125 
Table 26 - Beneficial Aspects of Supervision Reported by Higher and Lower-Order Clinical Sample. . . . 129

Table 27 - Inhibiting Aspects of Supervision Reported by Clinical Sample . . . . . . . . . 130

Table 28 - Inhibiting Aspects of Supervision Reported by Traditional Sample. . . . . . . . . 133 
LIST OF FIGURES

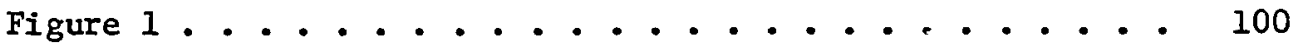


Chapter 1

\author{
Introduction of the Subject and Statement \\ of the Problem
}

Teaching children to read is one of the most complex tasks in education that occurs dafly in thousands of classrooms throughout the nation. What makes it so complex is the host of wants, drives, and learning needs that students bring to the classroom. These include: levels of aspiration and commitment, motivational orientation, need structure, stage of cognitive and moral development, concept of self, level of maturation, and so on. Interestingly, teachers also mirror these various behaviors. They behave in certain ways, perform at certain levels, possess certain skills, and teach with certain interest and commitment. Given these differences, they are analagous to a class of students at differing need levels.

This scenario poses quite a challenge to instructional supervisors responsible for teacher effectiveness and school academic growth. Principals and other supervisors must ask themselves what supervisory strategy is most useful for meeting the needs of teachers who possess varying need strengths and who have different views regarding supervisory effectiveness. This study 
explored two contemporary models--clinical and traditional supervision. Specifically, the study was designed to examine the effects, if any, of clinical and traditional supervision on the satisfaction levels of higher-order and lower-order need teachers.

Nearly three decades ago, the distinguished psychologist, Abraham Maslow (1954) proposed a theory of human motivation which focused upon human needs and helped form an operational basis for supervisory behavior. Maslow (1954) theorized that people are motivated by five drives; physiological, safety, social, esteem, and self-actualization. The five needs are classified and arranged into a hierarchy of prepotency. That is, a first-level need must be fulfilled before a second-level need can be satisfied.

According to Maslow, the physiological need represents the lowest level within the hierarchy although it assumes primary importance when it is deprived. "What this means specifically is that in the human being who is missing everything in an extreme fashion, it is most likely that the major motivation would be the physiological needs rather than any others"(pp.36-37). This need is concerned with the basic survival needs of humanity including food, water, clothing, and shelter (p.38).

When these drives are fulfilled, the individual concentrates on the next higher need, safety, and so on up the hierarchy. Safety needs include protection against danger, threat, and deprivation, and the need for structure, law, and order. Maslow stated that safety needs are basically for self-preservation, and in our culture 
largely satisfied and therefore not considered active motivators by the average, healthy person (p.39).

Above the safety needs are the social needs. They represent a person's desire for meaningful relationships with his/her peers and community, and for giving and receiving friendship and love. In Maslow's view, social needs are critical for survival in a highly mobile society where there is prevalent urbanization and a scattering of families (pp.43-44).

The next level is defined as esteem. Maslow divided esteem into two levels--self-esteem and reputation. The needs that relate to one's self-esteem are considered independence, achievement, knowledge, and self-confidence. The needs relating to one's reputation included status, recognition, and appreciation (p.45).

At the uppermost level in the Maslow hierarchy is the need for self-actualization. He defined this as the desire for self-fulfillment and to "become more and more what one idiosyncratically is, to become everything that one is capable of becoming" (p.46).

Porter (1962) adopted Maslow's hierarchical need structure and modified the levels of prepotency. He eliminated the physioiogical need and substituted another category labeled "autonomy." In his view, physiological needs are basically guaranteed in our society and therefore lack motivation behavior, whereas the need for autonomy is representative of the values of modern society (p.375). According to Sergiovanni and Starratt (1983), Porter's model has 
"particular relevance to education, for while physiological needs have tended to depreciate in importance, teachers and students have expressed a demand for control over their work environment and, indeed, over their destiny" (p.126).

These authors categorized teacher motivation into two types; participation investment and performance investment. Participation investment, they stated, is basic to all teachers and requires standard responsibilities. These include meeting classes, preparing lessons, following school rules, attending faculty meetings, and so on. Participation investment demands a fair day's work for a fair day's pay (p.127).

In contrast, the performance investment exceeds the requirements of the participation investment and the legal work relationship between employer and employee. It is characterized by teachers giving more than is required or "reasonably expected." These teachers are described as seeking challenging work, promoting innovation and creativity, and interested in improving their professional skills (p.127).

Sergiovanni and Starratt sensed that teachers demonstrating the participation investment tended to be concerned with lower-order needs. They stated:

The lower-order needs are those which are available to teachers as they make the participation investment in schools. The school exchanges money, benefits, position, friendship, protection, interpersonal gratification, and 
the like, for satisfactory participation of teachers. (p.128)

On the other hand, teachers exhibiting the performance investment are in pursuit of their esteem, autonomy, and self-actualization needs. Sergiovanni and Starratt noted that the motivational potency of these teachers focuses upon higher-order needs ( $p .128)$.

According to Porter, Lawler, and Hackman (1975), the needs and values of individuals are susceptible to gradual change as a consequence of outcomes they experience in the job environment. They stated that it would be possible for a lower-order person, receiving outcomes satisfying lower-order needs over a long period of time, to gradually raise his/her need level. Conversely, these authors indicated that a change from higher-order to lower-order is also possible (p.126). They added:

If, on the other hand, the individual is never given the opportunity to experience higher-order need satisfactions (even though he [or she] may have a desire to do so), he [or she] may gradually lose that desire and become "locked into" a pattern of work behavior in which personal growth is neither sought nor valued. If Kipsey [person in case study] were to remain in her present job for a long period of time, we might expect to observe precisely such a long-term deterioration of her own need or desire for higher-order need satisfactions. (pp.126-127) 
Frederick Herzberg (1959) developed a theory of work motivation which is relevant to higher and lower-order needs. The motivationhygiene theory involved extensive interviews with some two hundred white-collar and professionally oriented workers. His data concluded that people have two different categories of need that are independent of each other and which influence behavior in different ways. The first category of needs he called hygiene factors. They are associated with the conditions of work and are extrinsic in nature. Examples are money, status, security, benefits, fair supervision, and interpersonal relations. Herzberg stated that hygiene factors serve as the primary function of preventing job dissatisfaction and maintaining the legal work relationship, but do not motivate performance. For these reasons, they are associated with our lower-order needs (p.114-115).

The second category of needs he called motivators. These factors are largely intrinsic and tend to be effective in motivating people to superior performance. They include achievement, recognition for accomplishment, challenging work, professional growth, and increased responsibility. Herzberg argued that motivators are associated with higher-order needs and although their absence does not cause dissatisfaction, it will inhibit increased growth in worker performance (p.116).

These researchers discovered that people have differing motives or need strengths which guide their behavior, and to a certain extent predict their behavior. For example, an individual 
exhibiting higher-order needs would be more inclined to initiate some innovative action and assume a moderate degree of risk in so doing, as opposed to a lower-order need person who is not achievement oriented and ignores risk-taking situations.

This researcher would argue that teachers fall under this same rubric. The assumptions and motives they bring into a classroom weigh heavily upon the overall management of classroom organization, and their beliefs with respect to the purposes of schooling and the nature of learning.

In fact, Masling and Stern (1963) noted that teacher motives influence a teacher's teaching style and his/her attitudes toward teaching (p.104). Their study uncovered ten motives repeatedly displayed by teachers. They are:

1. Teachers with dominant motives who display their superiority over students and find gratification from the subordinate status of the pupil.

2. Teachers with nurturant motives who are characterized by a pervasive feeling of affection for children and consider a pupil's first need to be warmth and tenderness. 3. Teachers with dependent motives who prefer close supervision and guidance from their superiors. 4. Teachers with preadult-fixated motives who prefer the society of children to that of their peers and the need to get children to accept them as a "pal." 5. Teachers with orderly motives who are characterized by 
a compulsive preoccupation with rules and procedures and require pupils to complete each assignment in specific fashion.

6. Teachers with exhibitionistic motives who feel the need to entertain pupils via clowning and showmanship. 7. Teachers with critical motives who are dedicated to educational reform for better pay, fringe benefits, retirement provisions, etc.

8. Teachers with practical motives whose involvement in teaching is limited to the workday hours and not beyond. 9. Teachers with nondirective motives who discourage pupil dependency on the teacher in the name of self-actualization.

10. Teachers with status-striving motives who reflect a pre-occupation with the ascribed status of the teacher and find gratification from the prestige that teaching confers on them. (pp.98-100)

The assumptions or motives that a teacher brings into the classroom help define the structure of the classroom, what information will and will not be considered, and how information will be transmitted in the form of intents, aims, objectives or purposes (Sergiovanni and Starratt, 1983:304).

However, Sergiovanni and Starratt pointed out that teacher motives are generally not well-known. That is, teachers tend to be unaware of their assumptions, theories, or objectives and the 
motives underlying their behavior (p.305). Argyris and Schon (1974) are authors who recognized this possibility. They commented on two theories that teachers bring into the classroom--an espoused theory and a theory in use. These theories form a part of a teacher's educational platform, and are not always known to the teacher or the supervisor. They stated:

When someone is asked how he would behave under certain circumstances, the answer he usually gives is his espoused theory of action for that situation. This is the theory of action to which he gives allegiance, and which, upon request, he communicates to others. However, the theory that actually governs his action is his theory in use. This theory may or may not be compatible with his espoused theory; furthermore, the individual may or may not be aware of the incompatibility of the two theories. (p.7)

When one's espoused theory is compatible with one's theory in use, they are considered to be congruent. However, Argyris and Schon pointed out that congruence is no guarantee for effective teaching. A "bad" espoused theory congruent with a theory in use, is less desirable from a supervisor's point of view, than a "good" espoused theory poorly matched (p.14).

These dilemmas present an added dimension of importance to the role of the supervisor and the nature of instructional supervision. They are compounded when administrators supervise teachers under an umbrella approach that does not account for need variations among 
teachers, and when supervisors fail to recognize how their supervisory methods impact upon teacher behavior. Glickman and Tamashiro (1980) offered evidence to suggest that this is true when they wrote:

Often because of day-to-day pressures, supervisors lose sight of beliefs and therefore fail to recognize the impact of supervisory methods on teacher behavior, and instead attempt to "wing it" using a singular approach without any conscious rationale of its effects upon teacher satisfaction and teacher behavior change. (p.75) McNergney (1980) underscored this view when he stated that "Today's supervisors explicitly or implicitly tend to operate as if their particular approach is unique and in fact the besc approach to supervision" (p.225). He noted that the problem lies beyond the search for the best way to supervise to the more appropriate question, "Best for whom and for what purpose?" (p. 225) Gage and Berliner (1975) touched upon the "best for whom" concept when they discussed the importance of a teacher's need to meet the individual differences of their students. They stated:

Time and time again we hear teachers, parents, and administrators tell us that 'method $A$ is superior to method B'. The thoughtful teacher will add, 'for some students; for some objectives'. When people argue about which of two methods is 'better', chances are that both claims have some validity, for some students. No one method, no one text, 
no one curriculum, no one version of any teaching-learning activity is likely to be equally successful with all students. The wide variety of variables on which people differ interacts with the methods we use to teach students. The thoughtful teacher should never lose sight of the need to monitor and then match stidents to treatments in some fashion that best fits the student. (pp. 197-198)

It seems fitting to this researcher that the "best for whom" concept should be no less true for supervisors. The effective supervisor should not lose sight of the need to monitor teachers and should attempt to match teachers to supervisory strategies that best fit the teacher.

However, McNergney pointed out that "the possibility different supervisory approaches have different effects on different teachers - - has not been taken into consideration any more than in passing" (p.225). Moreover, research on teacher supervision has been further characterized as parochial and being of limited scope (Natriello, 1977; Weller, 1971).

This research was an attempt to improve this responsibility. It sought to explore the current nature of instructional supervision through clinical and traditional supervisory approaches, and provide information regarding each method's level of satisfaction and effect among experienced and inexperienced teachers, and those considered to possess higher-order and lower-order needs. 
The problem that this study examined is important for a number of reasons. First, the study will add to the sparse literature on instructional supervision and provide empirical data for strengthening the state of the art in supervision. The study should provide decision-makers with relevant information that might lead to more credible and effective means of teacher supervision, and alert supervisors to examine their supervisory methods in light of other, more effective, approaches.

Second, it will be one of the first studies to address the relationship between contemporary supervision methods and their effect upon teachers with varying need strengths. Third, it will initiate research that might begin to build a theory of supervision based on the individual differences of teachers. Finally, given the fact that fewer teachers are entering the profession, this study should help supervisors recognize the importance of the use of appropriate strategies that promote teacher effectiveness and lessen teacher stultification.

\section{Statement of the Problem}

The problem that this study addressed can best be stated in the form of a question: What (if any) effect does clinical and traditional supervision have on the satisfaction levels of higher and lower-order need teachers? The purpose of the study was to examine the relationship between clinical and traditional 
supervision models and teacher need strengths. The study assessed the satisfaction levels of both higher and lower-order need teachers supervised by either clinical or traditional methods.

The study employed two questionnaires to gather data and help draw conclusions. The Higher Order Need Strength Measure B was used to group teachers into either higher or lower-order need categories. Specifically, it provided the following information:

1. The identification of each respondent's need strengths.

2. The categorization of the respondent's need strengths into either higher-order or lower-order need groups.

The second instrument used was a Likert-scale questionnaire developed by the researcher. This questionnaire examined the relationship between higher-order and lower-order need teachers and their satisfaction with either clinical or traditional supervision methods. The questionnaire addressed the following areas:

1. The satisfaction levels of higher and lower-order need teachers supervised by clinical methods.

2. The satisfaction levels of higher and lower-order need zeachers supervised by traditional methods.

3. The relationship between years of teaching experience of higher and lower-order need teachers and their satisfaction toward clinical and traditional supervision.

4. The relationship between tenured and non-tenured teachers of both higher and lower-order categories and their satisfaction toward clinical and traditional supervision methods. 
In addition, the questionnaire posed a series of open-ended questions in order to provide descriptive depth to the quantitative statistics of the survey. The open-ended format asked respondents to describe their principal's supervisory methods and their frequency levels. This served as supplementary data for determining whether each principal actually inftlated his/her supervisory methods as espoused to the researcher. Furthermore, the descriptive data compiled information relative to:

1. The most beneficial aspects of clinical and traditional supervision.

2. The most inhibiting aspects of clinical and traditional supervision.

3. The reasons for teacher need fulfillment or the lack of it when supervised within the clinical and traditional framework.

\section{Statement of the Null Hypotheses}

The level of probability at which the hypotheses were rejected was the .05 leve1. The hypotheses of this study, stated in the null form, included the following:

1. The method of teacher supervision used, whether clinical or traditional, does not effect higher-order need teacher's satisfaction toward supervision.

2. The method of teacher supervision used, whether clinical or traditional, does not effect lower-order need teacher's satisfaction toward supervision. 
3. The method of teacher supervision used, whether clinical or traditional, does not effect nontenured teacher's satisfaction toward supervision.

4. The method of teacher supervision used, whether clinical or traditional, does not effect tenured teacher's satisfaction toward supervision.

5. The method of teacher supervision used, whether clinical or traditional, does not effect nontenured lower-order need teacher's satisfaction toward supervision.

6. The method of teacher supervision used, whether clinical or traditional, does not effect tenured lower-order need teacher's satisfaction toward supervision.

7. The method of teacher supervision used, whether clinical or traditional, does not effect nontenured higher-order need teacher's satisfaction toward supervision.

8. The method of teacher supervision used, whether clinical or traditional, does not effect tenured higher-order need teacher's satisfaction toward supervision.

9. There is no difference between higher-order and lower-order need teachers in their attitude toward supervision.

10. There is no difference in the attitudes of clinical and traditional teachers toward supervision. 
Delimitations of the Study

The scope of the study was delimited by the writer in the following manner:

1. The participants in the study were employed in elementary public schools in southern California.

2. Schools with a student body size between 300 and 700 were sampled in an effort to avoid the influence of large urban areas, which often employ vice-principals to assist with teacher supervision responsibilities, or the practice of having administrators also act as teachers which is sometimes the case in extremely small school districts.

3. Principals, excluding vice-principals and other supervisors who had the responsibility for supervising teachers were sampled.

4. Principals that utilized clinical or traditional supervision methods exclusively were included.

\section{Limitations of the Study}

The study was limited by certain conditions beyond the researcher's control. They included:

1. The limitations of the Higher Order Need Strength Measure B. Because the instrument remains under current empirical review, there is the possibility that Measure $B$ assessed specific need strengths while the existence of other needs was a clear possibility.

2. The principal's consistency in practicing clinical or traditional supervision methods. Although principals were carefully 
screened with respect to their supervision practices and the researcher randomly "shadowed" twenty percent of the principals to substantiate these methods, there may have been instances where clinical and traditional methods were not practiced exclusively with the participating teachers.

3. The principal's integrity in following study procedures. While principals were given specific instructions for randomly selecting the participating teachers, the sampling process was not observed by the researcher.

4. The willingness of the subjects to give thoughtful and honest responses to both questionnaires. It would be possible for respondents to answer in a manner inconsistent with their true feelings and thereby distort the results of the questionnaires.

\section{Definition of Terms}

The following terms are defined for purposes of clarification and because of their frequent use in the chapters that follow. Clinical supervision. Clinical supervision was defined as a supervisory process which focuses on helping teachers improve their performance through active teacher-supervisor interaction within three principal cycles: pre-conference discussion, classroom observation, and feedback conference.

Traditional supervision. Traditional supervision was defined as a supervisory practice which focuses on helping teachers improve their performance through a one-directional form of feedback 
initiated by the supervisor.

Higher-Order Need Teachers. Higher-order need teachers were defined as those teachers who desire for (a) participation in decision-making, (b) the use of a variety of valued skills and abilities, (c) freedom and independence, (d) challenge, (e) expression of creativity, and (f) an opportunity for learning.

Lower-Order Need Teachers. Lower-order need teachers were defined as those who desire for (a) high pay, (b) fringe benefits, (c) job security, (d) friendly co-workers, and (e) considerate supervision.

Tenured teachers. Tenured teachers were defined as those certificated teachers who had taught in the California public school system for more than three years.

Non-tenured teachers. Non-tenured teachers were defined as those certificated teachers who had taught in the California public school system for less than three years.

\section{Organization of Study Chapters}

Chapter 1 includes an introduction to the subject and poses the problem that this researcher addressed. It provides an account of the importance of the study along with definitions of key terms and the limitations and delimitations that the researcher experienced.

Chapter 2 will provide a review of the pertinent literature, commencing with a review of historical significances in supervision 
and including literature that examines current information with respect to clinical and traditional supervision methods and teacher need strengths.

In Chapter 3, the research design and methodology will be discussed. Specifically, the statement of the hypotheses, description of the subjects and instrumentation, and treatment of the data will be highlighted.

Chapter 4 will present the findings of the study inciuding statistical information and empirical data related to the stated hypotheses.

Chapter 5 will conclude this work and present conclusions and recommendations for future research. 
Chapter 2

\section{Review of the Related Literature}

The literature review section was divided into four parts. Part one presents a historical perspective of school supervision and its relationship to organizational theories. Part two includes an assessment of contemporary supervision models. Specifically, it examines clinical and traditional supervision through four variables. The four variables are defined as follows:

1. Basic Assumptions Undergirding Model. The conceptual base, theories, values, and attitudes that form the boundaries and distinctive characteristics of each supervisory model.

2. Focus of Supervision. The key aspects in the teaching/ learning process that supervisors believe to be essential for ensuring adequate student instruction (e.g., behavioral objectives, salient teaching patterns).

3. Role of Supervisor. The supervisory strategy [and behavior] based upon one's conceptualization of the role of supervisor and the purposes of supervision which he or she acknowledges (Glickman and Esposito, 1979:111).

4. Structure of Model. The procedures that guide supervisors 
in evaluating a teaching performance (e.g., frequency of classroom observations, use of rating scales, methods of data collection).

The third part includes an analysis of the related research pertinent to clinical and traditional supervisory approaches and their relationship to teacher satisfaction and teacher behavior change. Part four reviews studies in the field of education that have been conducted to assess need strengths in educators.

In addition, the analysis includes a critique of the research articles that have been published in the area, their strong and weak points, and other possible interpretations of the research findings.

\section{Historical Perspective of Supervision}

Modern school supervision has a diverse theoretical past. In the first quarter of the century, supervision adopted a classical view of man and institutions (Barr, Burton and Brueckner, 1938; Butts and Cremin, 1953). Instructional supervisors displayed authoritative leadership styles which directed and dominated. Teachers were viewed as appendages of management and as such hired to carry out the detailed instructions imposed upon them by their supervisors. Once told what to do they were closely supervised to ensure they had complied with the directive (Lucio, 1967:4). Wiles and Lovell (1975) reasoned this was because "teachers were not trained as they are now. Some started teaching as soon as they had left high school, with very little pre-service education". (p. 3) 
Others, however, saw classical supervision adopting the principles of organizational behavior promoted by classical theorists, such as Max Weber (a German sociologist), Henri Fayol (a French industrialist), and Frederick Taylor (an American industrial engineer). (Hanson, 1979; Lucio, 1967; Owens, 1981)

These three individuals--Taylor, Fayol, and Weber--were giants in the pre-World War I years and led the way in the early efforts to master the problems of managing modern organizations. [Although] there is no precise and universally agreed-upon beginning or end of this era, the period from 1910 to 1935 generally can be thought of as the era of scientific management. (Owens, 1981:12) According to Owens (1981), these classical theorists examined the problems of management, organization, and administration, and identified principles akin to scientific management. These principles included the concept of hierarchy, and "the contention that authority and responsibility should flow in as direct and unbroken a path as possible, from the top policy level down through the organization to the lowest member" (p.14).

A second central principle dealt with unity of command, and the fact that "no one in the organization should receive orders from more than one superordinate" (p.14). Another, the exception principle, established the need for delegating authority to 
subordinates for routine decision-making and freeing superordinates from routine matters. A fourth principle, span of control, limited the number of people reporting to a supervisor, thereby increasing control and coordination (pp.14-15).

Callahan (1962) cited reasons for the influx of scientific management principles in the educational system:

The sudden propulsion of sclentific management into prominence and the subsequent saturation of American society with the idea of efficiency together with the attacks on education by the popular journals made it certain that public education would be greatly influenced. (p.52)

Because school superintendents were most vulnerable to public opinion and pressure, they saw scientific management providing them greater job security, and affording the school system the same financial success bestowed upon the business sector who had previously adopted scientific management principles (Callahan, 1962:77). Moreover, stated Callahan, scientific management would "elevate the work of education from where it was, based upon guess-work and personal opinion, to scientific accuracy" (p.98). Lucio and McNeiI (1979) stated that under scientific management the supervisory staff assumed the key role in determining the "best" teaching methods for teachers (p.9). They added:

The burden of finding the best methods was too great and 
too complex to be laid on the shoulders of teachers. Teachers were expected to be specialists in the practice that would produce "the product"; supervisors were to be specialists in the science relating to the process. Supervisors were to (1) discover the best procedures in the performance of particular educational tasks, and (2) give these best methods to the teachers for their guidance. (p.9) The use of science to determine these methods was listed by March and Simon (1961) as follows:

1. Use time and methods study to find the "one best way" of performing a job. .

2. Provide the worker with an incentive to perform the job in the best way and at a good pace... 3. Use specialized experts (functional foremen) to establish the various conditions surrounding the worker's task methods, machine speeds, task priorities, etc. (p.19) However, in the 1930s, discoveries recognizing the importance of the socio-psychological needs of the worker and his/her group spread quickly through the public, business and educational sectors of organizational life. The well-known Hawthorne Studies conducted by Elton Mayo and others seriously challenged the principles of scientific management (Mayo, 1933; Roethlisberger and Dickson, 1939). "The discovery that workers could control the production process to a considerable degree, independent of the demands of 
management, shattered many of the precepts central to classical theory" (Hanson, 1979:10).

The growing awareness of need differences between the individual and the organization gave birth to a human relations philosophy. The argument went that by bringing into harmony the basic needs of the employees with the goals of the organization, a democratic environment would evolve and as such lead to greater efficiency (Hanson, 1979:10).

The human relations methodology maintained that "employees should have a feeling that the company's goal is worth their efforts; they should feel themselves part of the company and take pride in their contributions to its goal" (Burleigh, 1945:283). Lucio (1967) offered an example of the influential aspects of Human Relations. He stated:

The human relationists pointed out that it is through the informal group that the social need-satisfaction is provided. The rash of company-sponsored bowling and baseball teams, company picnics, and company recreational facilities provided by industry during the $1930-40$ period can be traced directly to the human relationist influence, since the human relationist model does not recognize any conflict between organizational objectives and the provision of such facilities. Satisfying the workers' social and psychological needs is entirely congruent with the organization's goals of effectiveness and productivity. 
$(\mathrm{p} .6)$

The strong emphasis on worker satisfaction similarly focused upon the behavioral characteristics of leaders. Research studies attempted to correlate psychological traits of leaders with effective leadership (Lewin, 1938; Stogdill, 1948). Such research produced endless traits (e.g., intelligence, scholarship, verbal articulation, etc.) that were thought to be consistent with good leadership. In addition, the styles of leadership behavior were also studied. These "early studies were developed around democratic and authoritarian styles and since the democratic style came out with favorable results, democratic supervision took on a new significance" (Wiles and Love11, 1975:36).

The impact of Human Relations was further underscored by the publications of important texts during this period:

1. John Bartky, Supervision as Human Relations, 1953...

2. Charles Boardman, Democratic Supervision in Secondary Schools, 1953. . .

3. William H. Burton and Leo J. Brueckner, Supervision, A Social Process, 1955.

These authors advocated cooperative planning, subordinate participation in decision-making, conflict resolution, open communications, etc. It was assumed that by establishing this environment, a staff would be easier to work with, lead, and control (Bartky, 1953; Boardman, 1953; Burton and Brueckner, 1955). Via this egalatarian framework, Lucio stated, supervisors became 
psychoanalytical evaluators. They made value judgements about teaching ("the teacher is warm and friendly") that had little correlation to effective teaching or the goals of schooling (p.6). As a result, Lucio (1967) argued:

-. supervisors tended to analyze the incidentals rather than the consequences of teaching, focused on personal attributes of teachers and pupils, described teacher behavior in terms of inference rather than in terms of observed effects on pupils, and tended to view effective teachers as those whose performance was congruent with some hypothetical mode1. (underlining author's emphasis) (p.6) While the human relations philosophy viewed satisfaction as a means of achieving greater efficiency in schools, it resulted in widespread neglect of teachers and curriculum. The participatory supervision appeal became permissive supervision to the point of laissez faire supervision (Sergiovanni and Starratt, 1983:4). Moreover, the approach had other deficiencies as Etzioni (1964) pointed out:

By providing an unrealistic (happy) picture, by viewing the factory as a family rather than as a power struggle among groups with some conflicting values and interests as well as some shared ones, and by seeing it as a major source of human satisfaction rather than alienation, Human Relations comes to gloss over the realities of work life. (p.42) 
In the mid 50's, instructional supervision assimilated aspects of human relations and classical theory. It combined the values of the authoritative supervisors who emphasized the organizational goals, and those of the Human Relationists who emphasized the social goals of individuals (Lucio, 1967:8). Owens (1981) stated:

This new concept recognized the dynamic interrelationships between (1) the structural characteristics of the organization and (2) the personal characteristics of the individual. It sought to understand the behavior of people at work in terms of the dynamic interrelationships between the organizational structure and the people who populated it. (pp.24-25)

Future historical developments, such as the Russian launch of Sputnik, prompted the contemporary development of instructional supervision (Goodlad, 1976:5). The period from 1957-1967, known as the Education Decade, witnessed federal legislation in support of school programs and personnel, curriculum revision, and the encouragement of innovative approaches to teaching and learning (Goodlad, 1976:6). Alfonso, Firth and Neville (1981) stated that instructional supervisors assumed a leading role in shaping efforts to improve instruction. This included identifying instructional problems, serving as a resource person, promoting interpersonal communications, serving as a change agent, and demonstrating the 
conceptual and technical abilities required for leadership in a collegial and unitary setting (p.36). This rational/technical approach assimilated a social system structure which gave impetus to contemporary traditional supervision (Alfonso, Firth and Neville, 1981; Lucio, 1967; Lucio and McNeil, 1979; Neagley and Evans, 1980). The central theme of this supervisory method is control, accountability, and efficiency (Sergiovanni and Starratt, 1983:4). An alternative to the rational and technical model is a holistic framework which treats supervision through a clinical perspective--"a shared function where supervisor and teacher conceptualize their tasks to be those of goal focus, facilitating adequate communication systems, equalizing power, building morale, nurturing teacher autonomy, and developing a problem-solving capacity" (G1ickman and Esposito, 1979:124). Here, the supervisor implements clinical supervision approaches which encourage face-to-face encounters with teachers about teaching with the goal of trying to help teachers achieve instructional improvement through a cooperative venture (Cogan, 1973; Goldhammer, 1969; Goldhammer, Anderson and Krajewski, 1980; Hunter, 1976; Luehe and Ehrgott, 1976; Mosher and Purpe1, 1972).

The rational/technical and clinical perspective represent recent images of instructional supervision. While they operate in distinct fashion, and are supported by distinct theories, they share one common strand--the improvement of teaching. In view of their distinction, the shape and form of the literature that follows 
examines the behavior, practices and methods of these contemporary supervisory approaches.

Assessment of Contemporary Instructional Supervision

Basic Assumptions Undergirding Models

Traditional supervision was perceived by Lucio and McNeil (1979) as a bureaucratic structure that is advantageous to the school and to the achievement of educational goals. They saw supervision as a means to establish patterns which expand the development of educational content, by observing precise methods that ensure intellectual ends ( $p .88$ ).

In order that pupils may become skilled and mature persons who are able to control their environment, attention must be given to the orderly development and organization of experiences and subject matter. There must be a scheme of organization that can achieve a cumulative effect in learning. (p.90)

Sergiovanni and Starratt (1983) found this approach to supervision linked to a detailed curriculum syllabus or performance objectives. Traditional supervisors control the work of teachers, the objectives they pursue, the materials they use, the curriculum they follow, the assignments and tests they give, and the schedule they follow (p.290). 
This responsibility is legitimized, Hanson (1979) stated, "in organizations based on legal-rational authority and which vest the authority of command in specific offices to be used by the people who occupy those offices" (p.24).

Lucio and McNell (1979) cited three important advantages for the use of authority in traditional supervision:

-. (I) it permits a decision to be made and carried out even when agreement cannot be reached; (2) it secures rational decisions, holding the staff team to account; and (3) it permits coordination of activity. (p.88) Alfonso, Firth, and Neville (1981) deemed authority to be essential if supervisors are to be effective. They stated: If instructional supervisory behavior is to be effective, the organization must confer on supervisors those prerogatives of authority and visible symbols of power and status that provide credibility and leverage in affecting the behavior of others. To maintain supervisors in positions of low or indeterminate positions of power is to render them much less effective. The effectiveness of supervisors can be enhanced by organizationally conferred status; supervisors can increase their status within the informal system by virtue of their own effective behavior. If a supervisor is to be held accountable for directly influencing teacher behavior and for achieving the goals of the organization, he or she must be given the power and 
status consistent with his or her job responsibility. (p.125)

Lucio and McNeil (1962) concurred when they cautioned supervisors about ignoring their positions of power. They indicated three outcomes that usually follow when equalitarian assumptions overshadow the nonequalitarian structure.

First, goals set by faculties that are inconsistent with district and the larger community goals are certain to create conflict and result in repudiation.

Supervisors cannot well afford to ignore the school's hierarchical structure in which special privileges and status differentials predominate. Certainly, supervisors should not give the impression that individual teachers determine school policy. If each teacher goes his way, there is no policy and disorder results. This is not to say that supervisors must not encourage wide participation in the determination of purpose and procedure. Nor is it meant that teachers and faculties should not be supported as they try new ideas and engage in self-regulation. Rather it is facing the fact that no school group is autonomous in the setting of expected outcomes of instruction and that the process of directing and overseeing the execution of public policy with respect to the school presently rests within hierarchical and formal structures. (pp.77-78) 
Second, supervisors incur disrespect when they deny the existence of the authoritative structure and attempt to play down or denounce their authority over others. In these instances, supervisors attempt to obligate their teachers by requesting their cooperation when they have the authority to issue action, tolerate prohibited practices and/or show excessive considerate supervision, all of which are seen as a weak posture on the part of the supervisor.

Third, the effectiveness of the school and the morale of teachers is weakened when supervisors fail to appreciate the value of their experience and knowledge in the supervisory process. Supervisors who assume that all teachers have the ability to provide appropriate learning experiences independently are committing a mistake. Many teachers require guidance and direction which, for them, is not interpreted as a criticism of their ability (pp.78-79). According to Blumberg (1980), supervisors who emphasized their line-office position with teachers initiated more direct behavior approaches. These supervisors, he argued, held basic assumptions about supervision. While these assumptions predominated, their degree of emphasis and use varied. The assumptions included:

1. The control of a situation is based on the authority of one's position in an organizational hierarachy. 
2. People in higher organizational positions have more expertise.

3. People in lower organizational positions can best be evaluated by those who are higher.

4. The most important external rewards of a job come to a person primarily from a person who holds a higher position.

5. Empathic listening to the teacher is not a necessary dimension of helping.

6. People learn best by being told what to do by someone in a higher organizational position.

7. Work is rational; there is little place in supervision for discussion of feelings or interpersonal relationships. 8. Collaborative problem solving between supervisor and teacher is not a critical concern in supervision.

9. Teaching as a skill can generally be separated into the right and wrong way of doing things. (p.88)

However, Alfonso, Firth, and Neville (1981) also pointed out that organizations promoting legal-rational authority recognized "the importance for supervisors to contribute to the development of a positive informal organizational system. This included the quality of communication among its members and the creation of a positive tone throughout the system" (p.87). These authors thought legal-rational organizations to be dynamic, open systems, rather than the closed bias their order and rationality emphasize. They are continuosly interacting with the environment in 
which they exist. They are affected and guided by events in the larger social system. The interaction and blending of individual goals and aspirations as against the purposes of the formal organization is continuous. Hence organizations can be studied as open systems--as arrangements that have direction and intent while also taking into account environmental conditions, including the needs and goals of those persons who serve and are served by a particular organization. (p.62)

This typology of organization and its supervisory assumptions is opposite a more indirect behavior system contemporarily recognized as clinical supervision (Acheson and Gall, 1980; Cogan, 1973; Goldhammer, 1969; Goldhammer, Anderson and Krajewski, 1980; Mosher and Purpel, 1972; Sergiovanni and Starratt, 1983). There are several assumptions upon which clinical supervision is based. First, supervision for the improvement of teaching is more likely to increase a teacher's self-development when implemented within the mutual support of a partnership throughout the year on a regularly scheduled basis (Flanders, 1970:10). "Flanders use of the word mutual support and partnership is very close to the concept of colleagueship in clinical supervision" (Cogan, 1973:67). According to Cogan, a teacher and supervisor enter into a colleagueship when they work together as associates and equals to attain the goal--higher levels of student achievement through improved methods of instruction (p.68). The staff-office position that a supervisor 
assumes is central to colleagueship and a basic proposition in clinical supervision (Pohland, 1976; Sullivan, 1980). Cogan underscored its importance when he added:

This relationship between teacher and clinical supervisor is maintained in force as long as they can work together productively as colleagues. It deteriorates significantly or ceases to exist when either assumes an ascendant role or is accorded an ascendant role by the other. (p.68)

A second assumption vested in clinical supervision is that teaching is behavior (Mosher and Purpel, 1972). Mosher and Purpel suggested this to mean what the teacher does and what the students do in an observable fashion and in an interactive process (p.69). "When clinical supervisors refer to teaching, they are referring to teacher behavior and student behavior relative to a curriculum and formal instruction in that curriculum" (Mosher and Purpel, 1972:79). Cogan identified the teacher's behavior as the appropriate focus of supervision when he stated:

The proper domain of the clinical supervisor is the classroom behavior of the teacher. That is, the proper subject of supervision is the teacher's classroom behavior, not the teacher as a person. This separation of behavior from the person behaving is artificial but strategically useful. It is designed to persuade the supervisor to limit himself [or herself] to the domain in which he is professionally trained; to focus on what happens in class 
rather than to attempt to change the teacher's personality--attributes, beliefs, needs, and values. (p.58) In addition, Mosher and Purpel reported that the primary objective in clinical supervision is translated into the "planning for, observation, analysis, and treatment of the teacher's classroom performance" (p.78). They continued:

Clinical supervision focuses on what and how teachers teach as they teach. The immediate objective is to alter (that is, improve) the materials and method of instruction directly, at the point of the teacher's interaction with students. It is this principle of direct application that makes the method of supervision "clinical": it addresses the doing, or practice, dimension of teaching. (pp.78-79) A third assumption by clinical supervision adherents, is that human behavior is patterned and that as a subset of this general behavior, teaching is also patterned (Cogan, 1973; Goldhammer, 1969; Goldhammer, Anderson and Krajewski, 1980; Mosher and Purpe1, 1972). Mosher and Purpel (1972) stated that "What the teacher does and says in teaching content to children does not occur randomly. Rather, it shows recurring and characteristic patterns" (p.80). They added:

A teacher, in communicating with students, may characteristically talk at them, question them or listen to them; intellectually, he [or she] may stimulate students or bore them; emotionally, he [or she] may be supportive and accessible or critical and remote. Whatever the teacher's 
characteristics, his [or her] performance will consistently reflect some such patterns of behavior and effect. (p.80) In Goldhammer's (1969) view, a teacher's salient patterns of behavior are likely to have cumulative effects on learners, for better or worse, since they are susceptible to repetition from day to day (p.94). He noted:

-. for supervision to have any palatable effects upon the students' lives, it must be aimed at strengthening, extinguishing, or in some other way modifying these saliencies of the teaching performance. Besides the fact that Teacher's patterns fill the air more than anything else about him [or her], one must appreciate how potently learnings resulting from certain stimuli can be reinforced by repetitions of those stimuli and of how important this can be either when what is learned makes particularly good sense or when what is learned is nonsense. (p.94) Cogan stressed that such patterns merit the attention of both supervisor and teacher since they help make sense and order out of classroom interaction data. This enables teachers to learn about and possibly modify patterns that they perceive to be related to teaching principles. Cogan stated that the identification of these patterns will often discourage a teacher from focusing on unimportant events and turn their attention to more significant behavior. In this way, teaching focuses upon the analysis of behavior rather than on the personality of the teacher (p.174). 


\section{Focus of Supervision}

The appraisal of teacher performance, from a traditional supervisory view, is linked to some set of observable standards assumed to be related to effective teaching (Glickman and Esposito, 1979; Lucio and McNeil, 1979). Wiles and Lovell (1975) found these standards to be performance objectives, and each professional persons' responsibility and contribution toward the attainment of the organization's goals and his/her own personal goals. These authors suggested that each staff member should delineate the personal goals he/she plans to achieve during the school year, the methods that will be implemented to achieve the goals, and the effort that will be expended in their pursuit (pp.242-243). Magers (1975) stated that instructional objectives are advantageous because (a) they provide a basis for designing curriculum content, (b) they help evaluate the success of instruction, and (c) they help teachers guide student efforts toward the attainment of important instructional intents (pp.3-4). Lucio and McNeil (1979) underscored the advantages of instructional objectives and offered traditional supervisors procedures for the appraisal of performance goals. These included the following:

1. Supervisors and teachers agree on realistic, attainable objectives and set the criteria for appraisal. Teachers are provided with all necessary resources to help them 
reach objectives. Success in attaining instructional objectives should at least equal that attained by other teachers in relatively similar assignments. Persistent lack of success in achieving results within a specified period is faced by supervisors and teachers. New or probationary teachers unable to achieve results contracted for within a specified period are not continued on the job. Experienced and/or tenured teachers who are not achieving satisfactory results and who show no signs of improvement in teaching after in-service training may be reassigned to other duties or counseled to leave teaching. 2. Appraisal of teaching performance is based on proximity--those who are closest to setting instructional ohjectives have this responsibility.

3. Authority of expertness is agreed upon as the major consideration-me ability on the part of supervisor and teacher to determine instructional outcomes, select and arrange learning contacts, appraise results, and, above all, predict the consequences of particular acts upon the learning of pupils.

4. No teacher-appraisal program is legitimate unless it offers protection to pupils and evidence that it has the power to increase the educational progress of pupils. A prime responsibility of supervisors is to insure that appraisals of teacher performance are related to measures 
of pupil learning. The happiness and welfare of teachers is secondary to this objective. Supervisors who assign high ratings, not substantiated by evidence of performance, in attempts to keep teachers happy abrogate their supervisory reponsibility and, indeed, may be guilty of professional malfeasance. (p.258)

In addition to performance objectives as the key focus in traditional supervision, Lucio and McNeil (1979) cited a primary task of supervisors and teachers to be that of change in pupil behavior. They stated that supervision by objectives "shifts the evaluation of teachers from how they teach (as if we know what constitutes the optimum in method) and from their particular personal characteristics to the results they obtain with learners" (p.107). They cited two reasons for the support of supervision by objectives.

First, the school is required to analyze and identify the concepts and skills that learners should acquire for the future and formulate objectives for their attainment. Once it is understood that teachers will be held accountable for student knowledge of specific skills, there is less evaluation of teacher competence with respect to process and more upon pupil performance.

Second, evaluation of teacher effectiveness by measured student achievement, eliminates the use of irrelevant criteria when appraising teacher performance. When teachers know that their evaluation does not rest upon the opinion of an administrator, but 
upon the extent to which they achieve the performance objectives they have agreed upon, methods of instruction will be improved (pp.106-107).

Proponents of clinical supervision also endorsed the usefulness of performance objectives for clearly specifying the outcomes of teaching (Cogan, 1973; Goldhammer, 1969; Goldhammer, Anderson and Krajewski 1980; Sergiovanni and Starratt, 1983). Cogan stated, that objectives written in appropriate behavioral terms will give the teacher the advantage of knowing what student behaviors to reinforce and will be able to direct positive reinforcement to relevant behaviors, avoiding reward of irrelevant activities. Futhermore, the objectives will help supervisors concentrate their observation on appropriate aspects of instruction and achievement (p.117). Sergiovanni (1976) reported that in addition to performance objectives, "the clinical supervisor needs to be concerned with two platforms the teacher brings to the classroom--an espoused platform and a platform in use" (p.25). According to this author: The major job of the clinical supervisor is to help construct platforms in use from observations of classroom behavior and from collections of artifacts that are the products of this behavior. Teacher plans, classroom organizational patterns, transcripts of dialogue, patterns of student influence, interaction patterns over time, reinforcement patterns, and video tapes of classroom activities are examples of only some of the behavior 
patterns and artifacts which might carefully be analyzed in order to adequately construct aspects of a teacher's platform in use. (p.27)

Several other authors identified data for clinical supervisors to consider in their classroom interaction analysis. These data included information relative to the student's behavior, the teacher's behavior, and the events in the classroom which effect student learning. This material was identified as unanticipated learnings, critical incidents, salient teaching patterns and teacher behavior, and principles of learning (Cogan, 1973; Goldhammer, 1969; Goldhammer, Anderson and Krajewski 1980; Hunter, 1969a, 1969b, 1969c; Mosher and Purpel, 1972).

Goldhammer (1969) defined unanticipated learnings as, "a great spectrum of things that pupils learn individually and collectively which the teacher did not intend them to learn, generally without the teacher's awareness that they have been learned" (p.12). He listed several examples of teaching and the unintended learnings they might foster:

1. Whenever a pupil gives a response, the teacher repeats his [or her] response verbatim. I learn: 'There is no point in listening to anyone in here besides the teacher because he [or she] will say everything eventually.' 2. The teacher responds to almost every pupil's recitation with a stereotyped, 'OK, very good.' I learn: 'Anything goes.' 
3. The teacher gives reading assignments to be done at home, but never refers to the material in class or on examinations. I learn not to do the assignments. 4. In situations where the teacher is recording pupils' successful responses on the board, he [or she] does so in precisely the language used by the pupil. I learn: 'This is a place in which my ideas count for something'. (pp.12-13)

Cogan pointed out that critical incidents should also be given important priority in the analysis of teaching (p.172). He defined critical incidents as "some single action by the teacher that is likely to have a strong and lasting effect upon students' learning, upon their affective relation to their learning, or upon their relationship to the teacher" (p.168). To illustrate, he wrote: -. if a teacher, in an outburst of anger, strikes a student in a school in which physical attack and corporal punishment are expressly and strongly taboo, his action--even if it is an isolated incident--may have serious and possibly irreversible consequences for the students' learning. (p.172) On the other hand, Cogan also stressed that clinical supervisors cannot afford to overlook a critical incident likely to have a favorable result. "The teacher whose students have achieved some sudden insight with lasting effect; the deep resonances of poetry or have come face to face with love, hate, pity, cruelty, or their own 
humanity, even if only ouce, should have the supervisor's help in recognizing the occasion and assessing its effects" (p.173). According to Mosher and Purpel (1972), "the most complex and valuable level of supervisory analysis involves identifying recurrent patterns in what is being taught, in the teaching itself, and in the ways students respond" (p.98). They indicated that the analysis of instruction is a means toward changing teacher behavior and encouraging teachers to behave in particular ways. This is attempted through a formal post-teaching conference focusing on patterns in content, instruction, or student behavior and their possible interrelations (p.98). Goldhamer described certain teaching patterns which he encountered repeatedly in classrooms he observed. They were:

1. Ninety percent or more of the words spoken during any given lesson are spoken by the teacher.

2. The teacher asserts that he [or she] will not call on people who call out of turn, but he [or she] often does. 3. The teacher calls only on children who have raised hands.

4. The teacher uses schoolwork as an instrument of punishment (e.g., students copy ' $W$ ' pages from the dictionary).

5. The pace of instruction and all sequences of instruction are determined by the teacher. (p.15) 
Madeline Hunter's (1973) work at U.C.L.A. in the early 70's also investigated the analysis of teaching through identifying basic competencies demonstrated by successful teachers. Hunter's work focused upon four instructional factors which she called the principles of learning. These principles include:

-. (1) principles that affect the learner's motivation;

(2) those that affect his [or her] rate and degree of learning; (3) those that influence his [or her] retention of what he [or she] had learned; and (4) those that contribute to his [or her] ability to transfer the learning achieved to new situations where that learning is applicable. (p.3)

According to Hunter (1969a), these principles operating together make learning meaningful, and should be a part of instruction (pp.56-57).

Luehe and Ehrgott (1976) underscored Hunter's principles of learning and their analysis in the teaching/learning process. They developed a Clinical Teaching Model that supervisors can use to analyze teacher lessons within three component areas.

The first component termed What, requires supervisors to identify the lesson objective and its complexity and appropriateness for the learners. Luehe and Ehrgott stated that by using Bloom's (1956) taxomonies (cognitive, affective, psychomotor) evaluators can help teachers arrive at decisions of appropriateness.

The second component, Who, assesses the degree to which the behavior, asked by the teacher, was appropriate for the content and 
realistic in relation to the students' age, readiness, and previous experiences.

The third component is the How component. This phase asks the supervisor to determine the appropriateness of the materials and activities with respect to the lesson objective. Moreover, the supervisor observes whether the teacher can monitor pupil performance and make appropriate corrections in the lesson plan. Furthermore, the How component analyzes the teacher's use of the psychological principles of learning identified by Hunter as motivation, reinforcement, retention and transfer (pp.9-12).

Luehe and Ehrgott further noted that these components become the central focus of the lesson analysis and, subsequently, the interaction between the teacher and the students which is recorded via the supervisor's anecdotal records (p.15).

\section{Role of the Supervisor:}

In a study conducted by Blumberg (1980), 166 teachers from elementary and secondary schools in urban, rural and suburban communities were asked to identify behavioral styles and the degree of emphasis they perceived their supervisors as placing on each type of behavior. The study results identified eight practices dealing with direct and indirect supervisory behavioral styles. The data suggested that direct behavior supervisors were more inclined to give their teachers opinions about current teaching practices, suggest they do things in specific ways or, in fact, tell them what 
to do, and criticize their teaching behavior (p.83). Blumberg added: If what is communicated to a teacher by a supervisor when his [or her] behavior, aside from what he [or she] actually says, is predominantly direct, we postulated a concern for controlling the behavior of the teacher, and a concern for evaluating the teacher. (p.83)

According to Sergiovanni and Starratt (1983), supervisors inclined to control the behavior of teachers and focus upon evaluation initiated traditional supervision practices (pp.296-298). They "are seen as emphasizing task-oriented leadership and a variety of quality-control mechanisms in efforts to push teacher and school closer to achieving objectives and increasing production" (Sergiovanni and Starratt, 1983:15-16). Glickman and Esposito (1979) reported on a similar supervisory approach called Alternative One. They stated that supervisors acting in congruence with this approach "see the process of supervision as including the functions of leading, controlling and directing" (p.112). Based on their experience and authority, Alternative One supervisors have definite ideas regarding what constitutes an effective teacher. They are primarily concerned with product evaluation and setting the parameters of the learning environment in such a way that there is minimum interference from students or teachers (p.112). Moreover, Glickman and Esposito saw these supervisors as task oriented and answering questions regarding their behavior in the following manner: 
1. I would most likely act as a spokesman for my

teachers. (always, frequently).

2. I would allow my teachers complete freedom in their work. (seldom, never).

3. I would encourage the use of uniform procedures.

(always, frequently).

4. I would keep the work moving at a rapid pace. (always, frequently).

5. I would decide what shall be done and how it shall be done. (always, frequently).

6. I would push for increased production. (always, frequently).

7. I would permit my teachers to set their own pace.

(seldom, never).

8. I would ask that teachers follow standard rules and regulations (always, frequently). (p.112)

Blumberg's study also mentioned predominate indirect supervisory behaviors as perceived by teachers. These indirect behaviors focused on five dominant tendencies:

1. Supervisors accept questions regarding a teaching problem and ask for clarification about a situation under consideration.

2. Supervisors ask uncritical questions about a teacher's behavior (that is, why you did what you did). 
3. Supervisors use praise in connection with a teacher's idea, plan of action, etc.

4. Supervisors ask for opinions about how to overcome a teacher's teaching problems.

5. Supervisors discuss a teacher's feelings about the productiveness, ease of communication, threat, etc., in the relationship with him [or her] as a supervisor. (p.83)

Blumberg noted that "When a supervisor is predominantly indirect, we postulate that he [or she] conveys a concern for the teacher as a person (with goals and feelings) and a concern for collaborative problem solving (engagement)" (p.83).

The role of the clinical supervisor as a collaborator was underscored by Cogan and others (Cogan, 1973; Goldhammer, 1969; Goldhammer, Anderson and Krajewski, 1980; Sergiovanni and Starratt, 1983). He stated that colleagueship must precede any attempt from the clinical supervisor to observe a lesson or teaching performance (p.88). The clinical supervisor's first role is to "help the teacher understand the objectives, ethics, policies, practices, and techniques of clinical supervision" (p.88). This includes the explanation of the prescribed roles that both teacher and supervisor play, and each individuals' rights and responsibilities with respect to lesson planning, lesson observation, and lesson analysis. In addition, the supervisor must also assure the teacher that clinical supervision is built around colleagueship and interaction as opposed to authoritarian intervention, and that such a program will be 
continuous and formative with a scheduled duration (pp.88-89).

Sullivan (1980) stated that the process of clinical supervision prescribes certain roles for both the teacher and the supervisor--some that are shared, others unique to one or the other. Shared roles, for example, require the teacher and supervisor to take part in conferencing, analyzing, and gathering data, and to act as decision-makers who may agree to disagree and try alternatives. On the other hand, the process of clinical supervision requires separate roles as well. Teachers are expected to plan for the lessons; supervisors plan for the conferences. The teacher instructs the students in the content of the curriculum, the supervisor instructs the teacher in the process and cycle of clinical supervision (p.12).

Although the literature portrayed delineated roles for clinical and traditional supervisors, or direct and indirect supervisors as identified by Blumberg, the latter warned that behavioral styles mainly represent a combination of patterns that, when taken together, identify dominant tendencies, and should not be considered one-dimensional in every situation or lead one to believe that direct and indirect supervisors are always so defined ( $p, 66)$.

\section{Structure of the Models}

"Since teachers are essential to managing the learning experiences of students and to implementing the various instructional strategies, their performance is important to the 
success or failure of student learning" (Neagley and Evans, 1980:326). This performance is of ten times gauged through the systematic process of some supervisory model that a supervisor follows.

According to Pohland (1976), the traditional supervisory model "has no clearly articulated structure," yet assesses classroom interaction via classroom visitations and the utilization of formal evaluation instruments (p.6).

Marks and Stoops (1978) discussed the importance of scheduled and unscheduled classroom visits conducted by the supervisor. They pointed out that scheduled visits should be regular, a minimum of once per month, focus upon the lesson objective, teacher attitude and knowledge of subject matter, teaching method, materials, classroom organization and student participation. These visits, they stated, should be preceded by a conference in order for the supervisor to acquaint himself or herself with the lesson objective and purpose (pp.213-217). In addition, Marks and Stoops urged the need for unscheduled classroom visits. These visits should be made to beginning and experienced teachers approximately four times each school year. Their purpose is to give the supervisor a feel for the general status of the school and its curricular program, and should not focus attention on individual teachers and/or problems since unscheduled visits are short in duration. Moreover, these authors suggested that supervisors should inform their staff about his/her intent to conduct unscheduled visits within a designated period as a 
human relations gesture (pp.217-218).

Neagley and Evans (1980) suggested, "There are at least three different types of observational visits that the supervisor might make for an overall view of the educational program" (p.192). One of these is a classroom visit made in the morning before the students arrive or in the afternoon after the students have been dismissed. The supervisor should look for evidence of special projects, learning centers, instructional supplies such as books, maps, study prints, audio-visual equipment, etc., pupil work on display and chalkboard writings. A second type of visit should be a series of five or ten minute observations to many classrooms over several days to gather impressions regarding pupil/teacher relationships and the climate of learning. A third type of visit calls for the supervisor to visit a number of classrooms and participate in the learning activities.

Neagley and Evans stated that supervisors, especially principals, are a part of the instructional team and should demonstrate to pupils and teachers that they are there to help. Furthermore, these authors reported that this approach is likely to keep the supervisor in touch with the entire program, and increase the likelihood of their welcome at other times when there are problems to be solved cooperatively (pp.192-193).

Neagley and Evans further noted that supervisory personnel utilizing the systems approach to school management must be specific and precise evaluators if they are going to help teachers improve 
their instructional skills (p.200). Hyman (1975) underscored this need when he stated:

The classroom is a complex and active place even when there appears to be little physical movement by the teacher and students. Much is going on at all times. It is important, obviously, that the observer focus on critical aspects. Here we return again to the essential activities... the logical and strategic acts of teaching. If the observer will focus on observing these logical and strategic acts in contrast to such items as teacher dress and window neatness, for example, the supervisor will be on the correct path.

Once it is established what to observe it is necessary to answer another basic question: "How does one observe these essential activites of teaching?" To answer this question, it is necessary to examine again what it means to observe. Observing is much more than mere seeing. Observing involves the intentional and methodical viewing of the teacher and students. Observing involves planned, careful, focused and active attention by the observer. Observing involves all the senses not just sight or hearing. From this concept of observing, it is quite clear that the observer must be selective . . This means that the observer must explicitly recognize the need to be selective and select the critical aspects of teaching to focus on. 
Futhermore, the teacher, who is observed, must recognize that the subsequent feedback is necessarily selective, too. Being selective involves taking a "point of view," and the easiest way to take one is to choose an observational instrument from among the many our educational researchers have developed. An instrument has a built-in framework, a point of view or vantage point, as well as a set of rules for systematically observing and organizing data. In addition to guiding the observer in selecting what to observe, an observational instrument yields reliable and specific data which form the basis of helpful feedback. (pp. 24-25)

Sergiovanni and Starratt (1983) pointed out that the use of rating scales enables the technical/rational supervisor [or traditional supervisor] "to be objective, to treat all teachers the same, and to ensure that the focus of the evaluation is on important events" (p. 298).

Marks and Stoops stated that rating instruments can be useful for recording data during a classroom observation if they are developed cooperatively between teachers and supervisors, and if they focus upon individual and school/district goals (p.221). They suggested that a typical visitation record could include the following observation criteria:

1. Classroom management and disciplinary control. . .

2. Knowledge of subject matter... 
3. Teaching techniques and instructional skills...

4. Student-teacher relationships...

5. Personal characteristics such as appearance, punctuality, tact, voice, cooperation, sense of humor, initiative, enthusiasm, poise, and good grooming. .

6. Student interest, activity, and reactions...

7. Physical characteristics such as ventilation, lighting, temperature, seating arrangements, bulletin boards, etc.

8. Professional conduct, ethics, and evidence of professional growth. (pp. 222-225)

Manatt and Palmer (1976) reported that their five year research study focusing on improved rating scales for assessing teacher performance identified a comprehensive, valid and reliable instrument "sufficiently powerful to separate high teacher performance from mediocre teacher performance" (pp.21-22). The instrument was developed after 1,277 performance appraisals were conducted on 69 elementary and secondary teachers by administrators, teachers and students. Thirty items were then selected for discriminating teacher performance. The items were grouped into five descriptive areas; (a) productive teaching techniques, (b) positive interpersonal relations, (c) organized/structured class management, (d) intellectual stimulation, and (e) desirable out-of-class behavior (p.22). According to Manatt and his team of researchers, rating scales 
that are objective, highlight observable events, and use performance criteria and operational procedures that are based upon the research for effective instruction and leadership can be both reliable and discriminating. They stated that administrators using these instruments for assessing teacher performance will find that student achievement will increase, the board and superintendent will have accurate information upon which to base decisions, and taxpayers will realize that teachers are being held accountable ( p.21). En totus, the instrument included the following performance descriptors: Productive Teaching Techniques 1. The teacher uses probing questions for understanding of concepts and relationships, and for feedback to the teacher. 2. The teacher uses student ideas in instruction.

3. The teacher uses structuring comments, such as examples, to serve as advance organizers. 4. The teacher uses varied teaching strategies and materials that stimulate student learning. 5. The teacher explains things well, puts ideas across logically and in an orderly way. 6. The teacher provides opportunities for pupils to learn material on which they will later be tested.

Positive Interpersonal Relations

1. The teacher shows respect for his [or her] pupils. 
2. The teacher is tolerant of students whose ideas differ from his [or her].

3. The teacher uses supportive criticism rather than blame, shame, or sarcasm.

4. The teacher is readily available to students.

5. The teacher is fair, impartial, and objective in treatment of pupils.

6. The teacher provides opportunities for all pupils to explain success.

Organized/Structured Class Management

1. The teacher constantly monitors pupil progress and adjusts the pace accordingly.

2. The teacher presents material in a well-organized fashion in order to use class time efficiently. 3. The teacher has well-defined objectives for his [or her] pupils, and works toward them. 4. The teacher uses pupil assignments that are relevant and sufficient for in-depth learning. 5. The teacher is businesslike and task-oriented in behavior.

6. The teacher keeps the "difficulty level of instruction" appropriate for each individual. 
Intellectual Stimulation

1. The teacher inspires students to seek more knowledge.

2. The teacher is an exciting, vibrant person.

3. The teacher is enthusiastic.

4. The teacher sustains pupil attention and response with activities appropriate to the various pupil levels.

5. The teacher makes classwork interesting.

6. The teacher and pupils share in the enjoyment of humorous situations.

Desirable Out-Of-Class Behavior

1. The teacher is a good team worker.

2. The teacher strives for improvement through positive participation in professional growth activities.

3. The teacher assumes responsibilities outside the classroom as they relate to school.

4. The teacher is committed to the primary goal of assisting pupil growth.

5. The teacher utilizes community resources in instruction. 6. The teacher effectively reports pupil progress to parents. (pp.22-23)

Manatt concluded that the six items relating to out-of-class behavior could be dropped with little loss in efficiency, however his research indicated that these items are important to board 
members and parents. He suggested that an administrator utilizing this approach conduct two or three classroom evaluations per evaluation cycle preceded by a pre-observation conference to discuss instructional objectives and followed by a post-observation session to exchange questions and agree on a plan of action. This process, he states, should be dynamic and lead to the reassessment of the performance descriptors every three to five years as district goals, values and expectations change (p.23).

The attributes of the clinical supervision model, according to Cogan (1976), focused upon the processes or cycles of supervision (p.14). Cogan's model included eight phases beginning with the establishment of the teacher-supervisor relationship. During this phase, the supervisor is responsible for interpreting the clinical supervision model to the teacher and helping him/her understand their role and function. Cogan related that this step must precede any observation in the classroom.

The second phase is dedicated to cooperative lesson planning between the teacher and the supervisor and the discussion of "outcomes, anticipated problems of instruction, materials and strategies of teaching, processes of learning, and provisions for feedback and evaluation" (p.14). Cogan (1973) further noted that this dyad:

- . enables the supervisor to gain valuable information about the teacher's views on the objectives of teaching, his [or her] teaching strategies, his [or her] perceptions 
about the students, his [or her] choice of the content and experiences to be embodied in the instruction, and the history of his [or her] instruction-what has happened before and its relation to what is yet to come. (pp.108-109)

Phase three calls upon the teacher and the supervisor to select the kinds and amounts of information that will be recorded by the supervisor during the lesson including patterns, critical incidents and unanticipated learnings.

Phase four involves the observation of instruction in the classroom and the collection of data with respect to teacher and student behavior. Cogan (1973) emphasized that any "Data collected during the observation must be detailed enough to permit systematic analysis and enable the supervisor to develop hunches and hypotheses about partial causes and partial effects" (p.149).

During phase five and six the supervisor analyzes the transcripts of the teaching-learning process and assesses the degree to which the teacher met his/her objective. Moreover, the analysis seeks to identify any salient patterns in the teacher's behavior and critical incidents occuring in the class (pp.164-168). This analysis is followed by a strategy session which gives the supervisor and teacher time to develop a plan for discussing the lesson. The teacher attempts to identify meaningful patterns and evaluate his/her success at reaching the lesson objective. The supervisor reviews the data collected during the observation and organizes it for ready accessibility. This strategy session, 
according to Cogan (1973), should be carried out by both parties as familiarity and ease increase (p.206).

In phase seven, the conference is conducted to "search for the meaning of instruction, for choices among alternative diagnoses, and for alternative strategies of improvement" (p.197). In Cogan's view, the conference has six objectives; (a) to identify the teacher's objectives; (b) to achieve a greater understanding of students' behavior and their learnings; (c) to relate the students' learnings to the teacher's objective; (d) to identify critical incidents and patterns; (e) to improve the teacher's role in the clinical conference; and (f) to increase the teacher's competence in self-supervision (pp.198-199).

The last phase in Cogan's (1976) model is called renewed planning. "At this point the cyclical nature of the supervisory process asserts itself, and the teacher and the supervisor stop the analysis and discussion of the lesson to begin planning the next lesson and the changes the teacher will attempt to make in his/her instruction" (p.15).

Goldhammer, Anderson and Krajewski (1980) viewed the cycles of supervision falling within five stages; (a) preobservation, (b) observation, (c) analysis and strategy, (d) supervision conference, and (e) post-conference. As such, Goldhammer et al. stated that these five stages are in concert with Cogan's eight phases. They affirmed that: 
[Of] the cycle presented by Cogan in eight phases, the first three (establishing the teacher-supervisor relationship, planning with the teacher) correspond with Goldhammer's Stage 1, and two others of which (analyzing the teaching-learning process, and planning the strategy of the conference) correspond with Goldhammer's Stage 3. Cogan's final phase (Number 8, renewed planning) treats the postobservation activity in a way somewhat different from Goldhammers, but it seems reasonable to claim that there are no major differences in the structure of the cycle of supervision as described by the two authors. (p.32)

The postobservation conference as noted in Goldhammer's second edition (1980) is a "self-improvement mechanism for assessing whether supervision is working productively" (p.177). Goldhammer et al. recommended that this session be conducted with the teacher or other colleagues for the purpose of evaluating the supervisor's skills in conducting the stages or cycles and examining "the pluses and minuses of supervision techniques used, the implicit and explicit assumptions made, the values and emotional variables considered, and the technical and process goals effected" (p.177). The cycles or sequences developed by Cogan and Goldhammer were also recognized by other proponents of clinical supervision (Luehe and Ehrgott, 1976; Mosher and Purpe1, 1972; Pohland, 1976; Sergiovanni and Starratt, 1983; Sullivan, 1980). Some of these advocates also endorsed observation techniques to be used in 
conjunction with clinical supervision, and in support of enabling teacher behavior change (Acheson and Gall, 1980; Flanders, 1970; Goldhamer, Anderson and Krajewski, 1980; Hunter, 1973; Luehe and Ehrgott, 1976).

Goldhammer, Anderson and Krajewski (1980) stated that "one of the most interesting procedural problems in the whole cycle of clinical supervision is how best to make a record of observed events" (pp.76-77). They offered two approaches. The first requires the supervisor to hand-record events in the classroom. The supervisor takes notes in verbatim fashion and focuses principally on the verbal interaction between the teacher and the students. For this task, these authors encourage supervisors to learn shorthand, or invent a speedwriting system in order to keep up with the "speed of events" happening in the classroom (p.78).

A second technique is videotaping. Goldhammer, Anderson and Krajewski deemed videotaping "an extremely helpful resource in supervision" although it cannot "do as selective a job tuning in to the events of a given lesson as can be done by a supervisor" (p.77). They stated:

The problem is that no person can write fast enough or keep sufficient track of everything seen or heard to take full advantage of the selective process that is going on. Futhermore, memory is fallible, and two hours later it is literally impossible to remember whose hands went up or what sort of expression was on the teacher's face when he 
or she looked at the door. On tape, with replay, one can be sure of at least the hands that were in camera range, and study at length the teacher's facial expression, if desired. (p.77)

Furthermore, they sensed "having the tape available during a conference also has great merit, both to verify or correct recollection and to enable additional analysis to occur" (pp.77-78). According to Flanders (1970), the Interaction Analysis system can be valuable for assessing teacher behavior. His system consisted of ten categories of verbal behavior which can be observed in a classroom lesson. The first seven categorles consist of "teacher talk" which are divided into direct and indirect influence. These categories include four indirect variables; (a) asking questions regarding content; (b) clarifying and building upon the ideas of students; (c) praising and encouraging student action; and (d) accepting the feeling tone of the students in a nonthreatening manner. The three direct influences include; (a) lecturing, (b) giving directions; and (c) criticizing or justifying teacher authority (p.34).

Categories eight and nine dealt with student talk, either in response to the teacher or talk initiated by the student. Category ten called "silence and confusion" included "pauses, short periods of silence and periods of confusion in which communication cannot be understood by the observer" (p.34).

Flander's system requires the supervisor to observe and classify 
the verbal behavior that is occurring every three seconds. This behavior is recorded on a matrix tally. Flanders noted that initially, the supervisor may want to record every five seconds or until he becomes familiar with the system and the three second intervals. The author believes that Interaction Analysis is a viable means of finding out what goes on in the classroom without requiring the supervisor to record everything in anecdotal fashion ( $p .21)$. Moreover, he found the system in concert with the act of teaching when he stated:

Teaching behavior, by its very nature, exists in a context of social interaction. The act of teaching leads to reciprocal contacts between the teacher and the pupils, and the interchange itself is called teaching. Techniques for analyzing classroom interaction are based on the notion that these reciprocal contacts can by perceived as a series of events which occur one after another. Each event occupies a small segment of time, and the chain of events can be spaced along a time dimension. It is clear that the event of the moment influences what is to follow and, in turn, was influenced by what preceded. (p.1) Cogan similarly concurred with Flanders and the usefulness of interaction analysis systems. He added:

As for the clinical supervisor himself, he finds interaction analysis systems useful for the objective and 
systematic feedback they make available about specific aspects of a teacher's classroom behavior. In addition, a knowledge of the research and speculation that form the basis for a well-conceptualized and well-developed system of interaction analysis expands and refines the supervisor's own power to observe, analyze, and interpret what happens in a classroom, and thus constitutes an important element in his [or her] professional education. (p.157)

Luehe and Ehrgott (1976) developed a Clinical Teaching Model that centers on lesson diagnosis, prescription and planning, lesson sequence, and the principles of learning. Their model offered clinical supervisors an Evaluation Summary Form for identifying these behaviors. Clinical supervisors are required to note, via anecdotal records and the observation form, any verbal and nonverbal evidence of teaching to an objective, monitoring pupil performance and making appropriate corrections in the lesson plan, and using the four principles of learning (p.V.31-33).

According to these authors, supervisors should focus upon the lesson sequence and development which consists of four fundamental steps. The first step, called the anticipatory set, focuses the learner on the purpose of the lesson. Luehe and Ehrgott stated: Research has shown that the brain is most attentive at the beginning of a lesson episode. It is important at this time to create a mental or anticipatory predisposition for 
the learning. By deliberately providing students with a

"set" for the lesson objective their learning is

facilitated. (p.I.9)

Luehe and Ehrgott pointed out that the set may be given either directly or indirectly. In direct fashion, the set includes a direct statement of the lesson objective, such as, "Today we are going to learn how to divide." In indirect fashion, the set includes the use of past learnings or experiences to facilitate new learnings. An example would be; "As you come to the reading circle think of the things you did between the time you got out of bed and the time you left for school, and be ready to list them in order (This sets the pupils for story sequence)" (p.I.9).

The second step focuses upon instruction and teacher modeling of the lesson. In this step, the supervisor observes the teacher's ability to instruct in terms of questions, directions, and activities. Luehe and Ehrgott urged that the following facts be considered:

1. Do the questions arouse interest and raise tension so that pupils will be motivated to become involved in the learning experience and lead learners to the discovery of a concept?

2. Do the questions match the learning level of the pupils?

3. Do the questions vary in complexity in light of Bloom's (1956) taxonomies? 
4. Are the directions formulated to accomodate slow, average, and fast learners?

5. Is reinforcement used during the lesson?

6. Is there clarity of meaning in the instruction?

7. Are directions given in sequence?

8. Are activities closely matched to the instructional objective?

9. Do the activities provide the learner with information about skills that he [or she] does not already possess?

10. Do the activities provide pupils an opportunity to apply the learning in new or varied situations?

11. Do the activities involve pupils so that children are doing the learning, not the teacher?

12. Are the activities designed so that learners proceed from concrete to abstract experiences and from simple to complex?

13. Are the activities designed at varying levels of difficulty? (pp.I.11-17)

In step three, guided practice, the teacher has the learners perform a sample of the behavior that they will display following the instruction. During this phase of the lesson, the teacher monitors the students' responses and actions, and provides "specific knowledge of results" (p.I.15). Hunter (1969a) defined specific knowledge of results as the "How am I doing" part of the instruction $(p .27)$. 
The fourth step is closure--"an activity that should be designed for nearly every session to capstone the learning by reinforcing the students' attention on the instructional objective" (pp.I.17-18). According to Luehe and Ehrgott, closure is a means of summarizing the learning and enabling the students an opportunity to express what they have learned, and "checking the learners' understanding of the directions before releasing them for independent activity" (p.I.15).

Luehe and Ehrgott concurred with Hunter in expressing the need for the principles of learning throughout the lesson sequence. Their diagnostic checklist directs supervisor attention on the teacher's use of motivation, reinforcement, retention, and transfer (Pp.IV.1-50).

Evidence of motivation, they stated, should be incorporated throughout the lesson.

In planning learning experiences, we need to include motivation throughout all lessons. We need to make lessons interesting. In beginning each lesson, it is a good idea to discuss the objective with the students to build expectancy. We want to remember that if there is no anxiety on the part of the learners, there is usually no learning going on, so we build in tension at an appropriate level. Since students are best motivated when they have good feelings about what they are doing, we also develop positive feelings in our learners, and plan many opportunities for all students to be successful. (p.IV.25) 
In Luehe and Ehrgott's view, "reinforcement is [another] major condition for most learning" (p.IV.1). They stated that teachers should be versed in applying positive reinforcement for strengthening a desired behavior by the learner, negative reinforcement for suppressing inappropriate behavior, and extinction to eliminate an undesired behavior through the act of ignoring (p.IV.4-5).

Lastly, retention and transfer principles are assessed to judge the concepts, details, and skills a student remembers and how well those concepts, details, and skills can be applied to a new area of instruction (pp.IV.31;IV.41). In terms of observation, Luehe and Ehrgott argued that supervisors should focus upon how the teacher builds meaning into the lesson and associates the content of instruction to the background experiences of students. For example, letting students write stories about experiences they had, or using learners' names in questions, problems, and examples (pp.IV.32-33). Hunter (1973) mentioned a Teacher Appraisal Instrument (TAI) that was developed to make "successful learning predictable and successful teaching explainable" (p.2). The TAI assesses teacher behaviors during the teaching act. The behaviors assessed include; instructing to an objective, using diagnostic/prescriptive skills, monitoring and adjusting levels of difficulty and incorporating the elements of reinforcement, motivation, retention, and transfer in the lesson (Smith, 1978:69). Utilizing the TAI, each behavior is 
rated on a ten-point scale; 0--unable to judge, not applicable; 1-not at all evident; 2, 3, 4--slightly evident; 5, 6--evident; 7, 8, 9;--usually evident; 10--very evident (Smith, 1978:70). According to Smith (1978), the TAI is valid and reliable when used by a trained observer. In his study of 84 elementary school teachers, Smith found that a principal trained in clinical supervision using the TAI could "evaluate instruction and make recommendations for instructional improvement without bias of personal knowledge of the staff or community" (p.101). Moreover, Smith reported that the TAI also demonstrated reliability in assessing teaching to an objective, and the elements of reinforcement, motivation, retention, and transfer (p.101). Acheson and Gall (1980) discussed the use of an observation instrument based on pupil seating charts. This instrument, called Seating Chart Observation Records (SCORE), focuses upon the verbal interaction between teacher and student. In use, the supervisor illustrates the classroom seating arrangement on the SCORE form or a blank sheet of paper, and attempts to depict the verbal interaction between the teacher and each student in the class. The supervisor draws a series of arrows to indicate the verbal flow--the base of the arrow indicating the person intiating the interaction, the head of the arrow indicating the receiver of the interaction (pp.115-116). According to Acheson and Gall, verbal flow data can be analyzed in three ways. One way is to gauge the degree of attention a teacher directs to students based on their physical location in the 
class. A second way is to measure any sex bias and determine whether the teacher interacts equally between boys and girls (p.119). A third way the SCORE instrument can be used is "to determine how frequently teacher and students use certain behaviors and whether they emphasize certain behaviors more than others" (p.119). These behaviors, stated Acheson and Gall, can be categorized as teacher and student question, teacher praise and criticism, and student correct and incorrect response (p.116).

The use of observation instruments such as SCORE and those previously mentioned in this chapter, represent only a limited percentage of such material available for assessing teacher performance. Moreover, they are not endorsed as superior to those that have been excluded, but are offered as samples of instruments utilized by clinical and traditional supervisors.

The literature contained numerous arguments in support of and in opposition to the validity and reliability of observation instruments and rating scales (Burton and Brueckner, 1955; Cogan, 1973; Goldhammer, Anderson and Krajewski, 1980; Gwynn, 1961; Harris, 1975; Marks and Stoops, 1978; Neagley and Evans, 1980; Sergiovanni and Starratt, 1983; Wiles and Love11, 1975;). The analysis of benefits and deficiencies would require a lengthy study that is not pertinent to this research. However, some cautions to supervisors interested in utilizing rating scales as instruments for observation and assessment should be mentioned. 
According to Evertson and Holley (1981), a human relations emphasis must be initiated from the outset with assurances that (a) the teacher to be observed is fully informed with respect to the purpose and nature of the observation, (b) that the observation be conducted in an unobtrusive manner with little interruption to instruction, and (c) that good communication be maintained throughout the evaluation process (p.93).

In addition, these authors felt that the effective use of classroom observation and observation instruments requires cooperative planning between the teacher and the supervisor, and the mutual examination of the observation instruments best suited to their situation (This was underscored by Marks and Stoops on page 55). Moreover, Evertson and Holley suggested that supervisors using observation instruments receive training prior to the instruments use in the classroom in order "to see the classroom through the terms of the instrument, and to code or record what is seen according to a method required by the instrument" (p.99).

Harris (1975) agreed with Evertson and Holley when he stated that "good observers are trained, not born" (p.174). He supported training as a necessary activity to help supervisors be systematic and control their biases, and because it is essential to effective observation, not only because it increases the ability to see and perceive but also because it promotes consistency and reliability" (p.174). 
Clinical and Traditional Supervision Research

Few studies have been conducted to gain information on clinical supervision in contrast to traditional supervision. One such study conducted by Reavis (1977) studied teacher attitudes toward clinical supervision in relation to six criteria. The criterion included interpersonal communication, teacher/supervisor conferences, classroom observation methods, suggestions for improvement, teacher self-perception and supervisor helpfulness.

A sample of teachers experienced three clinical supervision cycles while another sample experienced three cycles of traditional supervision. Both types of supervision were conducted by the same supervisors. In the traditional model, teachers were observed in the classroom and invited to a follow-up conference for lesson analysis between the teacher and the supervisor. In the clinical model, the supervisors conducted a preobservation conference followed by a lesson observation, and then developed a strategy for the postconference to mutually discuss the lesson analysis with the teacher. An attituile survey administered to the participating teachers revealed the following information:

1. Teachers favored clinical supervision on all six criteria studied (communication, conferences, observations, suggestions for improvement, self-perception and supervisor helpfulness). 
2. In two categories, communication and self-perceptions, the clinical approach was rated significantly better than the traditional.

3. Traditional supervision was not preferred in any category.

Although Reavis (1977) found the clinical approach favored among teachers, one could argue that the same supervisors conducting both supervision methods could have expressed some bias. This was discounted by Reavis, however, in his study. Moreover, Reavis further analyzed the differences between the democratic/autocratic verbal behaviors of supervision in the two styles. Using the Flanders' Interaction Analysis, no significant differences were found in 11 of the 13 categories relating to verbal behavior between the supervisor and the teacher in both the clinical and traditional treatments. However, Reavis mentioned that significant differences were found in two categories--"Supervisor accepts or uses teacher's ideas" and "Supervisor asks for teacher's opinion." Reavis suggested that these two dimensions may be highly significant in promoting teacher motivation for classroom behavior change.

A second study conducted by Putnal (1981), identified 248 teachers and 53 supervisors from throughout the United States who had experienced clinical supervision. Via a questionnaire, the researcher investigated teacher perceptions toward clinical supervision in contrast to other supervisory approaches. Moreover, Putnal was interested in finding whether clinical practices were 
more effective with relation to grade level and teacher experiences.

The results, based on chi-square tests, indicated that clinical supervision appears to be a process which is most beneficial for teachers early in their careers. However, both teachers and supervisors found it to be a time consuming process which does not implicitly streng then supervisor-supervisee relationships solely because of its human resources overtures. Lafferty (1980) sought to find if teacher self-development as determined by self-perception of performance, was perceived as better facilitated via clinical supervision compared to regular supervision. The study covered a six-month period and included a sample of 40 teachers in ten secondary Catholic schools in the Pittsburgh area.

The 40 teachers were randomly assigned to the control and experimental group. The control group received regular supervision while the experimental group received clinical supervision implemented by the researcher.

The summary of the data from the study showed there was a significant difference between the groups in teacher perceptions of supervision and their teaching competence. Lafferty concluded that clinical supervision facilitated teacher development and the process contributed to the develoment of the teacher who was able to analyze and evaluate his/her teaching performance. Furthermore, she stated that clinical supervision provided a systematic model for teachers to mover toward improved perceptions of supervision and their own teaching competence. 
In a more recent study, Mattes (1983) compared the effects of clinical and traditional supervision on teachers' perceptions of teacher development of performance and supervision practices. The researcher posed several questions in his study:

1. Does clinical supervision enhance teacher development and his/her perception of performance when compared to traditional practices of supervision?

2. Does clinical supervision enhance teachers' perceptions of supervision compared to traditional practices of supervision? Mattes' study included 183 teachers in junior and senior high schools from suburban school districts in Colorado. His study also consisted of ten clinical and eleven traditional principals and assistant principals of which seventeen were male and four female.

According to Mattes, neither clinical nor traditional supervision was perceived to be more or less enhancing of teacher development and performance. However, Mattes also reported that teachers who had clinical supervision were more positive about the existing level of supervision than those teachers who had traditional supervisors. These results were found to be statistically significant.

Need Strengths In Teachers

In the field of education, relatively little has been done to assess teacher need strengths. In one attempt to measure need levels of teachers, Trusty and Sergfovanni (1971) gauged teacher 
perceptions of need deficiencies in their work environment. Teachers were asked to respond to a 13-item need deficiency questionnaire modeled after the Maslow hierarchical need structure, i.e. security, social, esteem, autonomy, and self-actualtization. Several statements on the questionnaire represented each Maslow need category. For example, a statement representing the self-actualization level was, "The opportunity for personal growth and development in my school position." For each statement, respondents were asked to indicate; (a) how much of the particular characteristic was currently available in their jobs (actual,) and (b) how much of this same characteristic they thought should be available in their school position (ideal.)

Trusty and Sergiovanni assumed that a teacher's need deficiency would be determined by subtracting the actual response from the ideal response. The higher the difference between actual and ideal, the higher the assumed index of dissatisfaction. Conversely, smaller scores indicated relative satisfaction. According to Trusty and Sergiovanni, higher-order needs such as esteem, autonomy, and self-actualization accounted for larger need deficiencies than items related to security and social needs. Moreover, women reported lesser need deficiencies than men and found their positions more satisfying. However, men seemed to have higher aspirations than women, and as a result seemed more difficult to please. This could account for the difference in need deficiencies between men and women. 
Pastor (1980) conducted a study to determine whether the needs of public school secondary teachers are higher-order or lower-order. The population for her study consisted of 150 secondary school teachers from ten school districts throughout the United States. Pastor utilized the Higher Order Need Strength Measure B to identify the teacher's need strength. She found that the need strengths of teachers were measureable and predominantly higher-order in nature. She stated that this predominance of higher-order needs was statistically significant for the entire sample of teachers and each individual school district. Pastor noted that approximately two-thirds of the secondary teachers had higher-order needs while one-third had lower-order needs. Moreover, of the six higher-order needs studied (see page 18 for definition of higher order needs,) freedom and independence was the strongest expressed need. Among the lower-order teachers, the desire for high pay was stressed most heavily.

Interestingly, Pastor concluded that teachers who were the main wage earners in the family and for whom teaching was a career profession were found to possess higher-order needs. This finding significantly correlated need strengths to a teacher's status as the main wage earner.

\section{Review of the Literature}

Chapter 2 presented a historical perspective of instructional supervision from the first quarter of the century to the present. 
It traced the path of supervision from the classical authoritarian style where principals directed and dominated teachers' instruction, to the era of human relations, methodology and the inftiation of a more democratic environment that emphasized the importance of interrelationships between the administration and the teachers.

The literature also presented the contemporary styles of supervision that are attributed to our modern times. These included the rational/technical approach known as traditional supervision and its emphasis on control, accountability, and efficiency, and a second model recognized for its concept of colleagueship known as clinical supervision.

In view of their distinction, the literature examined the behavior, practices and methods of these contemporary supervisory approaches. It was mentioned that traditional supervision emphasized a line-office posture with teachers and held that supervisors must use their authority in directing and overseeing the execution of school goals. However, while this approach superseded the establishment of egalitarian relationships, it did not discourage supervisors from engaging teacher participation in the determination of purposes and procedures, yet mainly supported limitations to autonomy.

Adherents to clinical supervision supported a staff-office position that assumed that the improvement of teaching is more likely to increase a teachers' self-development when implemented within the mutual support of a partnership between teacher and 
supervisor. This concept was recognized as colleagueship. Additional reference was made to the areas of product and process orientation. Traditional supervisors were recognized for setting the parameters of the learning environment is such a way that all teachers contributed to the attainment of school goals, and thereby collectively emphasized student achievement. It was stated that once teachers understood that they would be held accountable for student knowledge of specific skills, there would be less evaluation of teacher competence with respect to process and more upon pupil performance.

In contrast, the process of clinical supervision prescribed the formative development of teachers. It focused upon a teacher's mastery of his/her teaching craft in greater proportion to the achievement of school/district goals. This development, it was stated, centered around the implementation of cycles or phases beginning with the establishment of the teacher-supervisor relationship. Other phases included the pre-conference session to gain information about the teacher's view on the objectives of the lesson, the lesson observation itself, the strategy session to analyze the transcripts of the observed lesson, and the post-conference to discuss the effectiveness of the lesson and to plan future strategies for improvement.

The traditional supervisory model did not endorse any specific articulated structure, yet assessed classroom interaction via a series of scheduled and unscheduled classroom visitations with the 
optional use of rating scales and checklists. The literature suggested that traditional supervision was nnre inspectional in process and attempted to gauge teacher performance through classroom observations of a frequent and short nature.

Empirical research focusing on the effectiveness of traditional and clinical supervision was additionally investigated, yet found to be limited. What was reviewed, however, indicated that clinical supervision was perceived more favorably than traditional supervision when assessed for communication, suggestions for improvement, effectiveness of conferences, and supervisor helpfulness. Moreover, current research stated that clinical supervision provided a better model for teachers to move toward improved perceptions of supervision and their own teaching competence.

With respect to need strengths, there were very few studies that had investigated the need levels of educators. Those mentioned stated that educators have predominantly higher-order needs which are associated with the esteem, autonomy and self-actualization hierarchical need structure. Moreover, teachers' levels of aspiration level downward with age as teachers become more realistic or resigned to things as they are.

The review did not uncover any research examining the relationship between supervision models and teacher need strengths. The absence of research in this area demonstrates the need for this study at a time when "school executives and other professionals with 
supervisory responsibility are largely ignorant of adult motivation--theoretically, conceptually, and in practice-and in dealing with adults have had to rely on intuition, experience, and mythology" (Carver and Sergiovanni, 1975:55). 
Chapter 3

Research Design and Methodology

Chapter 3 will present the methods and procedures that were followed to extrapolate the study results. For purposes of presentation, the chapter is divided into four sections: (a) description of the subjects, (b) description of the research instrumentation, (c) description of the procedures, and (d) treatment of the data.

\section{Description of the Subjects}

The participants in this study were elementary school principals and teachers presently employed within the San Diego and Los Angeles county areas. The school districts from which the principals and teachers were selected are listed in Appendix A.

The study included twenty principals who had the responsibility for supervising teachers and who utilized either clinical or traditional supervision methods. Ten principals represented each supervisory category. A comparison of principals by sex is noted in Table 1. 
Table 1

Comparison in Numbers of Clincial and Traditional

Principals by Sex

$\mathrm{N}=20$

\begin{tabular}{cccc}
\hline Sex & $\begin{array}{l}\text { Clinical } \\
\text { Principals }\end{array}$ & $\begin{array}{l}\text { Traditional } \\
\text { Principals }\end{array}$ & Total \\
\hline Male & 4 & 9 & 13 \\
Female & 6 & 1 & 07 \\
\hline
\end{tabular}

One hundred fifty-seven teachers were also included in the study. These teachers were randomly selected by their principal using the systematic random sampling technique. Each principal was given instructions to compile a random listing of his/her certificated teachers, excluding itinerant staff. Principals were asked to divide this population by ten. The numerical value of ten represented the number of teachers requested for the sample from each school. The resulting calculation represented the random order (or nth number) for the selection of teachers.

In total, 74 teachers were supervised via clinical methods and 83 by traditional approaches. Tables 2 through 4 indicate the frequency and percent for each of the demographic characteristics for the participating teachers.

The greatest percentage of the sample was between 31 and 35 years of age. This group accounted for $22.29 \%$ of the sample. While 
this age range was also the majority in the clinical group, the 50 and above years of age group represented the largest percentage in the traditionally supervised schools.

Table 2

Frequency and (Percentage) of Sample by Age

$$
\mathrm{N}=157
$$

\begin{tabular}{lccc}
\hline Age Range & $\begin{array}{c}\text { Clinical } \\
\text { Group }\end{array}$ & $\begin{array}{c}\text { Traditional } \\
\text { Group }\end{array}$ & Tota1 Sample \\
\hline $21-25$ & $3(4 \%)$ & $2(3 \%)$ & $5(3.18 \%)$ \\
$26-30$ & $14(19 \%)$ & $11(13 \%)$ & $25(15.92 \%)$ \\
$31-35$ & $18(24 \%)$ & $17(20 \%)$ & $35(22.29 \%)$ \\
$36-40$ & $12(16 \%)$ & $17(20 \%)$ & $29(18.47 \%)$ \\
$41-45$ & $10(14 \%)$ & $10(13 \%)$ & $20(12.74 \%)$ \\
$46-50$ & $6(8 \%)$ & $7(8 \%)$ & $13(8.28 \%)$ \\
$50+$ & $11(15 \%)$ & $19(23 \%)$ & $30(19.11 \%)$
\end{tabular}

The years of experience was greatest in the category of eight to eleven years. Nearly $25 \%$ of the sample subjects fell within this range. Moreover, the total range between four and eleven years accounted for $43.24 \%$ of the clinical group and $42.17 \%$ of the traditional sample, respectively.

A third demographic characteristic was teacher classification as per the California Education Code. The total sample included $79.62 \%$ tenured teachers and $20.38 \%$ nontenured. This variable was selected to 
determine if teacher age and experience had any relationship to satisfaction with supervision.

Table 3

Frequency and (Percentage) of Sample

by Years of Experience

$\mathrm{N}=157$

\begin{tabular}{llcl}
\hline Years & $\begin{array}{c}\text { Clinical } \\
\text { Group }\end{array}$ & $\begin{array}{c}\text { Traditional } \\
\text { Group }\end{array}$ & Total Sample \\
\hline $0-1$ & $2(2.70 \%)$ & $3(3.61 \%)$ & $5(3.18 \%)$ \\
$2-3$ & $6(8.11 \%)$ & $4(4.82 \%)$ & $10(6.37 \%)$ \\
$4-7$ & $16(21.62 \%)$ & $12(14.46 \%)$ & $28(17.83 \%)$ \\
$8-11$ & $16(21.62 \%)$ & $23(27.71 \%)$ & $39(24.84 \%)$ \\
$12-15$ & $10(13.51 \%)$ & $14(16.87 \%)$ & $24(15.29 \%)$ \\
$16-20$ & $10(13.51 \%)$ & $12(14.46 \%)$ & $22(14.01 \%)$ \\
$21+$ & $14(18.92 \%)$ & $15(18.07 \%)$ & $29(18.47 \%)$ \\
\hline
\end{tabular}

Table 4

Frequency and (Percentage) of Sample

by Teacher Classification

$\mathrm{N}=157$

\begin{tabular}{lccc}
\hline Classification & $\begin{array}{c}\text { Clinical } \\
\text { Group }\end{array}$ & $\begin{array}{c}\text { Traditional } \\
\text { Group }\end{array}$ & Total Sample \\
\hline Tenured & $55(74.32 \%)$ & $70(84.34 \%)$ & $125(79.62 \%)$ \\
Nontenured & $19(25.68 \%)$ & $13(15.66 \%)$ & $32(20.38 \%)$ \\
\hline
\end{tabular}


Description of the Instrumentation

In order to adequately categorize teachers into higher-order and lower-order groups, a questionnaire developed by Hackman and Oldham (1974) was used. The instrument, called the Higher-Order Need Strength Measure B, was developed by Hackman and Oldham to test the growth need strengths of employees. Measure B was designed in a job choice format which asked respondents to choose between pairs of hypothetical jobs with characteristics relevant to growth needs (higher-order) and other needs (lower-order). For example, respondents were asked to choose between "a job where the pay is very good" vs. "a job where there is considerable opportunity to be creative and innovative". The twelve job pairs that comprised the questionnaire were arranged in a Likert-type scale and required some ten to fifteen minutes to complete. A copy of the instrument is found in Appendix B.

Measure B was a submeasure of Hackman and Oldham's Job Diagnostic Survey (JDS). The JDS, including Measure B, had been normed on over 6,900 employees in 876 different jobs in 56 organizations. The jobs involved included blue-collar, white-collar and professional employees in the business sector (Hackman and 01dham, 1980:105). Moreover, it had undergone three major revisions and been subjected to a variety of empirical tests (Cathcart, Goddard and Youngblood, 1978; Dunham, 1976; O1dham, Hackman and Stepina, 1979). As of the questionnaires administration, the items composing the growth need strength scale represented an internal 
consistency reliability of .71 (Hackman and 01dham, 1975:164).

Hackman and 01dham stated that reliability measures were computed by obtaining the median inter-item correlation for all items and adjusting the median by using Spearman-Brown procedures (1975:163).

In terms of substantive validity, the authors reported that the variables measured by the JDS related to one another as generally predicted. In addition, they stated that the dependent measures were stronger for individuals high in growth need strengths than for individuals who did not strongly desire for growth satisfaction (1974:168).

Measure B's validity for identifying the need strength levels of teachers was addressed in a recent study conducted by Pastor (1980). She found that the need strengths of teachers were measureable and that Measure B functioned satisfactorily. This study included 150 secondary school teachers. Moreover, the researcher had the instrument field tested for purposes of substantiating validity for use with elementary school teachers. Measure $B$ was sampled with a pilot group as a means of gauging teacher's perceptions to the questionnaire and its application to teachers and their jobs. The sampling included elementary teachers not included in the actual research. The researcher randomly selected thirty teachers in the National School District in National City, California, and mailed them an introductory letter indicating the purposes of the field test.

Teachers were asked to review the instrument in terms of its 
content and face validity. They were directly asked, "Do you feel this instrument would be satisfactory for distinguishing a teacher's preference for either higher-order or lower-order needs?" Moreover, they were asked to carefully examine each job pair and assess its relevance to education and their job world. Refer to Appendix $C$ for a copy of the letter.

Fifty percent of the sampled subjects returned their assessment of the questionnaire. In all cases, teachers indicated that Measure B would be appropriate for use in categorizing a teacher's need preferences. They reported that the job pairs were relevant examples and associated to elementary education. Specific comments ranged from, "OK, interesting selections," to "Yes, I think this instrument might be useful for distinguishing higher-order or lower-order needs. It certainly would give clues to an individual about how a person would perform at his maximum."

The second instrument that was utilized in this study was developed by the researcher. The questionnaire was also of a Likert-type and was administered to both higher-order and lower-order need teachers. The purpose of the questionnaire was to measure each teacher's degree of satisfaction with either the clincial or traditional supervisory approach implemented by the principal. Specifically, the questionnaire measured teacher perceptions regarding (a) the principal's methods for evaluating the effectiveness of a teaching lesson and helping teachers improve instruction, (b) the principal's methods for collecting data and 
providing feedback regarding a lesson, and (c) the level of interpersonal relations effected by the supervision process. Teacher satisfaction was determined by reviewing the mean scores of the clinical and traditional groups with respect to the 15-item Teacher Supervision Practices Questionnaire, and applying ANOVA procedures for determining significance. Moreover, respondents were asked several open-ended questions and invited to state their level of satisfaction with their principal's supervisory process. See Appendix $D$ for a sample copy of the instrument.

The Teacher Supervision Practices Questionnaire was field tested, in two samplings, on practicing elementary school teachers in San Diego County. The first sampling asked pilot subjects to comment directly on the questionnaire in terms of face validity and the level of clarity and understanding. On the basis of these suggestions, the questionnaire was revised and piloted on a second group. The primary purpose of the field test was (a) to test the clarity of instructions and the items listed so that reliable data would be generated, and (b) to determine the appropriateness of the questionnaire with respect to the survey sample. To test the first purpose, the completed questionnaire was examined to see if the respondents had been able to follow the instructions accurately. The second purpose was accomplished by talking individually to the pilot subjects to find out their reactions to the survey questions and to obtain feedback on whether or not they felt that the questions accurately expressed the desired information. Ten 
teachers were surveyed in each sampling. In addition, reactions to the questionnaire were generated from five clinical and five traditional principals.

The information gathered from the first sampling suggested that the Teacher Supervision Practices Questionnaire included items representative of supervision practices. Teachers and principals found the questionnaire instructions clear and concise, yet suggested several changes that were ultimately incorporated in the revised questionnaire. First, several respondents suggested that for each statement an example be provided to increase clarity. Second, there were changes made with respect to wording and the elimination of a particular statement not felt to be congruent to the supervision topic.

The second field test was also favorable in terms of content validity. The pilot subjects suggested minor modifications to the format and recommended that the researcher clearly outline assurances of teacher confidentiality. Both of these acknowledgements were incorporated in the final revision.

A test for establishing content validity was conducted by computing an item intercorrelation for each of the 15 questionnaire statements. The results demonstrated that the questionnaire, on the whole, had a moderate range of correlation. All but six correlations were significant at the .05 level. Table 5 provides a list of the correlation distribution for all items. 
TABLE 5

Item Intercorrelation Distribution

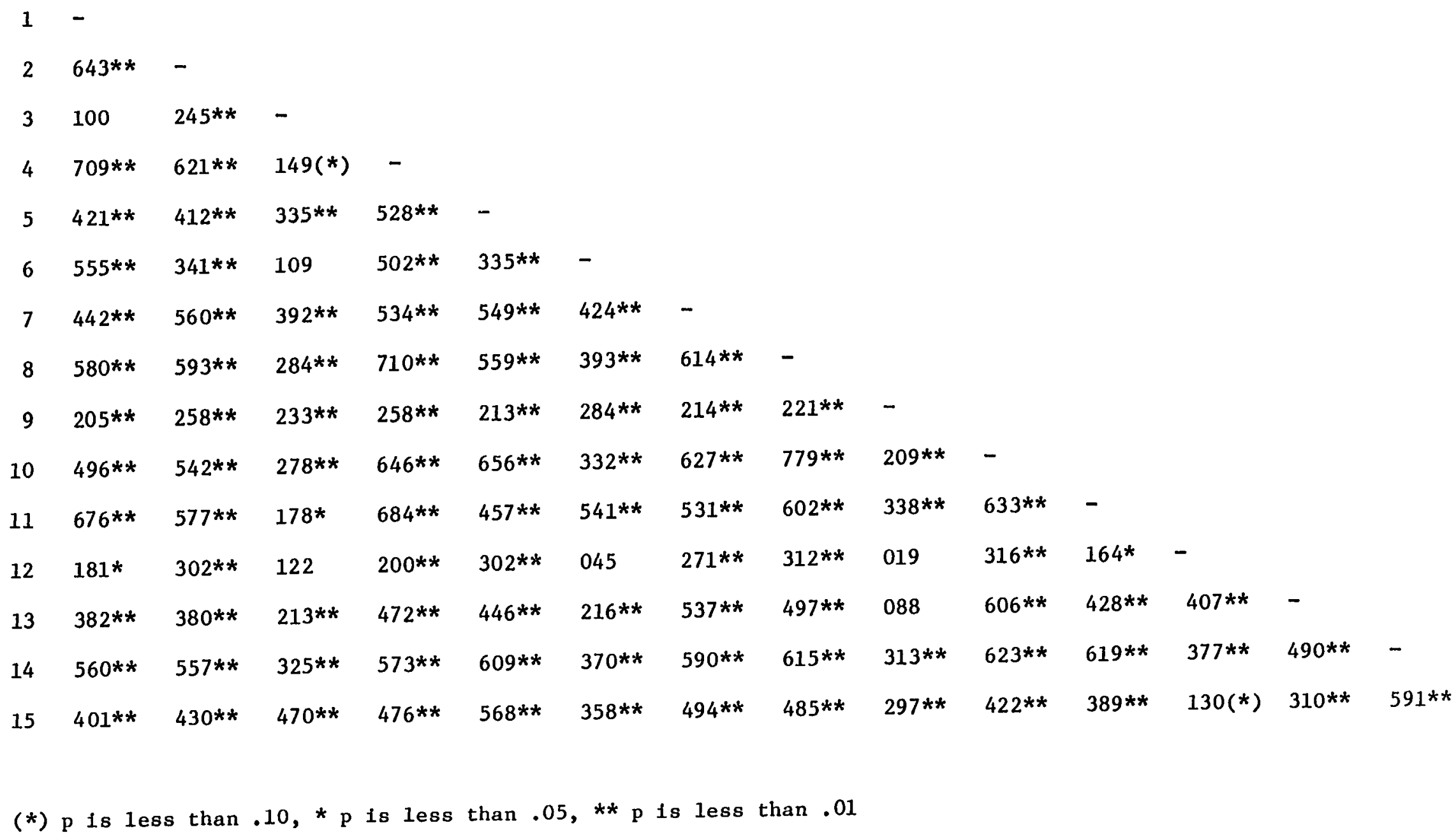


The questionnaire was also measured for reliability using the split-half method. The reseacher divided the test into two parts, with items $1,4,6,8,10,12$, and 14 accounting for part one, and items $2,5,7,9,11,13$, and 15 as part two. In addition, item 3 was eliminated from the reliability test because it had the poorest correlation of any item and because it enabled the equation to consider an equal number of positively and negatively stated items.

The split-half method generated an uncorrected value of .8660 . When the Spearman-Brown Prophecy formula was applied, test reliability equaled .9283. According to Guilford (1950), "When this estimation formula is used, comparability of halves must be assumed. Comparability is indicated to some degree by the fact of similar means and standard deviations" (p. 493). Table 6 demonstrates the comparability of both halves.

Table 6

Comparability of Split-Half Correlation

\begin{tabular}{lll}
\hline Test Half & Mean & S.D. \\
\hline Part One & 25.9299 & 5.4280 \\
Part Two & 25.6178 & 4.8298 \\
\hline
\end{tabular}

In addition, the questionnaire's reliability was further confirmed by the highly consistent mean differences between the 
clinical and traditional groups which were beyond the .01 level of confidence for each of the 15 questionnaire items.

Although the results indicated excellent reliability and content validity, they did not indicate that the content could be grouped into the subcategories--higher and lower-order needs, and tenured and non-tenured. This will be explained in greater detail in the subsequent chapter.

\section{Description of the Procedures}

Elementary school principals were the first participants to be selected for the study. The researcher communicated with the San Diego and Los Angeles County Departments of Education for a listing of elementary principals who practiced either clinical or traditional supervision methods. Via discussion with contact personnel including district superintendents, deputy superintendents, and county department of education directors, the listing of clinical and traditional principals was augmented. From the list of recommended principals, 10 were randomly selected for each category. The researcher mailed each a letter of intent which outlined study procedures and expressed some future time for a telephone interview. A copy of this letter is found in Appendix E. During the interview, each principal was given a further explanation of the study, with assurances that teacher responses would be held in the strictest of confidence, and that teachers would not be asked to rate his/her principal on a personal level but rather focus on supervision strategies solely. The 
researcher posed the following questions during the interview:

1. What procedures do you use to supervise your teachers?

2. Have you been trained in any process for supervising teachers?

3. Are you knowledgeable of clinical supervision methods?

4. Do you practice clinical supervision techniques?

Principals who did not satisfy the study definitions based on the aforementioned interview questions were not included in the sample and the next principal in random order was interviewed.

In addition, the researcher attempted to validate whether principals initiated their supervisory methods as espoused, by observing a subsample of principals supervising teachers. The subsample accounted for $20 \%$ of both clinical and traditional principals. A $10 \mathrm{~g}$ of this activity is listed in Appendix F. The validation of each principal's supervisory method was further confirmed via teacher response to an open-ended question in the follow-up questionnaire. Specifically, teachers were asked to describe the supervisory procedures their principal used and their frequency levels.

The participating teachers were also selected by using a random sampling technique. Each principal compiled a list of his/her certificated teaching staff and used the systematic sampling technique to randomly select 10 teachers for the study. Teachers were then divided into either higher-order or lower-order by virtue 
of their response on the Higher Order Need Strength Measure B.

Table 7 illustrates the number of teachers that participated.

Table 7

Teacher Sample

$\mathrm{N}=157$

\begin{tabular}{lcc}
\hline Teacher Groups & n & Total per Group \\
\hline Clinical & 47 & 74 \\
Higher-Order & 27 & \\
Lower-Order & & \\
& & \\
Traditional & 55 & \\
Higher-Order & 28 & \\
Lower-Order & & \\
\end{tabular}

Teachers completed Measure B in October and submitted it to their principal for return to the researcher. The researcher obtained permission to use the instrument via a letter directed to Professor J. R. Hackman at Yale University. A copy of the letter is found in Appendix G.

The teachers were asked to identify their survey with their mother's maiden name. This insured anonymity and enabled the researcher to identify both higher-order and lower-order teachers 
for the follow-up questionnaire. After a three month period, the researcher mailed each teacher the Teacher Supervision Practices Questionnaire. The questionnaire was mailed in sealed envelopes and addressed with each teacher's mother's maiden name. A self-addressed stamped envelope was also provided for direct mailing to the researcher. The returned response represented $86 \%$ of the sampled population. The three-month period between questionnaires provided principals an opportunity to observe teachers and initiate their supervisory methods. This period of time was between November 1983 and February 1984.

\section{Treatment of the Data}

The data collected from the Teacher Supervision Practices Questionnaire were analyzed by a three factor analysis of variance (ANOVA). The ANOVA was used to determine whether there was a significant difference between two or more means at the .05 probability level.

The factors used in the design included; (a) supervision--two levels (clinical and traditional); (b) need strength--two levels (higher-order and lower-order); and (c) teacher classification--two levels (tenured and non-tenured). The Statistical Package for the Social Sciences (Nie, et al., 1975) was used to analyze these data. Moreover, the schematic representation of the experimental design is presented in Figure 1. 
In addition, the open-ended questions yielded data with respect to supervision practices in clinical and traditional categories. Descriptive statistics were used in tabulating and summarizing this data for analysis and presentation.

Figure 1

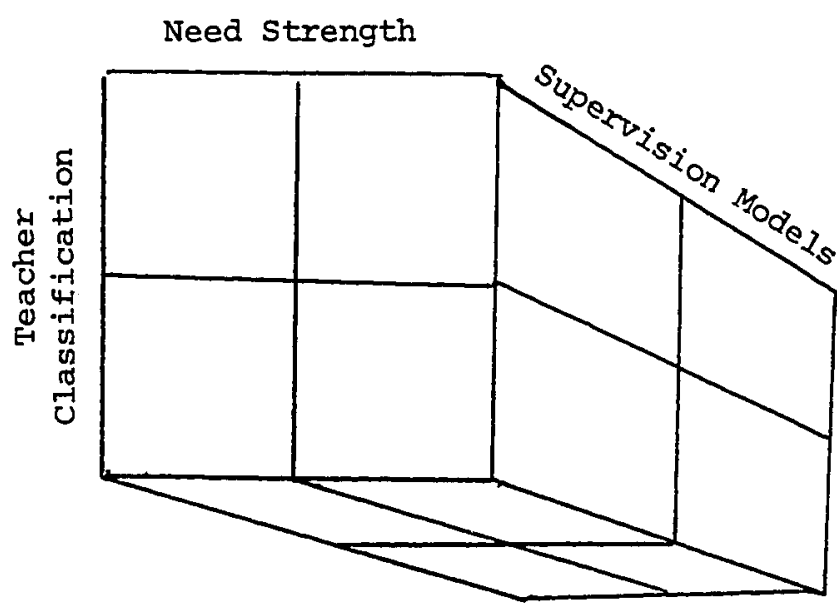




\section{Chapter 4}

\section{Presentation and Analysis of the Data}

This chapter presents the findings of the study with respect to the satisfaction levels of teachers when supervised by either clinical or traditional approaches. It further examines the descriptive data that teachers provided via the open-ended format questions and describes the central tendency and variability of these data.

The data reported are presented in the following sections: (a) teacher need strength results, (b) analysis of the statistical findings, and (c) open-ended question results.

\section{Teacher Need Strength Results}

Hackman and Oldham (1974) categorized need strengths into either higher-order or lower-order. Higher-order needs, they stated, are defined as a desire for: (a) participation in decision-making, (b) the use of a variety of valued skills and abilities, (c) freedom and independence, (d) challenge, (e) expression and creativity, and (f) an opportunity for learning. Lower order needs, on the other hand, are a desire for (a) high pay, 
fringe benefits, (c) job security, (d) friendly co-workers, and

(e) considerate supervision.

Hackman and Oldham developed the Higher Order Need Strength, Measure $B$ in an effort to discriminate an individual's need strengths. The teachers who participated in this study completed Measure B for this reason. The instrument contained 12 items which encompassed a five-point likert scale. The score recorded for each teacher was the mean of the item scores. A mean below 3.00 indicated a more frequent choice in the lower-order needs range while a score above 3.00 indicated a more frequent choice in the higher-order needs range. The range of scores for the entire sample was from 1.92 to 4.75 .

The grand mean for the sample was 3.14. Table 8 reports the frequency for each score. Scores of 3.08 and 3.25 , respectively, represented the highest rate of frequency. These scores accounted for nearly $18 \%$ of the sample. Scores of $2.83,3.00$ and 3.17 were also more frequent.

The cumulative percent calculation indicated that $35.03 \%$ of the total sample scored below 3.00 or in the lower-order need range, while $64.98 \%$ scored at or above 3.00 and in the higher-order need range. These findings approximated those achieved by Pastor (1980) in her recent study of 150 secondary school teachers. Pastor's sample represented a mean score of 3.23 with $31.33 \%$ scoring in the lower-order need range and $68.67 \%$ scoring in the higher-order need range. 
When the need strength scores of both the clinically-supervised and the traditionally-supervised groups were analyzed, there appeared to be congruence with the total sample. Approximately two-thirds of the teachers in each group demonstrated a preference for higher-order needs. The clincially-supervised group had $63.51 \%$ of its teachers in the higher-order range to $66.26 \%$ of the traditionally-supervised teachers. Appendices $B$ and I present these data.

Table 8

Need Strength Scores

$$
\mathrm{N}=157
$$

\begin{tabular}{cccc}
\hline Score & Frequency & Percentage & $\begin{array}{c}\text { Cumulative } \\
\text { Percentage }\end{array}$ \\
\hline 1.92 & 1 & 0.64 & 0.64 \\
2.08 & 1 & 0.64 & 1.28 \\
2.17 & 1 & 0.64 & 1.92 \\
2.25 & 3 & 1.91 & 3.83 \\
2.33 & 1 & 0.64 & 4.47 \\
2.50 & 2 & 1.27 & 5.74 \\
2.58 & 5 & 3.18 & 8.92 \\
2.67 & 9 & 5.73 & 14.65 \\
2.75 & 10 & 6.37 & 21.02 \\
& & & (table continues)
\end{tabular}




\begin{tabular}{|c|c|c|c|}
\hline Score & Frequency & Percentage & $\begin{array}{l}\text { Cumulative } \\
\text { Percentage }\end{array}$ \\
\hline 2.83 & 12 & 7.64 & 28.66 \\
\hline 2.92 & 10 & 6.37 & 35.03 \\
\hline 3.00 & 12 & 7.64 & 42.67 \\
\hline 3.08 & 14 & 8.92 & 51.59 \\
\hline 3.17 & 12 & 7.64 & 59.23 \\
\hline 3.25 & 14 & 8.92 & 68.15 \\
\hline 3.33 & 11 & 7.01 & 75.16 \\
\hline 3.42 & 4 & 2.55 & 77.71 \\
\hline 3.50 & 8 & 5.10 & 82.81 \\
\hline 3.58 & 6 & 3.82 & 86.63 \\
\hline 3.67 & 5 & 3.18 & 89.81 \\
\hline 3.75 & 3 & 1.91 & 91.72 \\
\hline 3.83 & 3 & 1.91 & 93.63 \\
\hline 3.92 & 2 & 1.27 & 94.90 \\
\hline 4.00 & 2 & 1.27 & 96.17 \\
\hline 4.08 & 1 & 0.64 & 96.81 \\
\hline 4.17 & 1 & 0.64 & 97.45 \\
\hline 4.25 & 1 & 0.64 & 98.09 \\
\hline 4.33 & 1 & 0.64 & 98.73 \\
\hline 4.42 & 1 & 0.64 & 99.37 \\
\hline 4.75 & 1 & 0.64 & 100.01 \\
\hline
\end{tabular}


Moreover, the sample means for each group were relatively similar. The clinical group achieved a mean of 3.09 while the traditional group scored slightly higher at 3.18 . These results seemed to indicate that both clinically-supervised and traditionally-supervised groups were equal with respect to need strengths. Table 9 illustrates these data.

Table 9

Mean Scores for Clinical and Traditional Samples

$$
\mathrm{N}=157
$$

\begin{tabular}{ccc}
\hline Group & Frequency & Mean \\
\hline Clinical & 74 & 3.09 \\
Traditional & 83 & 3.18 \\
\hline
\end{tabular}

Analysis of the Statistical Findings

The data collected from the higher-order and lower-order need teachers supervised by clinical and traditional methods were analyzed by a three factor analysis of variance. The design was a 2 X $2 \times 2$ type. The factors used in the design were supervision--two levels (clinical and traditional), need strength--two levels (higher-order and lower-order), and teacher classification--two levels (tenured and non-tenured). 
As can be seen from the analysis of variance summarized in Table 10 significant differences were found among the clinical and traditional groups with respect to satisfaction toward supervision.

Table 10

Analysis of Variance of Satisfaction Toward

Clinical or Traditional Supervision

\begin{tabular}{lrrrrr}
\hline Source & SS & df & MS & F Ratio & Sig. \\
\hline & & & & & \\
Between Groups & 4938.865 & 1 & 4938.865 & 65.199 & $0.0000(*)$ \\
Within Groups & 11741.415 & 155 & 75.751 & & \\
\hline
\end{tabular}

$*=p$ is less than .001

The F-ratio for this analysis was 65.199 and the degrees of freedom were 1 and 155 . The mean satisfaction scores for the clinical and traditional sample were 61.18 and 49.94 respectively. These data indicated that clinically-supervised teachers were more positive about the existing level of supervision than those teachers traditionally-supervised. Moreover, when the responses between the clinical and traditional samples were analyzed via ANOVA procedures, with respect to each of the 15 items comprising the Teacher Supervision Practices Questionnaire, it was determined that there 
were significant differences between the two groups beyond the .05 level of confidence for each item. These data are illustrated in Table 11.

The interaction of need strength by supervision type was not found to be statistically significant. The summary of means comprising this interaction are presented in Table 12.

Table 12

Summary of the Mean Satisfaction Scores for the Higher and Lower-Order Teachers by Supervision Type

\begin{tabular}{llll}
\hline Group & $\mathrm{n}$ & Mean & $\mathrm{SD}$ \\
\hline & & & \\
Clinical & 47 & 60.79 & 6.65 \\
Higher order & 27 & 61.85 & 8.71 \\
Lower order & & & \\
Traditional & 55 & 50.58 & 8.82 \\
Higher order & 28 & 48.68 & 11.30 \\
Lower order & & & \\
\hline
\end{tabular}

As can be seen by this table, there is considerable difference between the clinical group and traditional group and practically no difference between the subgroupings within the clinical and traditional groups. 
Table 11

Item Means, Standard Deviations, F-Ratios and Correlations

for Satisfaction Rating

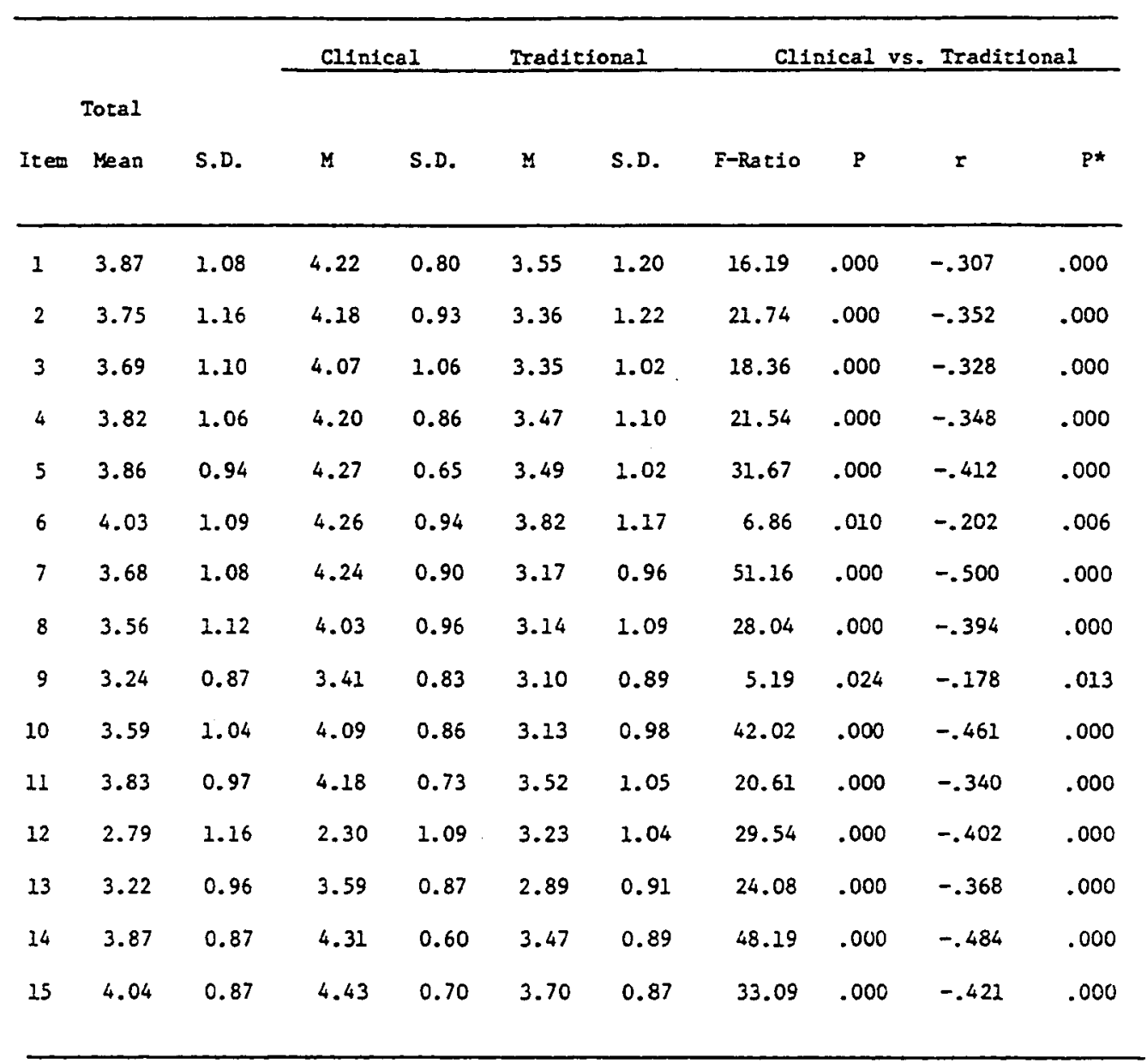


This would suggest that a teacher's satisfaction toward supervision is related to the type of supervision implemented irrespective of need strength level. When an analysis of variance was applied to determine if any significant differences existed between the higher and lower-order groups, the test indicated that no significant differences existed. This is illustrated in Table 13.

Table 13

Analysis of Variance of Satisfaction Scores for

Higher and Lower-Order Teachers

\begin{tabular}{lrrrrr}
\hline Source & SS & df & MS & F Ratio & Sig. \\
\hline Between Groups & 0.689 & 1 & 0.689 & 0.0006 & 0.9363 \\
Within Groups & 16679.591 & 155 & 107.610 & & \\
\hline
\end{tabular}

The summary of the mean scores for the tenured and non-tenured teachers supervised by clinical and traditional approaches is summarized in Table 14.

These data indicate that there are, again, significant differences between clinical and traditional groups, yet minimal differences between the tenured and non-tenured categories within each supervision type. Therefore, it is evident that satisfaction toward supervision is related to supervision type rather than 
teaching experience. Moreover, an ANOVA procedure tested the interaction between tenured and non-tenured groups and determined that no significant differences were present at the .05 level of confidence. This can be seen in Table 15 .

The analysis of the three factor interaction of need strength by teaching experience by supervision type reiterated that significant differences at the .05 levei existed for supervision type only. The summary of the mean satisfaction scores comprising this interaction is presented in Table 16.

Table 14

Summary of Mean Satisfaction Scores for

Tenured and Non-tenured Teachers

by Supervision Type

\begin{tabular}{lccc}
\hline Group & $\mathrm{n}$ & Mean & $\mathrm{SD}$ \\
\hline Clinical & 55 & 60.85 & 7.51 \\
Tenured & 19 & 62.11 & 7.30 \\
Non-tenured & & & \\
Traditional & 70 & 49.80 & 9.34 \\
Tenured & 13 & 50.69 & 11.83 \\
Non-tenured & & & \\
\hline
\end{tabular}


Table 15

Analysis of Variance of Satisfaction Scores

for Tenured and Non-tenured Teachers

\begin{tabular}{lrrrrr}
\hline Source & SS & df & MS & F Ratio & Sig. \\
\hline Between Groups & 200.424 & 1 & 200.424 & 1.885 & 0.1717 \\
Within Groups & 16479.857 & 155 & 106.322 & & \\
\hline
\end{tabular}

Table 16

Summary of the Mean Satisfaction Scores for the Tenured and Non-tenured Teachers with Higher and Lower-Order Need Strengths in Clinical and Traditional Settings

\begin{tabular}{lllllll}
\hline Group & Need Strength & n & Tenured & SD & Non-tenured & SD \\
& & & & & & \\
\hline \multirow{2}{*}{ Clinical } & Higher order & 47 & 61.09 & 6.63 & 60.07 & 6.89 \\
& Lower order & 27 & 60.50 & 8.82 & 67.80 & 5.54 \\
\multirow{2}{*}{ Traditional } & Higher order & 55 & 50.47 & 7.71 & 51.10 & 13.27 \\
& Lower order & 28 & 48.60 & 11.83 & 49.33 & 6.66 \\
\hline
\end{tabular}


Open-ended Format Question Results

Teachers were invited to share their perceptions of their principal's supervisory practices by responding to four research inquiries dealing with supervision. Their comments provided descriptive data that was in addition to the quantitative statistics of the study. Data gathered from the questionnaire was used to answer each research statement and/or question posed by the study.

Research Inquiry 1: Briefly describe the process your principal used to supervise your teaching performance and its frequency.

In an effort to validate the supervision methods that each principal espoused to the researcher, teachers were asked to describe their principal's supervisory practice and indicate its level of frequency. Teacher comments were analyzed within the clincial and traditional framework.

Seventy-one clinically-supervised teachers responded to Research Inquiry 1. This represented $96 \%$ of the clinical sample. In 58 or $82 \%$ of the cases, teachers made direct citations to the use of clinical supervision methods. In these instances, teachers made reference to the six-step lesson design, the Madeline Hunter approach, the pre-conference, observation, and post-conference process, or used the term Clinical Supervision. When comments were analyzed with regard to individual principals, it was stated that clinical methods were being implemented. This is illustrated in Table 17. 
Table 17

Validation of Clinical Supervision Practices

$$
N=71
$$

\begin{tabular}{|c|c|c|c|}
\hline \multirow{2}{*}{$\begin{array}{l}\text { Clinical } \\
\text { Principals }\end{array}$} & \multirow[b]{2}{*}{$\mathbf{n}$} & \multicolumn{2}{|c|}{ Respondents to Inquiry 1} \\
\hline & & Citing $\mathrm{C} / \mathrm{S}$ * Use & Percentage \\
\hline 1 & 6 & 6 & 100 \\
\hline 2 & 6 & 6 & 100 \\
\hline 3 & 8 & 5 & 63 \\
\hline 4 & 9 & 8 & 89 \\
\hline 5 & 9 & 7 & 78 \\
\hline 6 & 1 & 1 & 100 \\
\hline 7 & 3 & 3 & 100 \\
\hline 8 & 9 & 8 & 89 \\
\hline 9 & 10 & 7 & 70 \\
\hline 10 & 10 & 7 & 70 \\
\hline
\end{tabular}

$*_{C} / \mathrm{S}=$ Clinical Supervision

Traditionally-supervised teachers similarly recounted their principal's supervisory methods. A total of 83 teachers, or $100 \%$ of the traditional sample responded to Research Inquiry 1. Seventy-five percent of these teachers provided information relative to supervision methods. Their responses centered around four general supervisory procedures. Table 18 cites their frequencies. 
Table 18

Teacher Perceptions of Traditional Supervision

Practices

$N=62$

\begin{tabular}{ccc}
\hline Method & Frequency & Percentage \\
\hline $\begin{array}{c}\text { Classroom Observation } \\
\text { Classroom Observation }\end{array}$ & 35 & 56.45 \\
With Post-Conference & 12 & 19.35 \\
Classroom Observation & & \\
W/Notes/Written Comments & 8 & 12.90 \\
Classroom Observation & & \\
Via Checklist & 7 & 11.29 \\
\end{tabular}

The most frequent procedure mentioned was classroom

observation. In $56 \%$ of the responses, teachers referred to classroom observation as a single activity without any reference to either pre-conference or post-conference discussion. In $19 \%$ of the cases, teachers mentioned that their principal arranged for a post-conference discussion following the observation. Another 13\% stated that their principal gave them a written summary of the observation following the lesson.

These data suggested that traditional principals were practicing supervisory methods distinct from clinical principals. Moreover, in 
80 or $96 \%$ of the total traditional sample, there was no mention of clinical supervision practices. In the three cases that did mention the term clinical supervision, the researcher was informed that measures were being studied yet had not been implemented with staff. The frequency with which supervision practices were implemented was of additional interest to this study. Data gathered from Research Inquiry 1 indicated large discrepancies between the frequency of classroom observations among the clinical and traditional supervisors. As noted in Table 19, clinical principals averaged nearly three times the number of classroom observations than their traditional counterparts.

Table 19

Frequency of Classroom Observations Reported by Clinical and Traditional Teachers

$$
\mathrm{N}=88
$$

\begin{tabular}{ccc}
\hline Observation & $\begin{array}{c}\text { Clinical } \\
\text { Frequency }\end{array}$ & $\begin{array}{c}\text { Traditional } \\
\text { Frequency }\end{array}$ \\
\hline 0 & - & 13 \\
1 & 6 & 22 \\
2 & 9 & 8 \\
3 & 7 & 5 \\
& & (table continues)
\end{tabular}




\begin{tabular}{ccc}
\hline Observation & $\begin{array}{c}\text { Clinical } \\
\text { Frequency }\end{array}$ & $\begin{array}{c}\text { Traditional } \\
\text { Frequency }\end{array}$ \\
\hline 4 & 14 & -- \\
$5+$ & 4 & - \\
\hline Frequency Average & 3.03 & 1.10 \\
\hline
\end{tabular}

The most frequent number of classroom observations conducted by the clinical principals was four per year. This is in contrast to the traditional principals who averaged one observation per year as reported by the traditionally-supervised teachers. Moreover, 13 teachers accounting for $16 \%$ of the traditional sample stated that their principal had not observed their teaching performance between the months of October through February.

Research Inquiry 2: Do your principal's supervision practices fulfill your needs?

Research Inquiry 2 attempted to gauge teachers' needs with respect to clinical and traditional supervision. Again, 71 clinically-supervised teachers responded to this question. Of this number, $79 \%$ stated that their principal's supervision practices fulfilled their needs. On a percentage-wise basis, this included 
$72 \%$ and $81 \%$ of the higher and lower-order need teachers, respectively. Tables 20 and 21 represent these data and the reasons for need fulfillment.

Table 20

Frequency of Responses to Research Inquiry 2

by Clinical Sample

$\mathrm{N}=71$

\begin{tabular}{|c|c|c|c|}
\hline & & Percentage & Percentage of \\
\hline Response & Frequency & of Sample & Group Membership \\
\hline
\end{tabular}

Yes

$\begin{array}{llll}\text { Higher-order } & 34 & 47.89 & 72.34 \\ \text { Lower-order } & 22 & 30.99 & 81.48\end{array}$

No

$\begin{array}{lrrr}\text { Higher-order } & 10 & 14.09 & 21.28 \\ \text { Lower-order } & 1 & 1.41 & 3.70\end{array}$

Uncertain

$\begin{array}{lllr}\text { Higher-order } & 1 & 1.41 & 2.31 \\ \text { Lower-order } & 3 & 4.23 & 11.11\end{array}$


Table 21

Reported Areas of Need Fulfillment in Clinical Supervision

$$
\mathrm{N}=52
$$

\begin{tabular}{|c|c|c|c|}
\hline \multirow[b]{3}{*}{ Areas of Fulfillment } & \multicolumn{3}{|c|}{ Number of Responses } \\
\hline & Higher-Order & Lower-Order & \\
\hline & Group & Group & Total \\
\hline Providing Helpful Feedback & 10 & 5 & 15 \\
\hline Supportive \& Fair Attitude & 8 & 6 & 14 \\
\hline \multicolumn{4}{|l|}{ Focus on Important Teaching } \\
\hline Aspects & 3 & 0 & 3 \\
\hline Open Communications & 1 & 0 & 1 \\
\hline \multicolumn{4}{|l|}{ Confirmation of Teachers' } \\
\hline Feeling of Success & 2 & 0 & 2 \\
\hline Encouragement of Self-improvement & 3 & 2 & 5 \\
\hline Lesson Analysis (post-conference) & 0 & 1 & 1 \\
\hline Principal's Efficiency & 0 & 1 & 1 \\
\hline Using Six-step Lesson Sequence & 4 & 2 & 6 \\
\hline Positive Reinforcement & $I$ & 3 & 4 \\
\hline
\end{tabular}


Providing helpful feedback was most cited as a source of fulfillment. Helpful feedback meant giving helpful suggestions by pointing out the pluses in a lesson, and providing items for strengthening any weak areas. Teachers further mentioned that useful feedback encouraged them to do their best. This area was also the most frequently cited among the higher-order teachers as can be seen in Table 21 .

Second most frequently mentioned was having a supportive and fair attitude. Teachers noted that supportive principals made teachers feel comfortable with the supervision process rather than threatened. Their principals were positive and knew how to provide constructive criticism in a tactful manner while encouraging teacher input in the discussion conference. Lower-order teachers indicated that this area was the most important with respect to need fulfillment. Thirty percent of the lower-order responses included descriptors such as supportive, caring, positive, encouraging, etc., when mentioning reasons for fulfillment. Less frequently cited were open communications and focusing on important teaching aspects. Open communications meant having the opportunity to go to the principal for information or advice at any given time. Focusing on important teaching aspects meant that principals critiqued lessons based on the six-step lesson design. One other area deserving mention was confirmation of a teacher's feeling of success. This area implied that, for some teachers, clinical supervision helped 
recognize a teacher's efforts and good work.

While sample frequencies did not indicate overwhelming trends within the higher and lower-order groups, higher order teachers credited clinical supervision for fulfilling their needs for instructional improvement via lesson feedback, while lower-order teachers felt fair and supportive supervision to be the primary reason for need fulfillment. These findings are in keeping with the proposed definition for higher and lower-order need teachers (see page 17). Moreover, when responses among the dissatisfied teachers were analyzed--those that responded negatively to research inquiry 2--there were predominantly more higher-order teachers (10) than lower-order teachers (1) represented. These higher-order teachers indicated that clinical supervision was lacking because ( 1 ) it did not cause a teacher to change his/her methods, (2) it did not encourage greater trust between the teacher and principal, (3) it took too much time, (4) it caused stressful situations, and (5) it regimented the teaching process (used six-step lesson design). These findings would suggest that for some higher-order teachers, the clinical supervision process appears to be confining. Moreover, the responses did not indicate any relationship to age. Research Inquiry 2 was of similar interest to $98 \%$ of the traditional sample. As such, $58 \%$ of the sample felt satisfied with their principal's supervision methods, while $32 \%$ reported no satisfaction. Some $10 \%$ embraced a neutral position. Tables 22 through 24 highlight these data. 
Table 22 further notes that the satisfied group was represented by $61 \%$ of the lower-order need sample and $55 \%$ of the higher-order need group. These teachers stated that their principal's supervision practices allowed them the autonomy and freedom to teach as professionals. The group indicated that freedom to be alone enabled them the opportunity to be their own critic, teach without the stress of regular observation, and leave the principal more time to deal with first-year teachers. However, several did mention that if they were inexperienced teachers, they would feel uncomfortable with the principal's supervisory practice. Interestingly, age appeared to relate to a teacher's preference for autonomy in the classroom. Fifty-eight percent of the teachers citing this as a reason for need fulfillment were over 46 years in age and had been teaching from 15 to 21 -plus years. Moreover, this group was slightly more represented by lower-order need teachers than higher-order need teachers. Nearly $18 \%$ of the lower-order need teachers to $11 \%$ of the higher-order need sample were included in this group.

The next most frequently mentioned reason for need fulfillment was principal support and positive attitude. This included principals who were trusting and demonstrated emotional concern and involvement for children. 
Table 22

Frequency of Responses to Research Inquiry 2

by Traditional Sample

$$
\mathrm{N}=81
$$

\begin{tabular}{|c|c|c|c|}
\hline Response & Frequency & $\begin{array}{l}\text { Percentage } \\
\text { of Sample }\end{array}$ & $\begin{array}{l}\text { Percentage of } \\
\text { Group Membership }\end{array}$ \\
\hline \multicolumn{4}{|l|}{ Yes } \\
\hline Higher-order & 30 & 37.03 & 54.55 \\
\hline Lower-order & 17 & 20.98 & 60.71 \\
\hline \multicolumn{4}{|l|}{ № } \\
\hline Higher-order & 20 & 24.69 & 36.36 \\
\hline Lower-order & 6 & 7.41 & 21.43 \\
\hline \multicolumn{4}{|l|}{ Uncertain } \\
\hline Higher-order & 3 & 3.70 & 5.45 \\
\hline Lower-order & 5 & 6.17 & 17.86 \\
\hline
\end{tabular}

Table 24 illustrates reason for the lack of need fulfillment with traditional supervision practices. The most frequently mentioned items were lack of lesson feedback and classroom observations. Teachers felt the need for principals to find out what's happening in the classroom. Moreover, this dissatisfaction was best exenplified by one teacher who indicated that "without 
constructive criticism and feedback, along with some praise, it becomes difficult to improve or refine one's teaching technique--self-evaluation is not enough!" The teachers citing these reasons for lack of need fulfillment were in contrast to the previously mentioned older and more experienced group of teachers who expressed need fulfillment within the traditional supervision framework. With the exception of one teacher between the ages of 41 to 45 , this group was represented by teachers between 26 and 35 years of age who had been teaching from 2 to 11 years. This group was represented by $22 \%$ of the higher-order need sample to $18 \%$ of the lower-order need group.

Table 23

Reported Areas of Need Fulfillment in Traditional Supervision

$$
N=36
$$

\begin{tabular}{lccc} 
& \multicolumn{3}{c}{ Number of Responses } \\
\cline { 2 - 4 } Areas of Fulfillment & $\begin{array}{c}\text { Bigher-Order } \\
\text { Group }\end{array}$ & $\begin{array}{c}\text { Lower-0rder } \\
\text { Group }\end{array}$ & Total \\
\hline Autonomy in Teaching & 10 & 9 & 19 \\
Supportive Attitude & 6 & 3 & 9 \\
Lesson Feedback & 4 & 1 & 5 \\
Principal Availability & 0 & 1 & 1 \\
Post-conference Discussion & 1 & 0 & 1 \\
Positive Reinforcement & 0 & 1 & 1 \\
\hline
\end{tabular}


Table 24

Reasons for Lack of Need Fulfillment in Traditional Supervision

$N=36$

\begin{tabular}{lccc}
\hline & \multicolumn{3}{c}{ Number of Responses } \\
\cline { 2 - 4 } Lack of Fulfillment & $\begin{array}{c}\text { Higher-Order } \\
\text { Group }\end{array}$ & $\begin{array}{c}\text { Lower-Order } \\
\text { Group }\end{array}$ & Total \\
\hline No Lesson Feedback & 7 & 2 & 9 \\
Too Few Observations & 5 & 3 & 8 \\
No Teacher Supervision & 4 & 2 & 6 \\
Lack of Principal's Knowledge & 4 & 1 & 5 \\
of Teaching Skills & & 1 & 4 \\
Lack of Teacher/Principal & 3 & & 3 \\
Communication & & 1 & 1 \\
Lack of Respect for Teacher's & 2 & 0 & \\
Opinion & 1 & & \\
Prefer Clinical Supervision & & & \\
\hline
\end{tabular}

Research Inquiry 3: What do you consider to be the most beneficial aspect of the supervision process?

Teachers were asked to outline what they considered to be the most beneficial aspect of clinical or traditional supervision. Responses were evaluated from $92 \%$ of the clinically-supervised teachers and $97 \%$ of the traditional sample.

The latter group identified numerous areas which they considered 
to be beneficial. In some instances, however, traditional teachers were reporting what they deemed to be positive attributes of supervision not necessarily associated with their principal's traditional methods. Table 25 lists these areas and their frequency.

Table 25

Beneficial Aspects of Supervision Reported by Higher and Lower-Order Traditional Sample

$$
N=80
$$

\begin{tabular}{lccc}
\hline & \multicolumn{3}{c}{ Number of Responses } \\
\cline { 2 - 4 } Areas & $\begin{array}{c}\text { Higher-Order } \\
\text { Group }\end{array}$ & $\begin{array}{c}\text { Lower-Order } \\
\text { Group }\end{array}$ & Total \\
\hline Lesson Feedback & 9 & 4 & 13 \\
Collegiality & 4 & 5 & 9 \\
Post-conference Discussion & 6 & 2 & 8 \\
Classroom Observation & 7 & 1 & 8 \\
Supportive Attitude & 4 & 3 & 7 \\
Nothing Beneficial & 3 & 1 & 4 \\
Helping Teachers in Need & 3 & 0 & 3 \\
Supporting School Policies & 1 & 1 & 2 \\
Clinical Supervision & 1 & 0 & 1 \\
Principal Availability & 2 & 3 & 5 \\
& & & $($ table continues)
\end{tabular}




\begin{tabular}{cccc}
\hline & \multicolumn{3}{c}{ Number of Responses } \\
\cline { 2 - 4 } Areas & $\begin{array}{c}\text { Higher-Order } \\
\text { Group }\end{array}$ & $\begin{array}{c}\text { Lower-Order } \\
\text { Group }\end{array}$ & Total \\
\hline Teacher Work Recognition & 3 & 2 & 5 \\
Continuous Teacher Development & 5 & 0 & 5 \\
Autonomy in Teaching & 2 & 3 & 5 \\
Positive Reinforcement & 3 & 2 & 5 \\
\hline
\end{tabular}

The most frequent response was lesson feedback. Traditionally-supervised teachers mentioned that constructive criticism regarding a lesson could be both stimulating and meaningful for improvement. Second most mentioned was collegiality. Teachers felt that trust and mutual respect between the principal and teacher to be important. Other terms mentioned included openness, honesty, genuine interest, personal attention, and gaining respect for one another as professionals.

Post-conference discussion and classroom observation were mentioned with equal frequency. Post-conference discussion meant dialogue following an observation between the principal and teacher to talk over the results of the lesson.

Classroom observation was also seen as a positive aspect because it enabled the principal to observe teacher strengths and weaknesses, and see first-hand the disabilities teachers dealt with each day. Another often cited aspect was supportive attitude. 
Teachers felt supervisors should be positive leaders who are aware of a teacher's program needs and back teachers with classroom problems and parental disputes when necessary. Among a group receiving five responses each, the following were included: principal availability for consultation, teacher work recognition and appreciation for classroom efforts and student progress, continuous development of professional skills, autonomy and freedom to teach without close supervision, and positive feedback or pats for a job well done.

When responses were compared between higher-order and lower-order teachers in the traditional sample, lesson feedback accounted for the greatest frequency among the higher-order teachers, while collegiality was cited with the greatest frequency in the lower-order group. This decision, interestingly, supported Hackman and Oldham (1974) and Sergiovanni and Starratt's (1983) claim that individuals expressing higher-order needs are more desirous of developing their professional skills, while lower-order individuals are more desirous of establishing friendships and egalitarian relationships. Further examples of this finding are seen in Table 25 . Some $57 \%$ of the higher-order need teachers cited a desire for increased teacher skills while mentioning the most beneficial aspect of supervision to be lesson feedback, post-conference discussion, classroom observation, and continuous teacher development. This was in contrast to $60 \%$ of the lower-order need sample which mentioned the importance of intra and 
interpersonal needs and relationships including collegiality, principal availability and supportive attitude, and positive reinforcement.

Among the clinically-supervised group, lesson feedback was also considered to be the most positive aspect of supervision. This area accounted for the greatest frequency as noted in Table 26. Teachers mentioned that lesson feedback was a valuable tool for improving their teaching skills and a motivational element when the supervisor offered positive reinforcement for good teaching practices.

The second most frequent response was post-conference discussion. Teachers indicated that the post-conference was important because it provided a time for sharing ideas with teachers and talking about lesson improvement. Several teachers, however, felt that clinical supervision most afforded teachers an opportunity to receive positive reinforcement. This, they stated, was associated with ego boosting for good lesson planning or instruction. Others thought that the most positive aspect of supervision was the development of their teaching skills since it helped teachers focus on effective teaching methods. Moreover, when responses were compared between higher and lower-order teachers, there was no indication of salient differences. 
Table 26

Beneficial Aspects of Supervision Reported by

Higher and Lower-Order Clincial Sample

$$
N=65
$$

\begin{tabular}{lccc}
\hline \multicolumn{1}{c}{ Number of Responses } & & \\
\cline { 2 - 3 } Areas & $\begin{array}{c}\text { Higher-Order } \\
\text { Group }\end{array}$ & $\begin{array}{c}\text { Lower-Order } \\
\text { Group }\end{array}$ & Total \\
\hline Lesson Feedback & 14 & 8 & 22 \\
Post-conference Discussion & 6 & 8 & 14 \\
Teacher Skill Development & 6 & 2 & 8 \\
Positive Reinforcement & 5 & 2 & 7 \\
Teacher Work Recognition & 4 & 1 & 5 \\
Supportive Principal Attitude & 4 & 0 & 4 \\
Teacher/Principal Communication & 2 & 0 & 2 \\
Pre-conference Discussion & 2 & 0 & 2 \\
Classroom Observation & 0 & 1 & 1 \\
\hline
\end{tabular}

Research Inquiry 4: What do you consider to be the most inhibiting aspect of the supervision process?

According to the clinically-supervised sample, the most inhibiting aspect of clinical supervision was classroom observation. Twelve subjects felt that it was difficult to feel at ease when the principal was observing their teaching performance. They indicated that the anticipation of the principal's visit 
further lead to questions of anxiety including: "Am I doing well?" "Will it seem like I'm prepared?" "Will my kids behave?", etc. Six teachers added, however, that their apprehension toward observation was not reflective of any negative feelings toward their principal, but rather a nervous condition that was self-inhibiting. Table 27 illustrates these data.

Table 27

Inhibiting Aspects of Supervision Reported by

Clinical Sample

$$
\mathrm{N}=54
$$

Number of Responses

\begin{tabular}{|c|c|c|c|}
\hline Areas & $\begin{array}{l}\text { Higher-Order } \\
\text { Group }\end{array}$ & \multirow{2}{*}{$\begin{array}{c}\text { Lower-0rder } \\
\text { Group }\end{array}$} & \multirow{2}{*}{$\frac{\text { Total }}{14}$} \\
\hline NTo Inhibitions & 5 & & \\
\hline Anxiety $\mathrm{w} / \mathrm{Cl}$ assroom Observation & 6 & 6 & 12 \\
\hline \multicolumn{4}{|l|}{ Principal Note Taking During } \\
\hline Observation & 4 & 2 & 6 \\
\hline \multicolumn{4}{|l|}{ Adherence to Six-step Lesson } \\
\hline Sequence & 3 & 2 & 5 \\
\hline \multicolumn{4}{|l|}{ Fear That Children Won't Per- } \\
\hline form Well & 4 & 0 & 4 \\
\hline \multicolumn{4}{|l|}{ Observation Used for Evalua- } \\
\hline tion Purposes & 3 & 0 & 3 \\
\hline & & (table & inues) \\
\hline
\end{tabular}




\begin{tabular}{lccc}
\hline & \multicolumn{3}{c}{ Number of Responses } \\
\cline { 2 - 4 } Areas & $\begin{array}{c}\text { Higher-Order } \\
\text { Group }\end{array}$ & $\begin{array}{c}\text { Lower-Order } \\
\text { Group }\end{array}$ & Total \\
\hline Too Many Observations & 2 & 0 & 2 \\
Heavy Criticism Regarding Lesson & 2 & 0 & 2 \\
Videotaping Lessons & 2 & 0 & 2 \\
Unscheduled Visits & 1 & 0 & 1 \\
Supervisor Intimidation & 0 & 1 & 1 \\
Lack of Supervisor Skills & 1 & 0 & 1 \\
Observation at Poor Times & 1 & 0 & 1 \\
\hline
\end{tabular}

Other inhibiting aspects mentioned by this group were principal note taking and the six-step lesson sequence. These two areas received five and six responses each. Teachers mentioned that when clinical principals observed lessons, they took notes on almost everything a teacher said and this became uncomfortable. Five other subjects reported that the six-step lesson approach required teachers to plan lessons amenable to the six elements that principals looked for in a lesson. Adherence to this practice was considered anxiety provoking. It should be noted also, however, that 14 subjects reported having no inhibitions with the clinical supervision process.

Nineteen traditionally-supervised subjects also indicated that their principal's supervision practices were not inhibiting. Among those who had a different opinion, were a group of thirteen teachers 
who felt that their principals conducted too few classroom observations. These responses were evenly distributed between higher and lower-order teachers as noted in Table 28. A commonly mentioned concern with this group was that, in their opinion, principals were basing teacher performance on cursory evidence, and had little knowledge of the learning experiences taking place in their classrooms.

Two areas mentioned with equal frequency included anxiety with lesson observation and supervisor indifference. Anxiety with lesson observation was a similar sentiment with the traditional sample as with their clinical counterparts. Their reasons for apprehension echoed those previously mentioned in the clinical sample.

Supervisor indifference, on the other hand, was reported to be inhibiting because it constrained communications, and contributed to a subdued atmosphere where teachers had no idea of their principal's standards and whether or not they met them.

A comparison of the responses from the clinical and traditional sample indicated areas of similarity and contrast. Both groups reported having no inhibitions with supervision in the greatest frequency. Moreover, clinical and traditional teachers felt apprehensive with respect to classroom observation irrespective of their feelings toward the principal. By contrast, traditional teachers cited a greater frequency of dissatisfaction with their principal's supervision methods than their clinical peers. The traditional sample registered their displeasure at having too few 


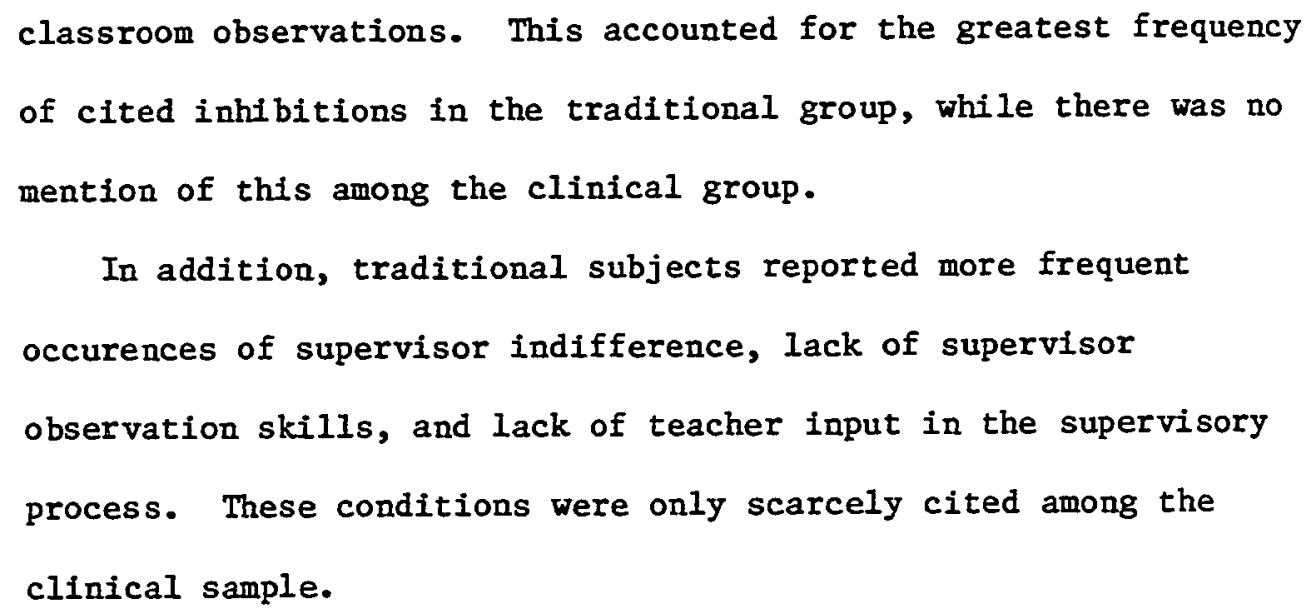

Table 28

Inhibiting Aspects of Supervision Reported by

Traditional Sample

$\mathrm{N}=67$

\begin{tabular}{lccc}
\hline & \multicolumn{3}{c}{ Number of Responses } \\
\cline { 2 - 4 } Areas & $\begin{array}{c}\text { Higher-Order } \\
\text { Group }\end{array}$ & $\begin{array}{c}\text { Lower-Order } \\
\text { Group }\end{array}$ & Total \\
\hline No Inhibitions & 11 & 8 & 19 \\
Too Few Observations & 8 & 5 & 13 \\
Anxiety With Classroom Obser- & 3 & & 7 \\
vation & 4 & 4 & 7 \\
Supervisor Indifference & 2 & 3 & 5 \\
Lack of Teacher Input & & 3 & 5 \\
Lack of Supervisor Obser- & 4 & 1 & (table continues) \\
vation Skills & & &
\end{tabular}




\begin{tabular}{|c|c|c|c|}
\hline \multirow[b]{2}{*}{ Areas } & \multicolumn{3}{|c|}{ Number of Responses } \\
\hline & $\begin{array}{l}\text { Higher-Order } \\
\text { Group }\end{array}$ & $\begin{array}{l}\text { Lower-Order } \\
\text { Group }\end{array}$ & Total \\
\hline \multicolumn{4}{|l|}{ Fear That Children Won't } \\
\hline Perform Well & 3 & 0 & 3 \\
\hline \multicolumn{4}{|l|}{ Pre-arranged Classroom } \\
\hline Observations & 2 & 0 & 2 \\
\hline \multicolumn{4}{|l|}{ Unschedule Classroom } \\
\hline Observations & 1 & 0 & 1 \\
\hline No Lesson Feedback & 1 & 0 & 1 \\
\hline Post-conference Discussion & 1 & 0 & 1 \\
\hline \multicolumn{4}{|l|}{ Supervision Used for Punish- } \\
\hline ment & 0 & 1 & 1 \\
\hline Principal Intimidation & 1 & 0 & 1 \\
\hline \multicolumn{4}{|l|}{ District Mandates Regarding } \\
\hline Use of Observation Checklist & 1 & 0 & 1 \\
\hline
\end{tabular}

Open-ended Results Summary

The open-ended format approach provided qualitative information to supplement the quantitative statistics of the study. In summary, the following information was gathered for the clinical, traditional and higher and lower-order need groups. 
1. Clinically-supervised teachers:

-were more supportive of their principals' supervision

practices in comparison to traditionally-supervised teachers -noted that their principals averaged three classroom observations per year

-cited lesson feedback to be the primary source of need fulfillment and the most beneficial aspect of supervision -indicated that anxiety with classroom observation was the most inhibiting aspect of the supervision process.

2. Traditionally-supervised teachers:

-cited a greater frequency of dissatisfaction with their principal's supervision methods than their clinical peers noted that their principals averaged one classroom observation per year -expressed dual views regarding supervision--the older and more experienced teachers noted that autonomy in teaching was a need fulfilling aspect, while the younger and less experienced reported that lesson feedback was the most fulfilling aspect in the supervision process -admitted that the lack of classroom observations was an inhibiting aspect of supervision and that lesson feedback was the most beneficial aspect. 
3. Higher-order need teachers:

-expressed a greater desire to develop their professional teaching skills irrespective of supervision type -indicated that for some of them $(21 \%)$, clinical supervision appeared to be confning -had more favorable perceptions toward supervision when clinically-supervised than when traditionally-supervised (72\% to $55 \%)$

-cited greater dissatisfaction toward supervision when traditionally-supervised than when clinically-supervised (36\% to $21 \%)$.

4. Lower-order need teachers:

-expressed a greater desire for considerate forms of supervision within the traditional supervision framework -expressed a greater desire to develop their teaching skills within the clinical supervision framework -had more favorable perceptions toward supervision when clinically-supervised than when traditionally-supervised $(81 \%$ to $61 \%)$

-cited greater dissatisfaction toward supervision when traditionally-supervised than when clinically-supervised $(21 \%$ to $4 \%)$. 


\section{Chapter 5}

Summary, Conclusions and Recommendations

Chapter 5 is divided into three sections. The first section examines the purpose of the study along with an abbreviated review of the literature, the stated hypotheses, and the methods utilized in the design of the study. The next section presents a summary of the findings and conclusions pertinent to each hypothesis, and a discussion of the problems encountered in the study including a discussion of practical implications. The final section presents suggestions for future research.

\section{Summary}

Purpose of the Study

The purpose of this study was to explore the current nature of instructional supervision through clinical and traditional supervisory approaches, and provide information regarding each methods level of satisfaction and effect among experienced and inexperienced teachers, and those considered to possess higher-order and lower-order needs. Specifically, the study examined the following relationships: 
1. The satisfaction levels of higher and lower-order need teachers supervised by clinical methods.

2. The satisfaction levels of higher and lower-order need teachers supervised by traditional methods.

3. The relationship between years of teaching experience of higher and lower-order need teachers and their satisfaction toward clinical and traditional supervision.

4. The relationship between tenured and non-tenured teachers of both higher and lower-order categories and their satisfaction toward clinical and traditional supervision methods.

In addition, the study posed a series of open-ended questions in order to provide descriptive depth to the quantitative statistics of the study. The descriptive data compiled information relative to:

1. The most beneficial aspects of clinical and traditional supervision.

2. The most inhibiting aspects of clinical and traditional supervision.

\section{Review of the Literature}

Chapter 2 presented a historical perspective of instructional supervision from the first quarter of the century to the present. It traced the path of supervision from the classical authoritarian style where principals directed and dominated teachers' instruction, to the era of human relations, methodology and the initiation of a 
more democratic environment that emphasized the importance of interrelationships between the administration and the teachers.

The literature also presented the concemporary styles of supervision that are attributed to our modern times. These included the rational/technical approach known as traditional supervision and its emphasis on control, accountability, and efficiency, and a second model recognized for its concept of colleagueship known as clinical supervision.

In view of their distinction, the literature examined the behavior, practices and methods of these contemporary supervisory approaches. It was mentioned that traditional supervision emphasized a line-office posture with teachers and held that supervisors must use their authority in directing and overseeing the execution of school goals. However, while this approach superseded the establishment of egalitarian relationsips, it did not discourage supervisors from engaging teacher participation in the determination of purposes and procedures, yet mainly supported limitations to autonomy.

Adherents to clinical supervision supported a staff-office position that assumed that the improvement of teaching is more likely to increase a teachers' self-development when implemented within the mutual support of a partnership between teacher and supervisor. This concept was recognized as colleagueship. Additional reference was made to the areas of product and process orientation. Traditional supervisors were recognized for 
setting the parameters of the learning environment is such a way that all teachers contributed to the attainment of school goals, and thereby collectively emphasized student achievement. It was stated that once teachers understood that they would be held accountable for student knowledge of specific skills, there would be less evaluation of teacher competence with respect to process and more upon pupil performance.

In contrast, the process of clinical supervision prescribed the formative development of teachers. It focused upon a teacher's mastery of his/her teaching craft in greater proportion to the achievement of school/district goals. This development, it was stated, centered around the implementation of cycles or phases beginning with the establishment of the teacher-supervisor relationship. Other phases included the pre-conference session to gain information about the teacher's view on the objectives of the lesson, the lesson observation itself, the strategy session to analyze the transcripts of the observed lesson, and the post-conference to discuss the effectiveness of the lesson and to plan future strategies for improvement.

The traditional supervisory model did not endorse any specific articulated structure, yet assessed classroom interaction via a series of scheduled and unscheduled classroom visitations with the optional use of rating scales and checklists. The literature suggested that traditional supervision was more inspectional in process and attempted to gauge teacher performance through classroom 
observations of a frequent and short nature.

Empirical research focusing on the effectiveness of traditional and clinical supervision was additionally investigated, yet found to be limited. What was reviewed, however, indicated that clinical supervision was perceived more favorably than traditional supervision when assessed for communication, suggestions for improvement, effectiveness of conferences, and supervisor helpfulness. Moreover, current research stated that clinical supervision provided a better model for teachers to move toward improved perceptions of supervision and their own teaching competence.

With respect to need strengths, there were very few studies that had investigated the need levels of educators. Those mentioned stated that educators have predominantly higher-order needs which are associated with the esteem, autonomy and self-actualization hierarchical need structure. Moreover, teachers' levels of aspiration level downward with age as teachers become more realistic or resigned to things as they are.

The review did not uncover any research examining the relationship between supervision models and teacher need strengths. The absence of research in this area demonstrates the need for this study at a time when "school executives and other professionals with supervisory responsibility are largely ignorant of adult motivation--theoretically, conceptually, and in practice--and in dealing with adults have had to rely on intuition, experience, and 
mythology" (Carver and Sergiovanni, 1975:55).

\section{Review of the Hypotheses}

The level of probability at which the hypotheses were rejected was the .05 level. The hypotheses of this study, stated in the null form, included the following:

1. The method of teacher supervision used, whether clinical or traditional, does not effect higher-order need teacher's satisfaction toward supervision.

2. The method of teacher supervision used, whether clinical or traditional, does not effect lower-order need teacher's satisfaction toward supervision.

3. The method of teacher supervision used, whether clinical or traditional, does not effect non-tenured teacher's satisfaction toward supervision.

4. The method of teacher superivision used, whether clinical or traditional, does not effect tenured teacher's satisfaction toward supervision.

5. The method of teacher supervision used, whether clinical or traditional, does not effect non-tenured lower-order need teacher's satisfaction toward supervision.

6. The method of teacher superivision used, whether clinical or traditinal, does not effect tenured lower-order need teacher's satisfaction toward supervision. 
7. The method of teacher supervision used, whether clinical or traditional, does not effect non-tenured higher-order need teacher's satisfaction toward supervision.

8. The method of teacher supervision used, whether clinical or traditional, does not effect tenured higher-order need teacher's satisfaction toward supervision.

9. There is no difference between higher-order and lower-order need teachers in their attitude toward supervision.

10. There is no difference in the attitudes of clinical and traditional teachers toward supervision.

\section{Review of the Methods}

The participants in this study were elementary school principals and teachers presently employed in a public school within the San Diego and Los Angeles county areas. The study included twenty principals who had the responsibility for supervising teachers and who utilized either clinical or traditional supervision methods. Ten principals represented each supervisory category.

One hundred fifty-seven teachers were also included in the study. These teachers were randomly selected by their principal using the systematic random sampling technique. In total, 74 teachers were supervised via clinical methods and 83 by traditional approaches.

In order to adequately categorize teachers into higher-order and lower-order groups, a questionnaire developed by Hackman and 01dham 
(1974) was used. The instrument, called the Higher-Order Need Strength Measure B, was developed by Hackman and Oldham to test the growth need strengths of employees. Measure B was designed in a job choice format which asked respondents to choose between pairs of hypothetical jobs with characteristics relevant to growth needs (higher-order) and other needs (lower-order).

After a three-month period, the identified higher and lower-order need teachers were mailed the Teacher Supervision Practices Questionnaire to measure each teacher's degree of satisfaction with either the clinical or traditional supervisory approach implemented by the principal. The questionnaire measured teacher perceptions regarding (a) the principal's methods for evaluating the effectiveness of a teaching lesson and helping teachers improve instruction, (b) the principal's methods for collecting data and providing feedback regarding a lesson, and (c) the level of interpersonal relations effected by the supervision process. Teacher satisfaction was determined by reviewing the mean scores of the clinical and traditional groups with respect to the 15-item Teacher Supervision Practices Questionnaire, and applying ANOVA procedures for determining significance.

\section{Summary of the Hypotheses}

Hypotheses one and two postulated that neither type of supervision would have an effect on higher-order and lower-order need teachers and their attitude toward supervision. In effect, 
teacher need strength had no significant relationship to supervision. Therefore, the null hypotheses were both accepted.

Although the teachers who had clinical supervisors had higher mean scores than the traditionally-supervised group in the Teacher Supervision Practices Questionnaire, the test of ANOVA indicated that this significant difference was attributed to the type of supervision implemented rather than any relationship to need streng th.

The third and fourth hypotheses dealt with the relationship between type of supervision and tenured and non-tenured classifications. Again, there was not found to be any correlation between supervision and teacher classification. The tenured and non-tenured teachers who were clinically supervised had higher satisfaction scores than the traditional sample. This significant finding, however, was again determined to be the result of the type of supervision irrespective of teacher classification, thus, hypotheses three and four were both accepted.

Hypotheses five, six, seven and eight measured the interaction between supervision groups, need strength, and teacher classification. No significant differences were found in any of these hypotheses, therefore each hypothesis was accepted.

The ninth hypothesis dealt with differences between higher-order and lower-order need teachers in their attitude toward supervision. Mean scores between the two groups were essentially equal and tests of ANOVA determined that there were no significant differences. The 
null hypothesis was therefore accepted.

The final hypothesis predicted that there would be no difference in attitude and satisfaction level between clinically-supervised and traditionally-supervised teachers in their perceptions toward supervision. The mean scores on the Teacher Supervision Practices Questionnaire showed a difference between the groups. The teachers who had clinical supervisors had a higher satisfaction rating than their traditional counterparts. This difference was tested by ANOVA and determined to be significant beyond the .01 level of probability. Therefore, clinical supervision was rated significantly higher than traditional supervision and the null hy pothesis was re jected.

\section{Conclusions}

Summary of Findings, Interpretations, and Literature Support

The analysis of the data collected relative to the principal objectives of the study indicated significant differences between the attitudes of clinically-supervised and traditionally-supervised teachers toward supervision. The analysis of differences between the sub-groupings, higher-order and lower-order, tenured and non-tenured, and combinations of the four variables did not reveal any significant relationships to supervision when tested by ANOVA.

In this researcher's opinion, these data indicated that clinical supervision practices are perceived as more effective than traditional supervision practices and enhance more positive 
perceptions among teachers. These data suggested that clinical supervisors are considered superior to traditional supervisors with respect to:

1. Methods for assessing the effectiveness of a teaching lesson.

2. Methods for helping teachers improve instruction.

3. Methods for collecting data regarding a lesson.

4. Methods for providing feedback regarding a lesson.

5. Methods for fostering interpersonal relations between teacher and principal.

Moreover, the findings revealed that clinical supervision achieved greater satisfaction than traditional supervision among higher and lower-order teachers and those in tenured and non-tenured classifications. The qualitative results of the study further indicated the following:

1. Clinical supervision is in a better position than traditional supervision in helping lower-order need teachers develop a desire for improving their teaching skills

2. Clinical supervision is in a better position than traditional supervision in helping higher-order need teachers continue their professional skill development.

3. For some higher-order need teachers, the clinical supervision approach is confining and generates dissatisfaction.

4. Clinical principals tend to spend more time in supervision than traditional principals as evidenced by the number of classroom observations conducted during the study. 
Interestingly, in previous research that compared clinical supervision to traditional supervision, there was evidence to suggest that clinical supervision was more effective and perceived more positively by teachers. Reavis' (1977) study supported clinical supervision over traditional supervision in relation to interpersonal comunication and teacher self-perception. Lafferty (1980) concluded that clinical supervision facilitated teacher development and that the process contributed to the development of the teacher who was able to analyze and evaluate his/her teaching performance. Finally, Mattes (1983) reported that clinical supervision approximated teachers' desired level of supervision when contrasted to traditional supervision.

This study, in retrospect, joins the previous research in suggesting that clinical supervision practices engender more positive perceptions and greater levels of satisfaction among elementary school teachers when compared to traditional supervision. Moreover, it concludes that clinical supervision is a better process than traditional supervision with respect to helping lower-order need teachers improve their teaching performance and helping higher-order need teachers continue their professional skill development 
Recommendations

\section{Discussion of the Problems and Limitations}

There were some problems and limitations that were encountered in the process of implementing this research which should be considered when interpreting these data.

1. There were discrepancies in the number of observations conducted by the clinical and traditional principals. In terms of assessing the value of each supervisory method on an equal basis, the difference in the number of observations may have influenced a teacher's perceptions of their principal's supervisory practice. In replications of this study, it is recommended that participating principals agree to conduct the same number of observations during a defined period.

2. Principals were given a three-month period in which to initiate their supervisory methods. This period of time included some major holidays which shortened the working calendar by ten days. This loss of time may have reduced the principal's opportunity to conduct a greater number of classroom observations and compounded the problem noted in number 1, above. Therefore, it is advisable that future researchers allow a minimum of four months in which to gather similar information.

3. The Higher-Order Need Strength Measure B lacked the power to effectively deal with those teachers who expressed borderline higher-order or lower-order preferences. Teachers who achieved a 
raw score slightly above or below 36, may represent a group that fluctuates between higher and lower-order needs. Their membership in either group may have been the result of this fluctuation and contributed to membership error. In future uses of Measure B, it is recommeded that researchers interview borderline teachers and thereby gather additional information that will help them effectively categorize these teachers.

\section{Discussion of the Practical Implications}

There were pertinent findings derived from the study which have practical implications for others involved in research or applied practice in the area.

1. School districts should consider adopting clinical supervision practices and initiate training methods for principals and other supervisors.

2. Administrator training in clinical supervision methods should be indepth, incremental, and periodic in order that meaningful skill development can take place.

3. Superintendents and school boards should issue clear indication to principals and other supervisors that clinical supervision expertise is a major priority.

4. Teachers should be given the opportunity to attend inservice training programs to familiarize themselves with clinical supervision methods. 
5. Principals practicing clinical supervision should be offered training in the aspect of coaching techniques for their highly skilled teachers (presumably higher-order types), in an effort to stimulate their continued growth and offer them a supervisory approach that meets their advanced needs.

\section{Recommendations for Future Research}

The review of the literature provided cogent documentation with respect to the historical changes in instructional supervision since the first quarter of the century. It showed how the incremental nature of these changes have been influenced by distinct organizational theories and of ten delegated by supervisors who were in the best position to enact change. The evidence further suggested that these changing conditions have placed new demands on supervisors and school principals with respect to their leadership in school affairs, including responsibilities for student learning growth and teacher professional development.

In all probability, instructional supervision will remain a future leadership function for school leaders. However, if it is to remain palatable to teachers while also improving teacher performance, it must continue to receive the attention of future researchers. Given this responsibility, the following recommendations are offered:

1. Future research should examine the correlation between frequency of observations and teacher behavior change. 
Specifically, the effects of different supervisory models on teacher performance within a given number of classroom observations.

2. Studies should examine teachers' perceptions regarding characteristics of effective school principals' supervision practices, and the effects of these behaviors on teacher performance, student learning, teacher self-development, etc.

3. Future research should examine higher and lower-order need teachers' perceptions regardng desired supervision practices and compare them to actual practices within the clinical and traditional framework.

4. Studies should explore the use of the clinical supervision approach and examine the variables that contribute toward its acceptance and rejection among higher-order need teachers.

5. Studies should examine the relationship between models of supervision to stages of teacher maturational levels.

6. There is a need for longitudinal studies related to supervision and teacher development. Researchers should consider following-up on previous studies to measure the long-term effects that a particular supervision model, such as clinical supervision, has had on a teacher's teaching performance, self-development, etc.

7. Research should explore the relationship between principals" developmental levels (need strength levels, age levels, training levels) and teacher satisfaction toward supervision. 
Acheson, K. A. \& Gall, M. D. (1980). Techniques in the Clinical

Supervsion of Teachers. New York: Longman Inc.

Alfonso, R. J., Firth, G. R., \& Neville, R. F. (1981).

Instructional Supervision--A Behavior System. Boston: Allyn and

Bacon, Inc.

Argyris, C. \& Schon, D. A. (1974). Theory in Practice: Increasing

Professional Effectiveness. San Francisco: Jossey-Bass.

Barr, A. S., Burton, W. H., \& Brueckner, L. J. (1938). Supervision,

Principles and Practices in the Improvement of Instruction.

New York: Appleton-Century Co.

Bartky, J. (1953). Supervision as Human Relations. New York:

McGraw-Hill Co.

Bloom, B. S. (1956). Taxonomy of Educational Objectives. New

York: David McKay Inc.

Blumberg, A. (1980). Supervisors and Teachers: A Private Cold War. Berkely, California: McCutchan Publishing Co.

Boardman, C. (1953). Democratic Supervision in Secondary Schools. New York: Houghton-Mifflin.

Burleigh, G. B. (1945). Human Relations in Industry. Chicago: Irwin.

Burton, W. H. \& Brueckner, L. J. (1955). Supervision, A Social

Process. New York: Appleton-Century Crofts.

Butts, R. F., \& Cremin L. A. (1953). A History of Education in

American Culture. New York: Henry Holt and Co. 


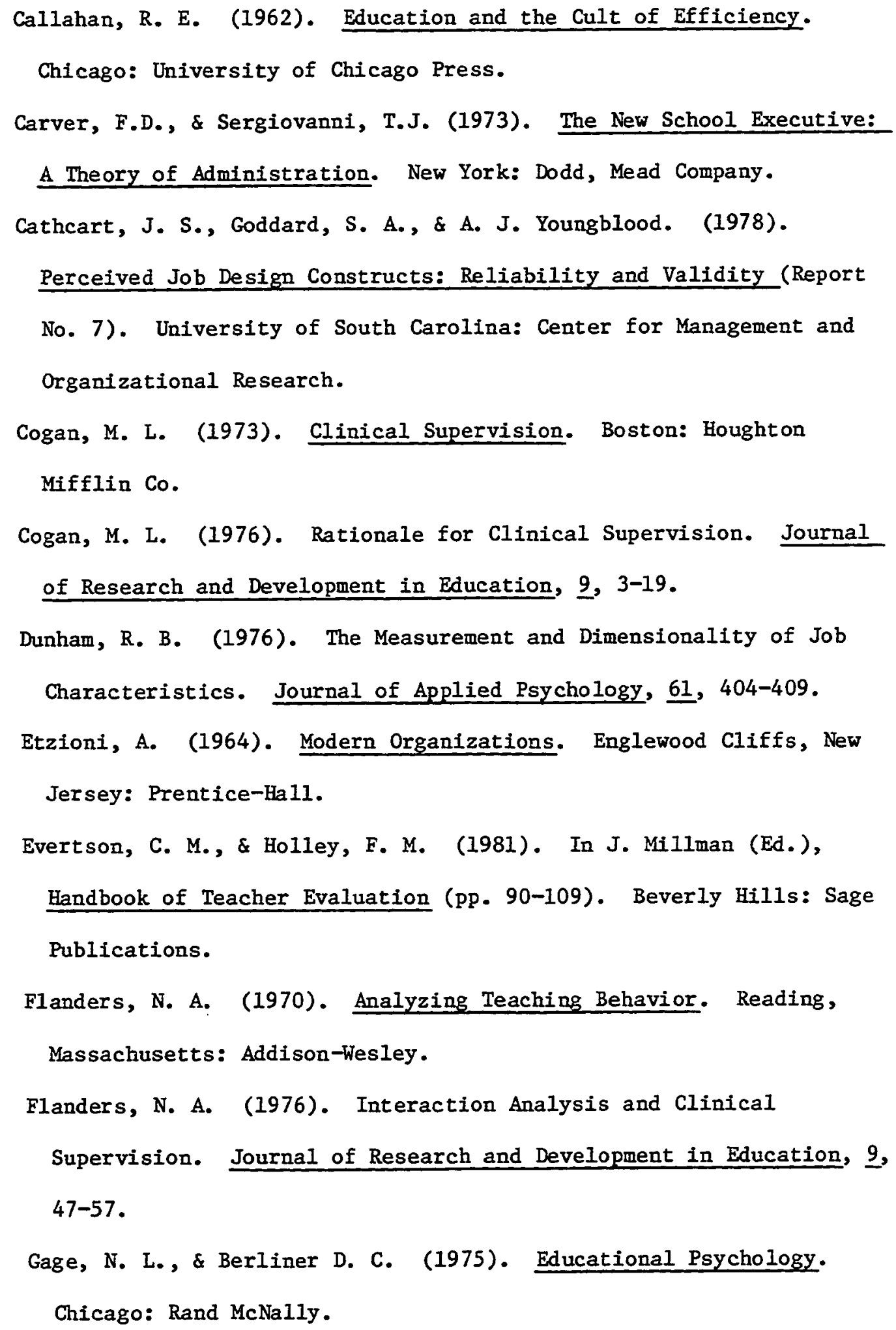


Glickman, C. D. (1980) The Developmental Approach to Supervision. Educational Leadership. $38,(2), 178-180$.

Glickman, C. D., \& Esposito, J. P. (1979). Leadership Guide For Elementary School Improvement. Boston: Allyn and Bacon Inc. Glickman, C. D., \& Tamashiro, R. T. (1980). Determining One's Beliefs Regarding Teacher Supervision. National Association of Secondary School Principals, 64, 74-80.

Goldhammer, R. (1969). Clinical Supervision. New York: Holt, Rinehart and Winston.

Goldhammer, R., Anderson, R. H., \& Krajewski, R. J. (1980). Clincal Supervision. New York: Holt, Rinehart and Winston.

Goodlad, J. I. (1976). Facing the Future. New York: McGraw-Hill Book Company.

Guilford, J.P. (1950). Fundamental Statistics in Psycnology and Education. New York: McGraw-Hill.

Gwynn, M. J. (1961). Theory and Practice of Supervision. New York: Dodd, Mead and Co. Hackman, J. R., \& Oldham, G. R. (1974). The Job Diagnostic Survey: An Instrument for the Diagnosis of Jobs and the Evaluation of Job Redesign Projects (NTIS No. AD 779828). Springfield, VA: U.S. Department of Commerce.

Hackman, J.R., \& OIdham, G. R. (1975). Development of the Job Diagnostic Survey. Journal of Applied Psychology, 60, 159-170. Hackman, J. R., \& Oldham, G. R. (1980). Work Redesign. Reading, Massachusetts: Addison-Wesley. 
Hanson, M. E. (1979). Educational Administration and Organizational Behavior. Boston: Allyn and Bacon Inc. Harris, B. M. (1975). Supervisory Behavior in Education. New Jersey: Prentice-Hall Inc.

Herzberg, F. (1959). The Motivation to Work. New York: Wiley. Hunter, M. (1969a). Motivation Theory for Teachers. El Segundo, California: TIP Publications.

Hunter, M. (1969b). Reinforcement Theory for Teachers. El Segundo, California: TIP Publications.

Hunter, M. (1969c). Retention Theory for Teachers. El Segundo, California: TIP Publications.

Hunter, M. (1973). Appraising the Instructional Process. Paper presented at Annual Conference of California Advisory Council of Educational Research. (ERIC Document Reproduction Service No. ED 139792

Hyman, R. T. (1975). School Administrator's Handbook of Teacher Supervision and Evaluation Methods. Englewood Cliffs, New Jersey: Prentice-Hall.

Lafferty, H. K. (1980). A Comparative Study of Teacher Development Under Standard Diocesan Supervisory Processes and Under Clinical Supervision in Selected Secondary Schools (Doctoral dissertation, University of Pittsburgh, 1980). Dissertation Abstracts Internationa1, $41,2426 \mathrm{~A}$.

Lewin, K. (1938). The Conceptual Representation and the Measurement of Psychological Forces. Durham, North Carolina: Duke University Press. 
Lucio, W. H. (1967). Supervision: Perspectives \& Propositions. Position paper prepared for the Association of Supervision and Curriculum Development, Washington D.C. (ERIC Document Reproduction Service No. ED 017999

Lucio, W. H., \& McNeil J. D. (1962). Supervision--A Synthesis of Thought and Action. New York: McGraw-Hill Book Co. Lucio, W. H., \& McNeil J. D. (1979). Supervision in Thought and Action. New York: McGraw-Hill Book Company. Luehe, W. F., \& Ehrgott, R. H. (1976). Clinical Teaching and Supervision. Visalia, California: Key Publications.

Magers, R. F. (1975). Preparing Instructional Objectives. Belmont, California: Fearon-Pitman Publishing. Manatt, R. P., \& Palmer, K. L. (1976). Evaluating Teacher Performance with Improved Rating Scales. National Association of Secondary School Principals, 60, 21-24.

March, J. G., \& Simon, H. A. (1961). Organizations. New York: John Wiley and Sons Inc.

Marks, J. R., \& Stoops, E. (1978). Handbook of Educational Supervision: A Guide for the Practioner. Boston: Allyn and Bacon, Inc.

Masling, J., \& Stern, G. (1963). Changes in Motives as a Result of Teaching. Theory into Practice, 12, (3), 95-104.

Maslow, A. (1954). Motivation and Personality (2nd ed.). New York: Harper and Row Publishers. 
Mattes, R. G. (1983). A Comparative Study of Teachers' Perceptions of Teacher Development and Supervisory Practices Under Clinical and Traditional Supervision Practices in Selected Colorado Schools (Doctoral dissertation, University of Colorado at Boulder, 1983). Dissertation Abstracts International, 44, 4404A. (University Microfilms No. 83-17682)

Mayo, E. (1933). The Human Problems of an Industrial

Civilization. New York: Macmillian.

McNergney, R. (1980). Supervising Different Teachers Differently. Planning and Changing, 9 , (4), 224-228.

Mosher, R. L., \& Purpel, D. E. (1972). Supervision: The Reluctant Profession. Boston: Houghton Mifflin Co.

Natriello, G. (1977). A Summary of Recent Literature on the Evaluation of Principals, Teachers, and Students. Occasional paper No. 16. Stanford University of California, Stanford Center for Research and Development in Teaching. (ERIC Document Reproduction Service No. ED 141 407)

Neagley, R. L., \& Evans, N. D. (1980). Handbook for Effective Supervision of Instruction. New Jersey: Prentice-Hall Inc.

Nie, H. H. (1975). Statistical Package for the Social Sciences (2nd ed.). New York: McGraw-Hill Book Co. Oldham, G. R., Hackman, J. R., \& Stepina, L. P. (1979). Norms for the Job Diagnostic Survey (Ms. No. 1819). Washington, D.C: American Psychological Association. 
Owens, R. G. (1981). Organizational Behavior in Education. New Jersey: Prentice-Hall Inc.

Pastor, M. C. (1980). Higher-Order Need Strengths and Job Satisfaction in Secondary Public School Teachers (Doctoral dissertation, Texas A\& M University, 1980). Dissertation Abstracts International, $\underline{41}, 2866 \mathrm{~A}$. (University Microfilms No. 81-01631)

Pohland, P. A. (1976). Perspectives on Instructional Supervision: The Model Muddle. Paper presented at the Annual Meeting of the American Educational Research Association, San Francisco, CA. (ERIC Document Reproduction Service No. ED 122 355)

Porter, L. (1962). Attitudes in Management: Perceived Deficiencies in Need Fulfillment as a Function of Job Level. Journal of Applied Psychology, 46, 375-384.

Porter, L., Lawler, E. E., \& Hackman, J. R. (1975). Behavior in Organizations. New York: McGraw-Hill. Putnal, J. (1981). Factors Identified by Selected Teachers and Supervisors as Problems in Clinical Supervision Which Might Contribute to its Limited Acceptance (Doctoral dissertation, Florida State University, 1981). Dissertation Abstracts International, 42, $2420 \mathrm{~A}$.

Reavis, C. (1977). A Test of the Clinical Supervision Model. Journal of Educational Research, 70, 311-315.

Roethlisberger, F. J., \& Dickson W. J. (1939). Management and the Worker. Cambridge, Massachusetts: Harvard University Press. 
Sergiovanni, T. J. (1976). Toward a Theory of Clinical Supervision. Journal of Research and Development in Education, 9 , 20-29. Sergiovanni, T. J., \& Starratt R. (1983). Supervision--Human Perspectives ( $3 r d$ ed.). New York: McGraw-Hill Book Company. Smith, Gary W. (1978). Analysis of Elementary Teachers Behavioral

Changes During Professional Development. Unpublished Doctoral dissertation, Walden University, Florida. Stogdill, R. M. (1948). Personal Factors Associated With Leadership: A Survey of the Literature. Journal of Psychology, $\underline{25}, 63$.

Sullivan, C. G. (1980). Clinical Supervision: A State of the Art Review. Paper presented at the meeting of the Association for Supervision and Curriculum Development, Alexandria, VA. (ERIC Document Reproduction Service No. ED 182822 Trusty, F., \& Sergiovanni, T. J. (1971). Administering Human Resources. Berkeley, CA: McCutchan. Weller, R. (1971). Verbal Communication in Instructional Supervision. New York: Teachers College Press. Wiles, K., \& Lovell J. T. (1975). Supervision For Better Schools. New Jersey: Prentice-Hall Inc. 
APPENDIX A

SCHOOL DISTRICTS INCLUDED IN STUDY

Reproduced with permission of the copyright owner. Further reproduction prohibited without permission. 


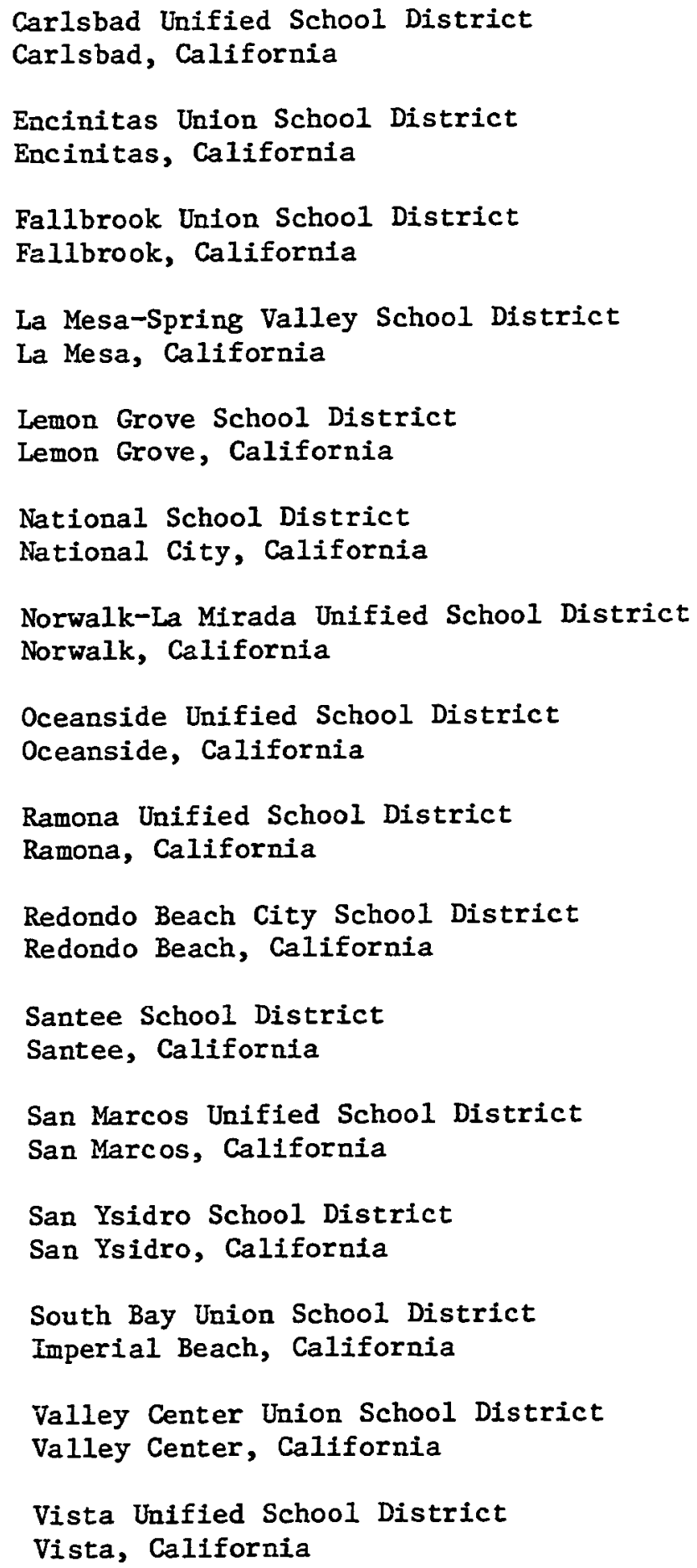


APPENDIX B

HIGHER-ORDER NEED STRENGTH MEASURE B

Reproduced with permission of the copyright owner. Further reproduction prohibited without permission. 
Dear Teacher:

The purpose of this brief questionnaire is to gauge your needs as elementary school teachers. Since the sample being studied is a relatively small one, your response will contribute significantly.

Please respond to the 12 survey questions. For each pair, indicate which job most accurately addresses your needs. Assume everything else about the job is the same. Check the neutral blank only if you find the two jobs equally attractive or unattractive.

Do not identify yourself by name on the questionnaire, but please identify your questionnaire by writing your mother's maiden name in the right-hand corner. This is very important since it is imperative that you receive the appropriate follow-up questionnaire in about three months. Rest assured that your answers will be kept completely confidential.

Thank you for your assistance with this study.

\section{$\underline{\text { JOB A }}$}

1. A job where the pay is very good. $\underline{\text { JOB B }}$

A job where there is considerable opportunity to be creative and innovative.

$\begin{array}{lllll}1 & -2 & -4 & -5 \\ \text { Strongly } & \text { S1ightly } & \text { Neutral } & \text { Slight ly } & \text { Strongly } \\ \text { Prefer A } & \text { Prefer A } & & \text { Prefer B } & \text { Prefer B }\end{array}$

2. A job where you are often required to make important

A job with many pleasant decisions. people to work with.

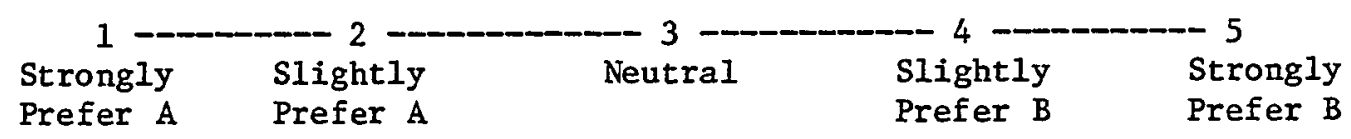


3. A job in which greater responsibility is given $A$ job in which greater responsibility is given to those who do the best to loyal employees who work. have the most seniority.

$\begin{array}{lllll}1 & & 3 & & \\ \text { Strongly } & \text { Slightly } & \text { Neutral } & \text { Slightly } & \text { Strongly } \\ \text { Prefer A } & \text { Prefer A } & & \text { Prefer B } & \text { Prefer B }\end{array}$

4. A job in an organization which is in financial trouble and might have to close down within a year.
A job in which you are not allowed to have any say whatever in how your work is scheduled, or in the procedures to be used in carrying it out.

$\begin{array}{lllll}1 & & 2 & & \\ \text { Strongly } & \text { Slightly } & \text { Neutral } & \text { Slightly } & \text { Strongly } \\ \text { Prefer A } & \text { Prefer A } & & \text { Prefer B } & \text { Prefer B }\end{array}$

5. A very routine job.

A job where your coworkers are not very friendly.

$\begin{array}{lllll}1 & & & & \\ \text { Strongly } & \text { Slightly } & \text { Neutral } & \text { Slightly } & \text { Strongly } \\ \text { Prefer A } & \text { Prefer A } & & \text { Prefer B } & \text { Prefer B }\end{array}$

6. A job with a supervisor who is often very critical of you and your work in front of other people.
A job which prevents you from using a number of skills that you worked hard to develop.

$\begin{array}{lllll}1 & & & & \\ \text { Strongly } & \text { Slightly } & \text { Neutral } & \text { Slightly } & \text { Strongly } \\ \text { Prefer A } & \text { Prefer A } & & \text { Prefer B } & \text { Prefer B }\end{array}$
7. A job with a supervisor who respects you and treats you fairly.
A job which provides constant opportunities for you to learn new and interesting things.

$\begin{array}{lllll}1 & & & & \\ \text { Strongly } & \text { Slightly } & \text { Neutral } & \text { Slightly } & \text { Strongly } \\ \text { Prefer A } & \text { Prefer A } & & \text { Prefer B } & \text { Prefer B }\end{array}$


8. A job where there is a real
$\begin{aligned} & \text { chance that you could be } \\ & \text { laid off. }\end{aligned}$

9. A job in which there is a real chance for you to develop new skills and advance in the organization.

1 -

$\begin{array}{ll}\text { Strongly } & \text { Slightly } \\ \text { Prefer A } & \text { Prefer A }\end{array}$

A job which provides lots of vacation time and an excellent fringe benefit package.

10. A job with little freedom and independence to do your work 3 4 Slightly Prefer $B$ Strongly Prefer B in the way you think best. A job where the working
conditions are poor.

\begin{tabular}{|c|c|c|c|c|}
\hline $\begin{array}{l}\text { Strongly } \\
\text { Prefer A }\end{array}$ & $\begin{array}{l}\text { Slightly } \\
\text { Prefer A }\end{array}$ & Neutral & $\begin{array}{l}\text { Slightly } \\
\text { Prefer B }\end{array}$ & $\begin{array}{l}\text { Strongly } \\
\text { Prefer B }\end{array}$ \\
\hline
\end{tabular}
11. A job with very satisfying
team-work.
A job which allows you to use your skills and abilities to the fullest extent.

\begin{tabular}{|c|c|c|c|c|}
\hline $\begin{array}{l}\text { Strongly } \\
\text { Prefer A }\end{array}$ & $\begin{array}{l}\text { Slightly } \\
\text { Prefer A }\end{array}$ & Neutral & $\begin{array}{l}\text { Slightly } \\
\text { Prefer B }\end{array}$ & $\begin{array}{l}\text { Strongly } \\
\text { Prefer B }\end{array}$ \\
\hline
\end{tabular}

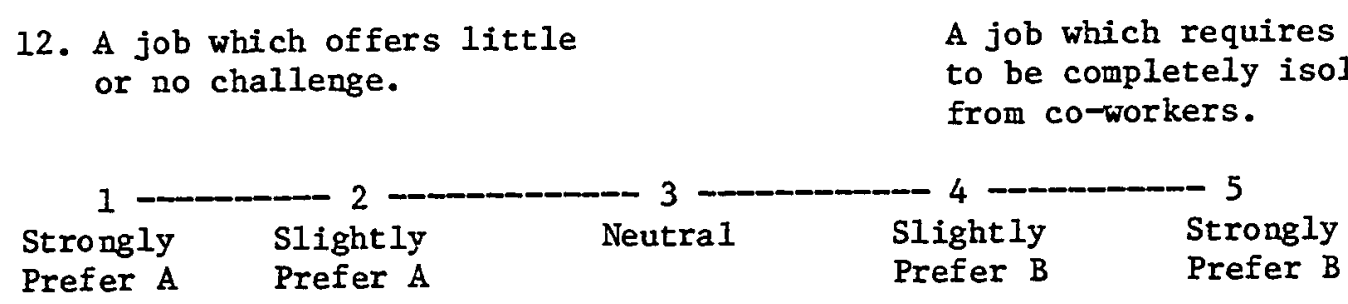

Please return questionnaire to your principal--Thank you 
APPENDIX C

LETTER OF INVITATION TO FIELD TEST MEASURE B 


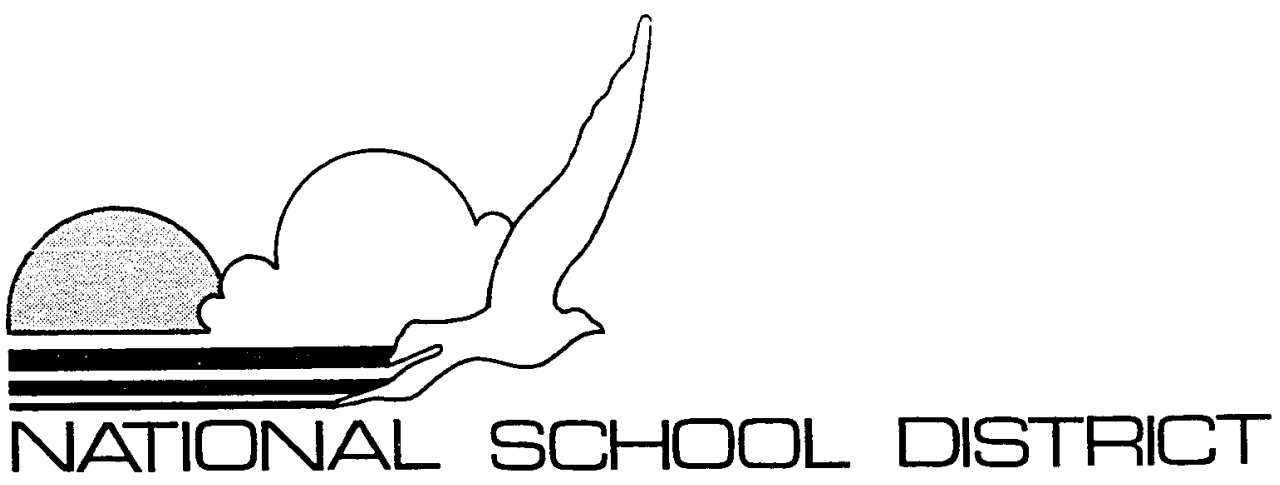

1500 N AVENUE • POST OFFICE BOXY • NATIONAL CITY, CA 92050 - (619) 474-6791

September 28, 1983

Dear Teacher:

The following survey is being considered for use in my dissertation. The instrument has been previously normed on over 6,900 employees in 876 different occupations not including education. Therefore, for purposes of establishing the validity of the instrument for use with elementary teachers, my study requires sampling a group of teachers to comment directly on the questionnaire in terms of the clarity of instructions and the appropriateness of the items.

The questionnaire is intended to assess teacher needs into either higher-order or lower-order categories. Measure $B$ is designed in a job choice format which asks respondents to choose between pairs of hypothetical jobs with characteristics revelant to higher-order needs and lower-order needs. My question to you is, "Do you feel this instrument would be satisfactory for distinguishing a teacher's preference for either higher-order or lower-order needs?"

Please write your comments on the survey and return to me at the district office. Your input will be greatly appreciated.

Thank you,

George Cameron

BOARD MEMBERS AUGIE BAREÑO. PRESIDENT. FRANK PEREZ. CLERK LARRY A TAGLE: FLORENCE UNGAB. CHARLOTE A WEBSTER DISTRICI SUPERINTENDENT. GARY W. SMMTH, PA D

BUSINESS MANAGER. MARCELE SEE 
APPENDIX D

TEACHER SUPERVISION PRACTICES QUESTIONNAIRE 


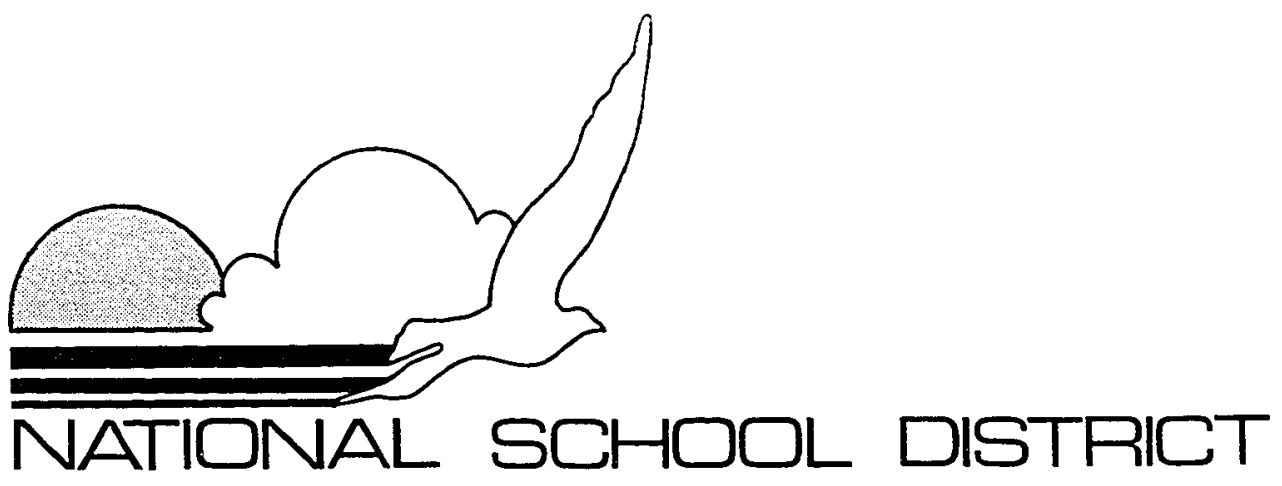

1500 N AVENUE • POST OFFICE BOXY • NATIONAL CITY, CA 92050 • (619) 474-6791

January 3, 1984

Dear Teacher "Carr":

Thank you for agreeing to participate in my dissertation study and for returning my first questionnaire in a timely manner. As you may recall, I mentioned that a second questionnaire would be forthcoming. This you will find enclosed. This questionnaire invites you to share your perceptions with respect to teacher supervision. The information is crucial to the success of my dissertation which is being conducted under the auspices of the University of San Diego.

Realizing the value of your time, the format has been designed to enable completion of the questionnaire in approximately fifteen minutes. It is hoped that the results will be helpful to school districts interested in improving their teacher supervision methods.

Since a very precise sample was selected for this investigation, the active participation of everyone in the sample is very important. Moreover, you can be assured that all responses will be held in the strictest of confidence.

The completion of the questionnaire and its return by January 20, 1984 will be greatly appreciated. I have enclosed a self-addressed stamped envelope for your convenience. For expending your valuable time and providing invaluable information, please accept the attached commemorative 1984 01ympic stamp for your personal use.

Thank you in advance for your contribution.

Sincrérelv.

George Cameron

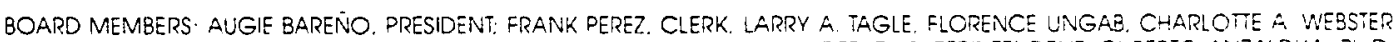
DISTRICT SUPERINTENDENT: GARY W. SMITH, PI D.

BUSINESS MANAGEP MARCELE SEE 
Teacher Supervision Practices Questionnaire

The following is a list of statements pertaining to your principal's supervision practices. Please read them carefully. The statements are intended to obtain your perceptions regarding your principal's supervisory practices. Please do not judge your principal's personal qualities, but rather your degree of satisfaction with the practices be/she utilizes as part of his/her supervision of teachers.

There are no trick statements. For each statement, examples are provided to improve clarification. Please treat them only as examples.

Your individual answers will be kept completely confidential. Please answer each item as honestly and frankly as possible.

1. My principal's supervisory practices encourage an open and trusting relationship (example: principal and teacher devote time to improving instruction by working together as colleagues.) 1 2 3

Strong1y

Disagree

Neutral

Agree 5 Disagree Strongly Agree

2. My principal devotes sufficient time to the supervisory process. (example: principal devotes sufficient time for lesson observation and for data gathering.)

$\begin{array}{ccccc}1 & 2 & 3 & 4 & 5 \\ \text { Strongly } & \text { Disagree } & \text { Neutral } & \text { Agree } & \text { Strongly } \\ \text { Disagree } & & & & \text { Agree }\end{array}$

3. My principal reports what went well and what didn't go well in a lesson without showing data (example: principal's feedback is not substantiated with supporting data; feedback information relies on memory.) $\begin{array}{ccccc}1 & 2 & 3 & 4 & 5 \\ \text { Strongly } & \text { Disagree } & \text { Neutral } & \text { Agree } & \text { Strongly } \\ \text { Disagree } & & & & \text { Agree }\end{array}$ 
4. My principal's supervisory process helps me develop a positive attitude about continuous professional development (example: his/her approach to supervision helps me realize that self-development and skill training are a career-long effort.)

$$
1
$$

Strongly

$$
2
$$

Disagree

3

Disagree

Neutral

4

5

Strongly

Agree

5. The data my principal collects during an observed lesson are a valid representation of what happens in my classroom (example: principal records specific events, observable behaviors, meaningful patterns, etc.)

$\begin{array}{ccccc}1 & 2 & 3 & 4 & 5 \\ \text { Strongly } & \text { Disagree } & \text { Neutral } & \text { Agree } & \text { Strongly } \\ \text { Disagree } & & & & \text { Agree }\end{array}$

6. My principal does not value my input in the supervisory process (example: principal does not elicit teacher involvement-ask about your feelings and opinions, or ask for clarification regarding a situation under consideration.)

$\begin{array}{ccccc}1 & 2 & 3 & 4 & 5 \\ \text { Strongly } & \text { Disagree } & \text { Neutral } & \text { Agree } & \text { Strongly } \\ \text { Disagree } & & & & \text { Agree }\end{array}$

7. My principal's methods for providing lesson feedback allow for lesson analysis (example: principal and teacher analyze and discuss lesson outcome during a post-observation conference.)
1
Strongly
Disagree
2
3
Neutral
4
Agree
5
Strongly
Disagree
Agree

8. My principal's supervision practices help me to become more self-analytical with respect to my teaching skills and approaches (example: the practices he/she uses motivates me to self-examine my lesson planning, delivery, effectiveness, etc.)
1
Disagree
3
4
5
Disagree
Neutral Agz=a
Strongly
Agree

9. My principal's observations focus on how well I contribute to the attainment of school/district goals, rather than how well I improve my personal teaching skills (example: principal emphasizes school goals to a greater degree than my mastery of teaching craft.)

$\begin{array}{ccccc}1 & 2 & 3 & 4 & 5 \\ \text { Strongly } & \text { Disagree } & \text { Neutral } & \text { Agree } & \text { Strongly } \\ \text { Disagree } & & & & \text { Agree }\end{array}$


10. The data my principal compiles during an observed lesson are useful for improving my teaching performance (example: the data help me to assess the success of my teaching procedures; for instance, the degree to which I reached my lesson objective.)

$\begin{array}{ccccc}1 & 2 & 3 & 4 & 5 \\ \text { Strongly } & \text { Disagree } & \text { Neutral } & \text { Agree } & \text { Strongly } \\ \text { Disagree } & & & & \text { Agree }\end{array}$

11. My principal's supervision practices encourage interaction and communication between principal and teacher (example: principal values the importance of dialogue/discussion regarding a lesson.)

$\begin{array}{ccccc}1 & 2 & 3 & 4 & 5 \\ \text { Strongly } & \text { Disagree } & \text { Neutral } & \text { Agree } & \text { Strongly } \\ \text { Disagree } & & & & \text { Agree }\end{array}$

12. Standards for defining good instruction are determined by my principal (example: the principal, chiefly, specifies what constitutes good teaching practices and suggests teachers follow those practices.)

$\begin{array}{ccccc}1 & 2 & 3 & 4 & 5 \\ \text { Strongly } & \text { Disagree } & \text { Neutral } & \text { Agree } & \text { Strongly } \\ \text { Disagree } & & & & \text { Agree }\end{array}$

13. My principal's lesson feedback includes plans for future instruction (example: ideas for future instruction are proposed within some post-observation activity/procedure.)

$\begin{array}{ccccc}1 & 2 & 3 & 4 & 5 \\ \text { Strongly } & \text { Disagree } & \text { Neutral } & \text { Agree } & \text { Strongly } \\ \text { Disagree } & & & & \text { Agree }\end{array}$

14. My principal focuses upon important aspects of the teaching/learning process during an observation (example: principal focuses attention on the lesson objective during an observation.)

$\begin{array}{ccccc}1 & 2 & 3 & 4 & 5 \\ \text { Strongly } & \text { Disagree } & \text { Neutral } & \text { Agree } & \text { Strongly } \\ \text { Disagree } & & & & \text { Agree }\end{array}$

15. The procedures my principal uses for collecting data during an observed lesson are inconsistent and non-systematic (example: principal does not rely on uniform methods for collecting data; data are inconsistent from one observation to the next.)

$\begin{array}{ccccc}1 & 2 & 3 & 4 & 5 \\ \text { Strongly } & \text { Disagree } & \text { Neutral } & \text { Agree } & \text { Strongly } \\ \text { Disagree } & & & & \text { Agree }\end{array}$


Open-ended questions

1. Briefly describe the process your principal uses to supervise your teaching performance and its frequency.

2. Do your principal's supervision practices fulfill your needs as a teacher? Why or why not?

3. What do you consider to be the most beneficial aspect of the supervision process? Please cite some examples.

THANK YOU FOR YOUR CONTRIBUTION 
APPENDIX E

LETIER OF TRANSMITTAL TO SCHOOL PRINCIPALS

Reproduced with permission of the copyright owner. Further reproduction prohibited without permission. 


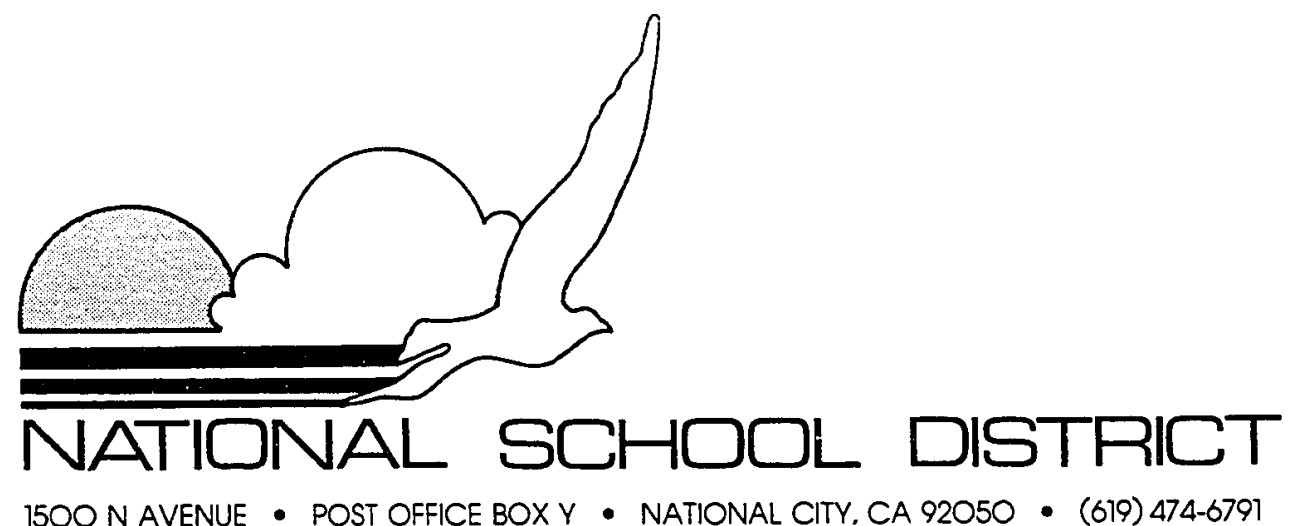

October 6, 1983

Oliver Do Right, Principal

U.S.A. Elementary School

1776 Independence Drive

San Diego, CA 90000

Dear Fellow Administrator:

Before you cast this letter aside and delve once again into your "priority 1's", permit me to state the purpose of this correspondence. I am presently the State and Federal project director in the National School District and a doctoral student at the University of San Diego.

Not holding this against me, I am also in the process of completing my dissertation in the area of clinical supervision. In connection with this research, I'm seeking the cooperation of elementary school principals who practice clinical supervision. Your name was recommended from a pool of principals who have been trained in this area. The pool was compiled, in part, with the help of my dissertation advisor, Ron Hockwalt, Superintendent of Cajon Valley.

The purpose of this study is to examine the relationship between clinical supervision and teacher need strengths. The study would take a limited portion of a principal's time and include two twelve-item questionnaires for teacher respondents to complete over a three-month period. In brief, principals would be asked to randomly select ten teachers who they would supervise in their normal manner during this period. These teachers would complete the short questionnaire to assess their need levels. After a three-month period, the same teachers would be asked to share their perceptions of their principal's supervisory methods. Of course, all responses would be confidential and teachers would not be asked to evaluate their principal on a personal level.

A difficult part of any research study is the ability to find cooperative participants, especially in cases such as these--where principals and teachers are busy people. However, I hope you can give this request your 
consideration and view it as a means of enriching the literature with respect to education and teacher supervision. Moreover, I would like to take the liberty of calling your office to introduce myself, clarify any questions and intentions, and hopefully make you an offer you simply can't refuse.

Thank you for taking time to read this. Now, back to those priority l's. Sincerelv.

Géớgè CämeT̃on 


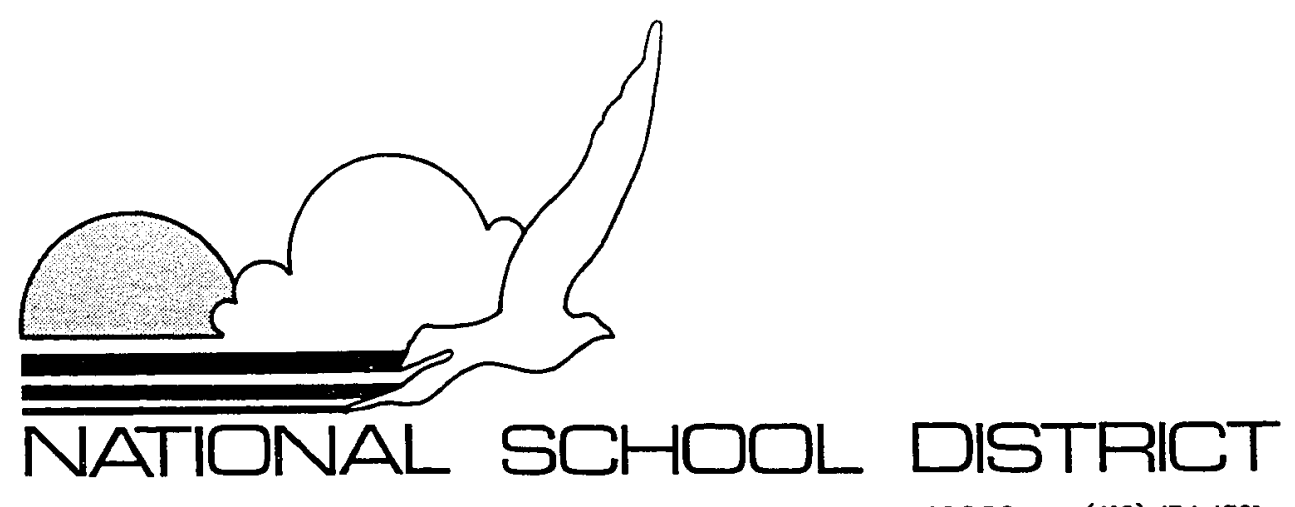

1500 N AVENUE • POST OFFICE BOXY • NATIONAL CITY, CA 92050 • (619) 474-6791

October 6, 1983

Sally Do Right, Principal

U.S.A. Elementary School

1776 Independence Drive

San Diego, CA 90000

Dear Fellow Administrator:

Before you cast this. letter aside and delve once again into your "priority l's", permit me to state the purpose of this correspondence. I am presently the State and Federal project director in the National School District and a doctoral student at the University of San Diego.

Not holding this against me, I am also in the process of completing my dissertation in the area of teacher supervision. In connection with this research, I'm seeking the cooperation of elementary school principals who practice traditional supervisory methods. Your name was recommended from a pool of principals who may be interested in participating.

I am defining traditional supervision as a supervisory practice which helps teachers improve their instruction via a series of scheduled and/or unscheduled classroom visitations which focus on observable standards related to effective teaching. These standards may include teacher attitude, student participation, materials, classroom organization, etc., and are often identified on rating scales, checklists, and the like, which principals may use to $\log$ their occurrence. Moreover, this process is not to be associated with clinical supervision.

The purpose of this study is to examine the relationship between traditional supervision and teacher need strengths. The study would take a limited portion of a principal's time and include two twelve-item questionnaires for teacher respondents to complete over a three-month period. In brief, principals would be asked to randomly select ten teachers who they would supervise in their normal manner during this period. These teachers would complete the short questionnaire to assess their need levels. After a 
three-month period, the same teachers would be asked to share their perceptions of their principal's supervisory methods. Of course, all responses would be confidential and teachers would not be asked to evaluate their principal on a personal level.

A difficult part of any research study is the ability to find cooperative participants, especially in cases such as these--where principals and teachers are busy people. However, I hope you can give this request your consideration and view it as a means of enriching the literature with respect to education and teacher supervision. Moreover, I would like to take the liberty of calling your office to introduce myself, clarify any questions and intentions, and hopefully make you an offer you simply can't refuse.

Thank you for taking time to read this. Now, back to those priority $1^{\prime}$ s. Sincerely.

Gerge Gameron 
APPENDIX F

OBSERVATION LOG OF RANDOMLY SHADOWED CLINICAL AND TRADITIONAL PRINCIPALS 
Clinical Principal Number 6

Mr. H followed each of the clinical supervision steps except the pre-conference level. He does not sit down with the teacher beforehand to gather pre-observation information. Mr. H used the script tape procedure where he takes verbatim notes of the teacher's actions. He stayed in the classroom to analyze the information, summarize the lesson quality in terms of the six-step lesson design and then scheduled a post-conference with the teacher that afternoon. During the conference, he first pointed out the positive aspects, then suggested an area for the teacher to work on.

\section{Clinical Principal Number 9}

Mr. S had a pre-conference with the teacher to find out what the lesson objective would be. He observed the entire lesson and took a checklist where he had identified the six-steps in a lesson and the principles of learning. He checked off each step as he discussed it in the lesson and wrote the key phrase/sentence that the teacher used to identify each step. After the lesson, he briefly listed the areas he would cover in the post-conference including commendations and recommendations. He shared these with the teacher during the post-conference.

\section{Traditional Principal Number 4}

Mr. H notified a probationary teacher that he wished to observe her class by placing a note in her mailbox indicating the time and day. The principal arrived when the lesson was in progress. After a few minutes of observation, the principal got involved with a group of children at a reading 
circle and began to proctor their work and move about the room. He then sat down and filled out a checklist that he considered to include "basic and important things critical to a lesson." These included discipline, teaching methods, student interest, etc. After the lesson, he scheduled a post-conference with the teacher to give her a carbon copy of the checklist. During the conference, he walked her through each area and provided positive reinforcement when appropriate. No suggestions for improvement were made.

\section{Traditional Principal Number 5}

This principal did not conduct a pre-conference and did not apprise the teacher of her intent to observe a lesson. The principal spent some 20 minutes in the class and took notes with respect to the students' time-on-task, noise level, lesson appropriateness, how the teacher moved from one activity/group to the next, etc. She also asked students that were doing seat work if they understood the work. Mrs. $M$ then gave her notes to her secretary so that they could be typed and passed on to the teacher. No recommendations or commendations were included. 
APPENDIX G

LETTER OF PERMISSION TO USE HIGHER-ORDER STRENGTH MEASURE B 


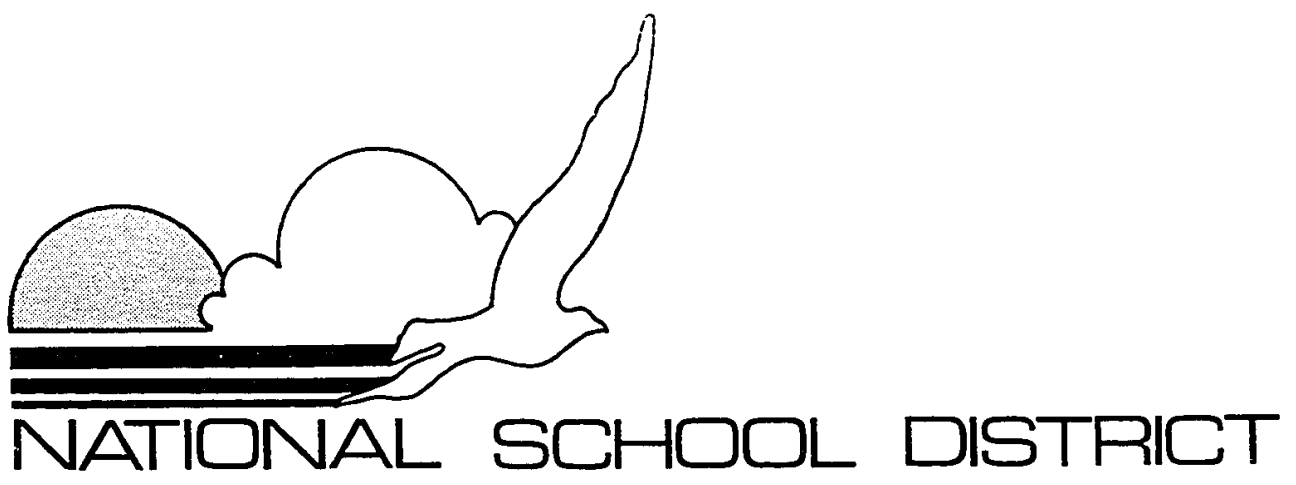

1500 N AVENUE - POST OFFICE BOXY • NATIONAL CITY. CA 92050 • (619) 474-6791

September 8, 1983

Professor J.R. Hackman

Yale University

School of Organization and

Management

Box 1-A

Newhaven, Connecticut 06510

Dear Professor Hackman:

I am a graduate student completing my dissertation in the area of clinical supervision at the University of San Diego. Toward this end, I would like to request permission to use the "Higher-Order Need Strength, Measure B", for my research.

I intend to categorize elementary school teachers into either higher order or lower order groups, then gauge their perceptions toward their principal's method of teacher supervision. While I understand that Margaret Pastor previously used your instrument for her research with secondary school teachers, can you tell me if this instrument has been used with elementary school teachers? The information would be helpful for reliability purposes.

Thank you in advance for your consideration of this request. If I can provide any additional information, I would be happy to do so.

\section{Sincerely,}

George camerox

Director of Support Services

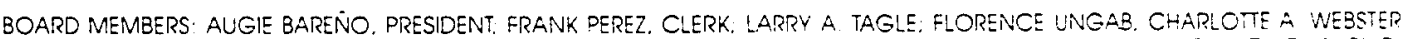
DISTRICT SUPERINTENDENT: GARY W. SMITH. PH. D

BUSINESS MANAGER MARCELE SEE 
APPENDIX H

NEED STRENGTH SCORES FOR CLINICAL GROUP 
Need Strength Scores for Clinical Group

$$
\mathrm{N}=74
$$

\begin{tabular}{|c|c|c|c|}
\hline Score & Frequency & Percentage & $\begin{array}{l}\text { Cumularive } \\
\text { Percentage }\end{array}$ \\
\hline 1.92 & 1 & 1.35 & 1.35 \\
\hline 2.08 & 1 & 1.35 & 2.70 \\
\hline 2.33 & 1 & 1.35 & 4.05 \\
\hline 2.58 & 2 & 2.70 & 6.75 \\
\hline 2.67 & 6 & 8.11 & 14.86 \\
\hline 2.75 & 6 & 8.11 & 22.97 \\
\hline 2.83 & 5 & 6.76 & 29.73 \\
\hline 2.92 & 5 & 6.76 & 36.49 \\
\hline 3.00 & 8 & 10.81 & 47.30 \\
\hline 3.08 & 8 & 10.81 & 58.11 \\
\hline 3.17 & 4 & 5.41 & 63.52 \\
\hline 3.25 & 9 & 12.16 & 75.68 \\
\hline 3.33 & 4 & 5.41 & 81.09 \\
\hline 3.42 & 1 & 1.35 & 82.44 \\
\hline 3.50 & 4 & 5.41 & 87.85 \\
\hline 3.58 & 2 & 2.70 & 90.55 \\
\hline 3.67 & 2 & 2.70 & 93.25 \\
\hline 3.75 & 2 & 2.70 & 95.95 \\
\hline 4.00 & 1 & 1.35 & 97.30 \\
\hline 4.33 & 1 & 1.35 & 98.65 \\
\hline 4.42 & 1 & 1.35 & 100.00 \\
\hline
\end{tabular}


APPENDIX I

NEED STRENGTH SCORES FOR TRADITIONAL GROUP 
Need Strength Scores for Traditional Group

$$
\mathrm{N}=83
$$

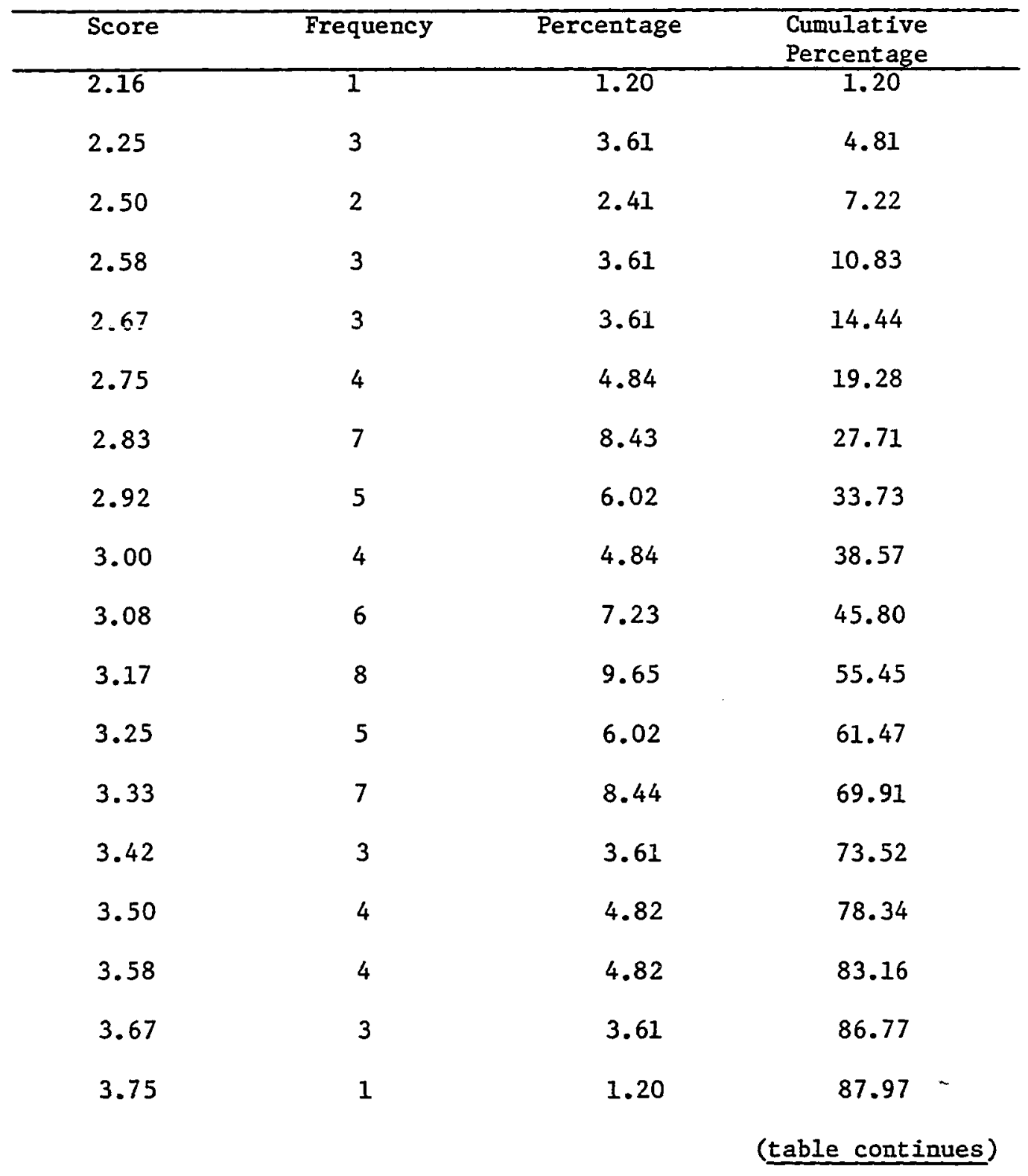




\begin{tabular}{cccc}
\hline Score & Frequency & Percentage & $\begin{array}{c}\text { Cumulative } \\
\text { Percentage }\end{array}$ \\
\hline 3.83 & 3 & 3.61 & 91.58 \\
3.92 & 2 & 2.41 & 93.99 \\
4.00 & 1 & 1.20 & 95.19 \\
4.08 & 1 & 1.20 & 96.39 \\
4.17 & 1 & 1.20 & 97.59 \\
4.25 & 1 & 1.20 & 98.79 \\
4.75 & 1 & 1.20 & 99.99 \\
\hline
\end{tabular}

